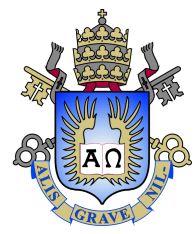

Mauro Vieira de Lima

\title{
Interferência Agregada de White Space Devices em Receptores de Sistemas Terrestres de Televisão Digital.
}

Tese de Doutorado

Tese apresentada como requisito parcial para obtenção do grau de Doutor pelo Programa de Pós-graduação em Engenharia Elétrica da PUC-Rio.

Orientador: Prof. José Mauro Pedro Fortes 


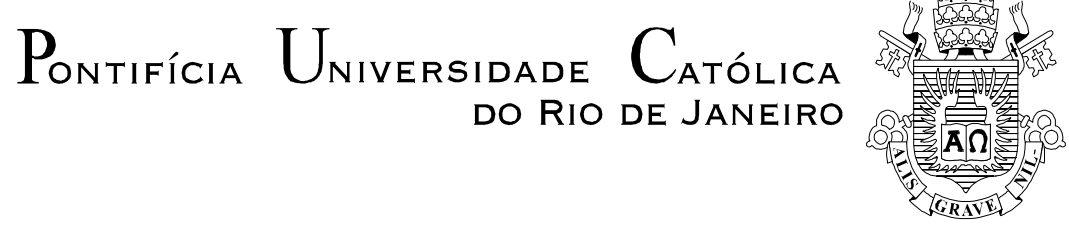

Mauro Vieira de Lima

\section{Interferência Agregada de White Space Devices em Receptores de Sistemas Terrestres de Televisão Digital}

Tese apresentada como requisito parcial para obtenção do grau de Doutor pelo Programa de Pós-Graduação em Engenharia Elétrica da PUC-Rio. Aprovada pela Comissão Examinadora abaixo assinada.

Prof. Jose Mauro Pedro Fortes Orientador Centro de Estudos em Telecomunicações - PUC-Rio

Prof. Luiz Alencar Reis da Silva Mello Centro de Estudos em Telecomunicações - PUC-Rio

Prof. Pedro Henrique Gouvêa Coelho UERJ

Prof. Paulo Roberto Rosa Lopes Nunes

IME

Prof. Cesar Augusto Medina Sotomayor

IME

Prof. Weiler Alves Finamore

UFJF

Prof. Márcio da Silveira Carvalho Coordenador Setorial do Centro Técnico Científico - PUC-Rio 
Todos os direitos reservados. É proibida a reprodução total ou parcial do trabalho sem autorização da universidade, do autor e do orientador.

\section{Mauro Vieira de Lima}

Graduou-se em Engenharia Eletrônica pela Universidade Federal do Rio de Janeiro (UFRJ) com mestrado em Engenharia Elétrica pela Pontifícia Universidade Católica do Rio de Janeiro (PUC-Rio). Trabalha como Pesquisador no Instituto Nacional de Metrologia, Qualidade e Tecnologia (Inmetro)

Ficha Catalográfica

Lima, Mauro Vieira de

Interferência Agregada de White Space Devices em Receptores de Sistemas Terrestres de Televisão Digital. / Mauro Vieira de Lima; orientador: José Mauro Pedro Fortes. - Rio de janeiro: PUC-Rio, Departamento de Engenharia Elétrica, 2017.

v., 118 f: il. color. ; $30 \mathrm{~cm}$

Tese (doutorado) - Pontifícia Universidade Católica do Rio de Janeiro, Departamento de Engenharia Elétrica.

Inclui bibliografia

1. Engenharia Elétrica - Teses. 2. White Space Device. 3. Interferência Agregada. 4. TV Digital. 5. Rádio Cognitivo. I. Fortes, José Mauro Pedro. II. Pontifícia Universidade Católica do Rio de Janeiro. Departamento de Engenharia Elétrica. III. Título.

CDD: 621.3 


\section{Agradecimentos}

Agradeço, em especial, a meu orientador José Mauro pela confiança depositada em mim e pela sua disponibilidade, apoio e competência.

Agradeço, também, a compreensão e estímulo de minha esposa Clarissa, meu filho Matheus e minha mãe Maura. 


\section{Resumo}

Lima, Mauro Vieira de; Fortes, José Mauro Pedro. Interferência Agregada de White Space Devices em Receptores de Sistemas Terrestres de Televisão Digital.. Rio de Janeiro, 2017. 118p. Tese de Doutorado - Departamento de Engenharia Elétrica, Pontifícia Universidade Católica do Rio de Janeiro.

A tecnologia do rádio cognitivo tem sido pesquisada para utilização mais eficiente do espectro, pois permite o aproveitamento de faixas de frequência subutilizadas. Dispositivos rádio cognitivos que operam na banda de frequência da TV digital são conhecidos como White Space Devices (WSD) e utilizam canais livres sob a condição de não provocar interferência acima do limite estabelecido pelo órgão regulador. A autoridade reguladora do Reino Unido, Office of Communication (Ofcom), publicou, em fevereiro de 2015, a primeira regulação européia permitindo a operação de sistemas WSD na banda da TV digital através do suporte de sistemas de banco de dados geolocalizados. O regulamento Ofcom define uma metodologia para calcular a potência de transmissão máxima de um WSD através de um método de entrada única (single-entry) da interferência intersistema máxima. Devido a isso, a interferência agregada de WSDs co-canais que operam na mesma região pode ultrapassar a interferência intersistema máxima. Além deste problema, verifica-se que a metodologia Ofcom não define a interferência intersistema máxima pelo mesmo critério da interferência intrasistema como foi definida pelo planejamento do sistema primário de TV. Esta tese desenvolve uma nova metodologia de cálculo da potência de transmissão dos WSDs que soluciona os problemas identificados na metodologia Ofcom. A metodologia proposta garante a proteção do receptor de TV digital através de uma abordagem de múltiplas entradas da interferência dos WSDs e, adicionalmente, aumenta a capacidade do sistema WSD quando comparada à metodologia Ofcom.

\section{Palavras-chave}

White Space Device; Interferência Agregada; TV Digital; Rádio Cognitivo; 


\section{Abstract}

Lima, Mauro Vieira de; Fortes, José Mauro Pedro (Advisor). Aggregate Interference from White Space Devices in Digital Terrestrial Television Receivers. Rio de Janeiro, 2017. 118p. Tese de doutorado - Departamento de Engenharia Elétrica, Pontifícia Universidade Católica do Rio de Janeiro.

The technology of cognitive radio has been researched for more efficient use of spectrum, since it allows the use of under-utilized frequency bands. Cognitive radio devices operating in the digital TV frequency band are known as White Space Devices (WSD) and use free channels under the condition of not causing interference above the limit set by the regulator. The UK regulatory authority, Office of Communication (Ofcom), published in February 2015, the first European regulation allowing WSD systems in the digital TV band through the support of geo-database systems. The Ofcom regulation defines a methodology to calculate the maximum WSD transmission power through a single-entry method for the maximum intersystem interference. Due to this, the aggregate interference of cochannel WSDs operating in the same region may exceed this maximum intersystem interference. In addition to this problem, it is verified that the Ofcom methodology does not define maximum intersystem interference by the same criterion of intrasystem interference as was defined by the primary TV system planning. This thesis develops a new methodology for calculating the transmission power of WSDs that solves the problems identified in the Ofcom methodology. The proposed methodology guarantees the protection of the digital TV receiver through a multiple-entry approach of the WSDs interference and, additionally, increases the WSD system capacity when compared to the Ofcom methodology.

\section{Keywords}

White Space Device; Aggregate Interference; Digital TV; Cognitive Radio; 


\section{Sumário}

1 Introdução $\quad 15$

$\begin{array}{lll}1.1 & \text { Rádios Cognitivos } & 15\end{array}$

$\begin{array}{lll}1.2 & \text { Regulação Européia } & 15\end{array}$

$\begin{array}{ll}1.3 \text { Visão Geral da Tese } & 17\end{array}$

$\begin{array}{lll}1.4 & \text { Organização do Texto } & 18\end{array}$

2 Metodologia Ofcom $\quad 20$

2.1 Introdução 20

2.2 Bancos de Dados e Admissão 22

2.3 Potência Interferente Intersistema Máxima $Z$

2.4 Máxima Emissão do WSD 27

2.5 Indeterminação da Localização do Receptor DTT 31

3 Descrição Detalhada do Problema $\quad 35$

3.1 Aspectos Relevantes da Metodologia Ofcom 35

3.2 Procedimento de Admissão Ofcom 39

3.3 Procedimento de Admissão Ecc.186 41

3.4 Incompatibilidade entre as Definições de $Z$ e $P_{U, k}$

3.5 Múltiplos WSDs Excedem Interferência Limite 46

4 Modelagem Matemática $\quad 49$

4.1 Critério de Interferência e e.i.r.p. Máxima 49

4.2 Interferência Agregada 51

4.2.1 Distribuição Espacial dos WSDs $\quad 52$

4.2.2 Conceito de Célula Mais Vulnerável 53

4.2.3 Cálculo da Potência Interferente Agregada 54

4.2.3.1 Soma de Variáveis Aleatórias com Distribuição Lognormal 55

4.2.3.2 Critério de Interferência para Caso Particular Lognormal 57

4.3 Resultados Preliminares Relativos à Interferência Agregada 59

4.3.1 Construção da Base de Dados $Z \quad 59$

4.3.2 Análise da Interferência Agregada na Metodologia Ofcom 61

5 Novo Procedimento de Admissão $\quad 67$

$\begin{array}{lll}5.1 & \text { Procedimento de Admissão lagg } & 67\end{array}$

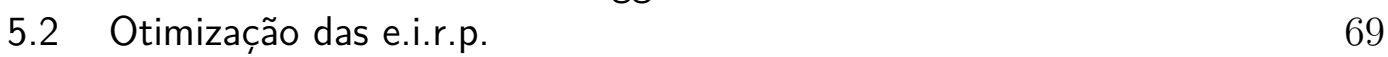

$\begin{array}{lll}\text { 5.2.1 Redução das e.i.r.p. } & 70\end{array}$

$\begin{array}{ll}\text { 5.2.2 Tempo Médio de Admissão } & 71\end{array}$

5.2.3 Máscara de Otimização 74

6 Resultados Numéricos $\quad 78$

6.1 Premissas e Parâmetros $\quad 78$

6.2 Simulação dos Procedimentos de Admissão $\quad 81$

6.2.1 Visão Geral da Simulação $\quad 82$

6.2.2 Geração de Redes WSD 84 
6.2.3 Simulação do Procedimento de Admissão Ecc.186 85

6.2.4 Simulação do Procedimento de Admissão Ofcom 86

6.2.5 Simulação do Procedimento de Admissão lagg 89

6.3 Atendimento ao Critério de Interferência 91

6.4 Taxa de Atendimento ao Critério de Interferência 94

7 Conclusões 100

8 Referências bibliográficas 103

A Aproximação de Schwartz-Yeh Modificada por Ho 107

B Geometria Estocástica $\quad 110$

B.1 Processos pontuais 111

B.2 Processo Pontual de Poisson 113

B.3 Função Distribuição da Distância do Vizinho Mais Próximo 116 


\section{Lista de figuras}

Figura 2.1 Faixa de frequência do Sistema DTT no Reino Unido. 21

Figura 2.2 Busca pelo Banco de Dados e Admissão do WSD. 23

$\begin{array}{lll}\text { Figura 2.3 Diagrama para cálculo da (e.i.r.p. })_{k j} & 28\end{array}$

$\begin{array}{lll}\text { Figura 2.4 Geometria para o cálculo da e.i.r.p. } E_{k j} & 28\end{array}$

Figura 2.5 Diagrama da discriminação angular da antena ITU-R BT.419-3.

Figura 2.6 Tiers ao redor de um WSD. $\quad 31$

Figura 2.7 Geometria para Tier 2. 32

Figura 2.8 Geometria para Tier 0/1. 34

Figura 3.1 Diagrama para cálculo da potência de transmissão $E_{k j} \quad 38$

Figura 3.2 WSDB informa canais e potências máximas permitidas ao WSD em processo de admissão. 39

Figura 3.3 Procedimento de admissão baseado na metodologia Ofcom. 40

Figura 3.4 Procedimento de admissão baseado na metodologia Ecc. 186.

Figura 3.5 Eventos associados a admissão do $\mathrm{WSD}_{0}$ no procedimento de admissão Ecc.186.

Figura 3.6 Tempo de retorno $\tau_{i}$ contado do instante de chegada do $\mathrm{WSD}_{0}$ até o retorno da comunicação do $\mathrm{WSD}_{i}$ com o banco de dados WSDB.

Figura 3.7 WSDs ocupam mesma célula e mesmo canal de frequência, irradiando com a potência de transmissão regulatória. Logo, cada um produz uma potência interferente $Z$ na célula mais vulnerável, logo a potência interferente agregada excede o limite $Z$ desta célula.

Figura 3.8 WSDs ocupam células próximas e mesmo canal de frequência, irradiando com a potência de transmissão regulatória. Logo, a potência interferente agregada na célula mais vulnerável de cada um dos WSD excede o limite de potência interferente $Z$ pelo valor da interferência do outro WSD.

Figura 4.1 Geometria para cálculo da e.i.r.p. $E_{k j}$

Figura 4.2 Área circular para cálculo da e.i.r.p. $E_{k j}$

Figura 4.3 Completa aleatoriedade espacial do processo pontual de Poisson. $A \cap B=\emptyset$, então $\Phi(A) \perp \Phi(B)$

Figura 4.4 Múltiplos WSDs interferentes.

Figura 4.5 Curva da função distribuição de probabilidade da potência interferente agregada. Os asteríscos preto e vermelho representam os valores de $Z_{0}$ e $I_{0}$, respectivamente. $\Delta=I_{0}-Z_{0}$ representa o quanto $I_{0}$ deve ser reduzido para atender o C.I.

Figura 4.6 Diagrama de blocos da construção da base de dados $Z$ 53

Figura 4.7 Potência interferente intersistema $Z$, em dBm, no canal de frequência 24 
Figura 4.8 Diagrama de blocos da análise do comportamento estatístico da potência interferente agregada em relação ao critério de interferferência na metodologia Ofcom

Figura 4.9 Representação das células da região de trabalho em azul e das células selecionadas para cálculo da e.i.r.p. $E_{k}$ na célula de menor latitude/longitude da região de trabalho.

Figura 4.10 Funções distribuição de probabilidade complementar condicionais e incondicional da potência interferente agregada afetando o canal 24 para 1000 amostras PPP com densidade $\lambda=1 \mathrm{WSD} / \mathrm{km}^{2}$.

Figura 4.11 Funções distribuição de probabilidade complementar da potência interferente agregada afetando canal 27 do receptor DTT, devido aos WSDs operando no canal 26 para densidades variando de 0.1 a 100.

Figura 4.12 Funções distribuição de probabilidade complementar da potência interferente agregada afetando canal 24 do receptor DTT, devido aos WSDs operando no canal 26 para densidades variando de 0.1 a 100.

Figura 4.13 Probabilidade da potência interferente agregada exceder o valor de referência $Z_{0}$ para cada um dos três canais de frequências do sistema DTT.

Figura 5.1 Procedimento de admissão da metodologia Iagg.

Figura 5.2 Eventos associados a admissão do novo WSD na metodologia Iagg.

Figura 5.3 Tempo de retorno $\tau_{i}$ contado do instante de chegada do $\mathrm{WSD}_{0}$ até o retorno da comunicação do $\mathrm{WSD}_{i}$ com o banco de dados WSDB.

Figura 5.4 Máscaras de otimização em função do parâmetro dec variando de 30 a $55 \mathrm{~dB}$. O círculo indica a posição da CMV e a cruz a posição do $\mathrm{WSD}_{0}$.

Figura 5.5 Distância máxima da CMV até borda da máscara em função da redução da interferência de borda (dec).

Figura 5.6 Máscaras de otimização selecionadas pelo valor de dec correspondente a $1 \mathrm{~dB}$ abaixo da $i_{\text {agg }}$ máxima de cada densidade $\lambda$. Os valores selecionados estão indicados por um círculo.

Figura 6.1 e.i.r.p regulatória máxima $E_{k, \max }$, média $E_{k}$ e mínima $E_{k, \min }$ da região de trabalho em função do limite $\epsilon$.

Figura 6.2 Diagrama de blocos da visão geral da simulação dos procedimentos de admissão Ecc.186, Ofcom e Iagg.

Figura 6.3 Diagrama de blocos da geração de redes WSD para os procedimentos de admissão Ecc.186, Ofcom e Iagg.

Figura 6.4 Diagrama de blocos do procedimento de admisssão Ecc.186 com avaliação do critério de interferência.

Figura 6.5 Diagrama de blocos do procedimento de admissão Ofcom com avaliação do critério de interferência.

Figura 6.6 Diagrama de blocos do procedimento de admissão Iagg. 
Figura 6.7 Probabilidade da interferência agregada $i_{\text {agg }}$ ultrapassar a interferência intersistema $Z_{0}$ em função da densidade no canal de frequência DTT 27.

Figura 6.8 Probabilidade da interferência agregada $i_{\text {agg }}$ ultrapassar a interferência intersistema $Z_{0}$ em função da densidade no canal de frequência DTT 24.

Figura 6.9 Taxa de atendimento ao C.I. em função da densidade no canal de frequência DTT 27 para as metodologias Ecc.186, Ofcom e Iagg. Cada gráfico utiliza um valor de média para a e.i.r.p. $P_{\ell}$. Os números que aparecem nos pontos das curvas correspondem ao tempo de admissão normalizado $t_{n}$.

Figura 6.10 Taxa de atendimento ao C.I. em função da densidade no canal de frequência 24 para as metodologias Ecc.186, Ofcom e Iagg. Cada gráfico utiliza um valor de média para a e.i.r.p. $P_{\ell}$. Os números que aparecem nos pontos das curvas correspondem ao tempo de admissão normalizado $t_{n}$.

Figura B.1 Exemplo de processo pontual binomial, N=1. 111

Figura B.2 Exemplo de processo pontual binomial, N=20. 112

Figura B.3 Interação entre pontos de processos pontuais. 113

Figura B.4 Independência entre conjuntos disjuntos em um PPP. 114 


\section{Lista de tabelas}

Tabela 2.1 Taxa de proteção $\rho\left(\Delta F, m_{S}\right)$, em dB, para WSD categoria low - classe 1.

Tabela 2.2 Ganho de acoplamento de referência para Tier 2. 33

Tabela 2.3 Ganho de acoplamento de referência para Tier 0/1. 34

Tabela 4.1 Parâmetros do Cenário para Análise da $i_{\text {agg }}$ na Metodologia Ofcom

Tabela 6.1 Parâmetros Adicionais do Cenário para Análise das Metodologias 


\section{Lista de Abreviaturas}

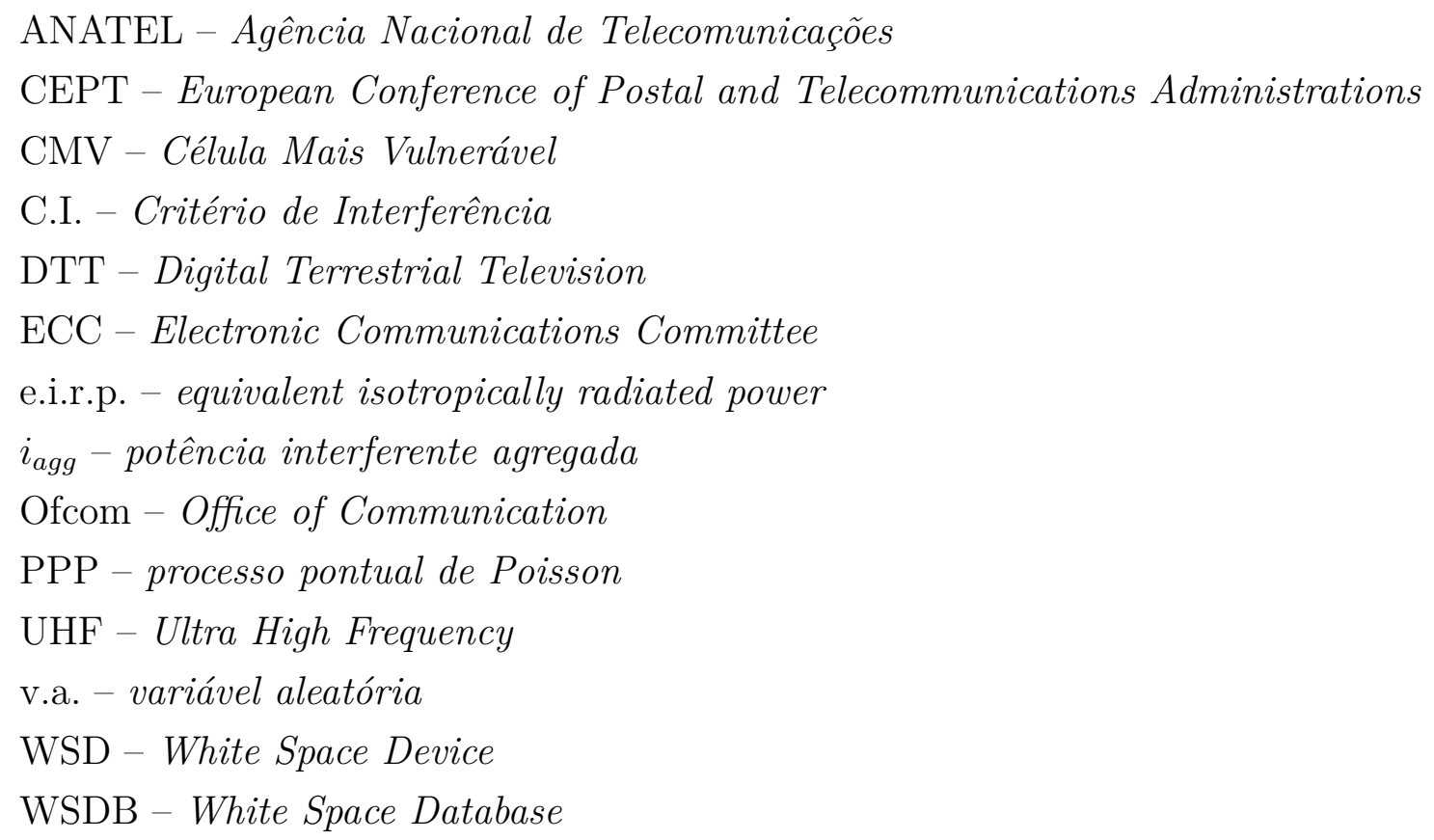


"A tarefa não é tanto ver aquilo que ninguém viu, mas pensar o que ninguém ainda pensou sobre aquilo que todo mundo vê".

Arthur Schopenhauer 


\section{Introdução}

\section{1}

\section{Rádios Cognitivos}

O trabalho de Mitola e Maguire [1] em 1999 que cunhou o termo rádio cognitivo e os estudos de medição do espectro que identificaram a subutilização do espectro radioelétrico impulsionaram as pesquisas sobre a utilização mais eficiente do espectro através de dispositivos rádio cognitivos.

A tecnologia do rádio cognitivo permite o aproveitamento de faixas de frequência subutilizadas, através de rádios reconfiguráveis com inteligência para entender e adaptar-se ao ambiente radioelétrico. Tais dispositivos utilizam a faixa de frequência em um esquema de acesso dinâmico do espectro através da identificação de canais livres, utilizando-os de forma oportunística sem causar interferência significativa nos dispositivos primários (dispositivos do serviço que possui a concessão da faixa de frequência em caráter primário) [2].

A forte demanda pelos serviços de telecomunicações sem fio tem motivado o uso dos canais de frequências liberados na migração da TV analógica para digital (dividendo digital) para operação de sistemas rádio cognitivos em um esquema de compartilhamento da banda de frequência de UHF [3].

Os dispositivos rádio cognitivos que operam na banda de frequência da TV digital, denominada DTT (Digital Terrestrial Television), são conhecidos como WSD (White Space Devices) e utilizam os canais livres (White Spaces) dos sistemas locais de radiodifusão de TV digital. A faixa de frequência em questão é alocada, em caráter secundário, ao serviço que utiliza WSDs. Esta alocação é feita sob a condição dos WSDs não provocarem, nos receptores DTT, interferência acima do limite estabelecido pelo órgão regulador. Os órgãos reguladores possuem, então, o desafio de definir as condições de operação dos sistemas WSD.

\section{2}

\section{Regulação Européia}

O órgão regulador europeu CEPT (European Conference of Postal and Telecommunications Administrations) através do seu grupo ECC (Electronic 
Communications Committee) apresentou os relatórios ECC.159 [4] e ECC.186 [5] com requisitos técnicos e operacionais para a implementação dos sistemas WSD na faixa de frequência utilizada pelo sistema DTT. Os relatórios contêm estudos e resultados sobre as técnicas cognitivas e concluem que o uso de sistemas de banco de dados geolocalizados é a solução viável para operação de sistemas WSDs. Além disso, uma metodologia de cálculo da potência máxima de emissão permitida para um WSD foi desenvolvida através de um valor máximo de degradação da cobertura de uma unidade de área do sistema DTT. O valor máximo da degradação e os valores dos parâmetros desta metodologia são deixados para escolha do órgão regulador de cada país.

O órgão regulador do Reino Unido, Ofcom (Office of Communication), publicou, em fevereiro de 2015, a primeira regulação européia permitindo a operação de sistemas WSD na banda DTT através do suporte de sistemas de banco de dados geolocalizados WSDB (White Space Database) [6]. Neste documento, a metodologia de cálculo do limite máximo de emissão de potência do WSD é definida de forma similar a do relatório ECC.186, porém com valores de degradação e parâmetros definidos para o cálculo inequívoco deste limite.

A metodologia de cálculo do regulamento Ofcom possui grande importância para a disseminação dos sistemas WSD, uma vez que será um exemplo a ser adotado pela maioria dos países europeus, bem como outros países fora da Europa. A evolução desta metodologia é de interesse internacional dado que a maioria dos países já realizaram ou possuem datas próximas para a migração dos sistemas de TV analógica para digital na mesma faixa de frequência do sistema do Reino Unido, abrindo a possibilidade de adotar regulação similar e se beneficiar da produção em escala de equipamentos.

O regulamento Ofcom assume que somente um WSD irradiará por célula e por canal de frequência. Entretanto, reconhece que um WSDB pode prover serviços para múltiplos WSDs na mesma área geográfica e no mesmo canal de frequência, resultando em uma agregação da interferência. O regulamento assume que a agregação de múltiplas entradas de interferência dos WSDs não será um problema a curto prazo.

A metodologia e premissas assumidas pelo regulamento Ofcom seguem a tradicional abordagem dos órgãos reguladores na definição de um limite de entrada única (single-entry) de interferência. Entretanto, a mudança de paradigma de um modelo de sistemas coordenados por um ou poucos operadores para um modelo de sistemas oportunísticos torna o limite single-entry insuficiente para garantir que a potência interferente agregada não ultrapasse o limite regulatório, conforme demonstramos em [8]. Este é um dos problemas da metodologia Ofcom, aqui denominado single-entry/aggregate. 
Uma vez que os bancos de dados WSDB operam com as informações de localização e parâmetros de equipamento do WSD, realizando cálculos para definição da potência de transmissão limite, torna-se viável definir e adotar uma metodologia de cálculo que utilize a potência interferente agregada para satisfazer o critério de interferência.

Para tal, os bancos de dados WSDB deverão atender a requisitos estreitos de desempenho relacionados ao custo computacional e de comunicação, atraso na admissão entre outros. Tais requisitos de desempenho e a inovação de um critério regulatório baseado em múltiplas entradas de interferência torna o desenvolvimento da metodologia de cálculo proposta um desafio.

\section{3}

\section{Visão Geral da Tese}

O regulamento Ofcom possui dois problemas relacionados a sua metodologia de cálculo da potência de transmissão máxima de um WSD. O primeiro está na definição da interferência intersistema máxima do sistema WSD que é diferente da definição das interferências intrasistema do sistema DTT. O segundo problema resulta da abordagem single-entry da metodologia Ofcom que não garante que a interferência agregada dos WSDs não ultrapasse a interferência intersistema máxima. Estes problemas são detalhados no Capítulo 3 e estão citados aqui para entendimento do escopo da tese.

Em [8] demonstramos que o receptor DTT está vulnerável ao agregado das interferências dos WSDs, em alguns casos, mesmo para baixas densidades de WSDs por $\mathrm{km}^{2}$. Além disso, a interferência intersistema máxima foi definida da mesma forma que a interferência intrasistema, solucionando o primeiro problema, e a potência de transmissão do WSD foi atribuida conforme indicado na metodologia de cálculo do relatório ECC.186, uma vez que o regulamento Ofcom não define como fazer esta atribuição.

Uma premissa da metodologia de cálculo Ofcom indica que, em geral, os WSDs utilizam uma potência de transmissão inferior a potência de transmissão máxima. Em [9], utilizamos esta premissa para definir a potência de transmissão do WSD como uma variável aleatória e desenvolver uma comparação entre as metodologias baseadas no relatório ECC.186 e no regulamento Ofcom, sendo demonstrado que ambas as metodologias violam o limite máximo de interferência.

Estes trabalhos evidenciam a vulnerabilidade do receptor DTT ante a interferência agregada dos transmissores WSD, motivando o desenvolvimento, no presente trabalho, de um procedimento de admissão dos WSDs no qual a potência de transmissão do WSD é calculada considerando-se as múltiplas 
entradas de interferência no receptor DTT. Além disso, o procedimento de admissão desenvolvido inclui métodos de cálculo que permitem aumentar a capacidade do sistema WSD e reduzir o custo computacional do banco de dados.

Em resumo, esta tese propõe uma nova metodologia de cálculo da potência de transmissão dos WSDs que soluciona os problemas identificados na metodologia Ofcom e garante a proteção do receptor DTT, comparando-a às metodologias baseadas no relatório ECC.186 e no regulamento Ofcom.

\section{4}

\section{Organização do Texto}

O Capítulo 2 aborda os principais aspectos da metodologia de cálculo do regulamento Ofcom cujo objetivo principal é definir a potência máxima de transmissão dos dispositivos rádio cognitivos WSDs que operam na faixa de frequência do sistema de televisão digital DTT. Neste capítulo, os conceitos e premissas da metodologia Ofcom são apresentados, bem como o cálculo da potência interferente intersistema limite e da máxima emissão de potência do WSD.

O Capítulo 3 desenvolve o detalhamento do problema singleentry/aggregate da metodologia Ofcom, demonstrando a vulnerabilidade do receptor DTT à potência interferente agregada das emissões dos WSDs. Primeiramente, descreve-se um resumo da metodologia de cálculo e apresentase os procedimentos de admissão Ofcom e Ecc.186. Descreve-se a diferença nas definições das potências interferentes intersistema e intrasistema e, por fim, demonstra-se através de exemplos como a potência interferente intersistema limite é ultrapassada pela potência interferente agregada dos WSDs localizados em uma mesma célula e em células diferentes.

No Capítulo 4, a teoria que serve de base para a metodologia de cálculo proposta é desenvolvida. O modelo matemático permite definir as expressões para o critério de interferência, a potência de transmissão máxima do WSD e a potência interferente agregada. Com base neste modelo, obtém-se resultados preliminares que comprovam o não atendimento do critério de interferência pela interferência agregada na metodologia de cálculo Ofcom.

O Capítulo 5 desenvolve um novo procedimento de admissão, nomeado Iagg, cujo critério de admissão é o próprio critério de interferência, sendo a potência interferente agregada utilizada para avaliação deste critério. Além disso, desenvolve as funções de otimização, tempo médio de admissão e máscara de otimização que são necessárias para a implementação do procedimento de admissão Iagg. 
O Capítulo 6 desenvolve uma análise comparativa das metodologias Ecc.186, Ofcom e Iagg. Inicialmente, as premissas e parâmetros utilizados nesta análise são demonstrados. Em seguida, a simulação conjunta dos procedimentos de admissão Iagg, Ofcom e Ecc.186 é detalhada. Esta simulação visa obter parâmetros de desempenho para realizar a comparação das metodologias. Uma análise do atendimento ao critério de interferência é desenvolvida, bem como uma avaliação de desempenho através da taxa de atendimento ao critério de interferência das três metodologias. Assim, utilizando-se desta análise comparativa, demonstra-se que a metodologia de cálculo Iagg soluciona os problemas da metodologia de cálculo Ofcom descritos no Capítulo 3.

Por fim, o Capítulo 7 apresenta as considerações finais. 


\section{2 \\ Metodologia Ofcom}

Este capítulo aborda os principais aspectos da metodologia de cálculo do regulamento Ofcom [6] e seus anexos [7] cujo objetivo principal é calcular a potência máxima de transmissão dos dispositivos rádio cognitivos que operam na faixa de frequência dos sistemas de televisão digital.

Os conceitos e premissas da metodologia Ofcom, mais relevantes para esta tese, são apresentados na Seção 2.1, enquanto o procedimento de admissão pelo banco de dados geolocalizado WSDB é descrito na Seção 2.2.

O cálculo da potência interferente intersistema máxima de cada célula e da máxima emissão de potência do WSD são descritos nas seções 2.3 e 2.4. O capítulo termina com a descrição do tratamento dado pela metodologia Ofcom para o problema da indeterminação da localização do receptor DTT na Seção 2.5 .

\section{1 \\ Introdução}

A metodologia Ofcom descrita no regulamento Implementing TV White Spaces [6] e seus anexos [7] visa permitir o acesso a canais de frequências não usados (White Spaces) na banda de 470 a $790 \mathrm{MHz}$ para compartilhamento dinâmico com sistemas WSD (White Space Device) controlados por um banco de dados geolocalizado WSDB (White Space Device DataBase).

Esta metodologia visa proteger os sistemas de banda larga DTT (Digital Terrestrial Television) e os sistemas de banda estreita PMSE (Programme Making and Special Events) que são os sistemas primários. O sistema PMSE possui o canal de frequência 38 dedicado. Entretanto, também pode utilizar outros canais de frequência. A Figura 2.1 obtida em [6] mostra a banda de frequência no Reino Unido (UK) e suas bandas vizinhas.

A modelagem matemática da metodologia Ofcom descrita nesta seção se concentra no sistema DTT. O órgão regulador de cada país deve avaliar qual serviço deve ser protegido e qual a melhor solução para um determinado serviço. Considera-se neste trabalho que a eficiência espectral justifica priorizar sistemas WSD banda larga em relação a sistemas PMSE banda estreita, uma vez que o sistema PMSE banda estreita pode prestar seus serviços em um 


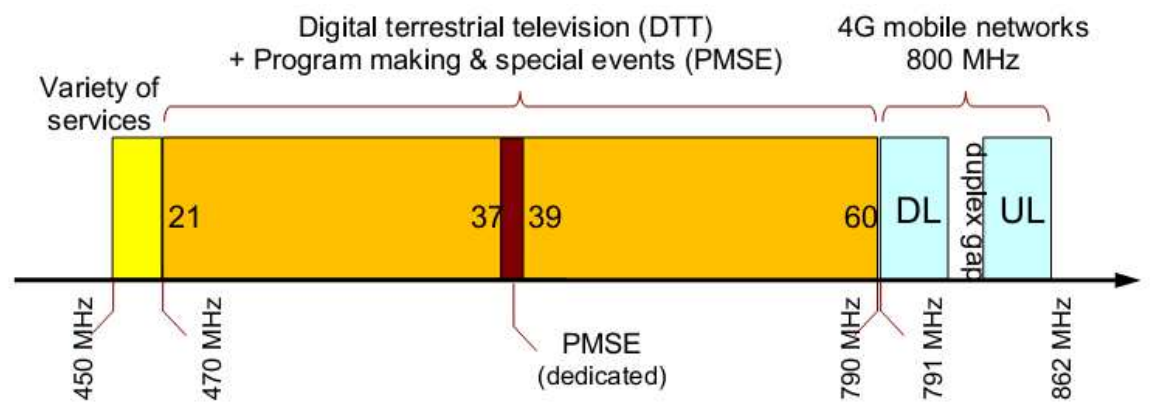

Figura 2.1: Faixa de frequência do Sistema DTT no Reino Unido.

ou mais canais dedicados, sendo plenamente atendido e não prejudicando a eficência de sistemas banda larga.

O planejamento de sistemas de TV, geralmente, subdivide a área de cobertura em unidades de área com dimensões típicas de 100m por 100m. Esta unidade de área é denominada célula neste trabalho, sendo a mesma referida como pixel no regulamento Ofcom.

A qualidade de recepção dentro de uma célula varia conforme a localização do receptor DTT. Um parâmetro de qualidade da cobertura de uma célula, conhecido como location probability, é definido pela fração de receptores que podem receber o serviço em uma célula [5].

A área de serviço que será protegida é apenas uma fração da área de cobertura. O serviço de radiodifusão de TV é planejado com sobreposição da cobertura de diferentes transmissores, sendo protegida apenas a melhor cobertura.

A metodologia Ofcom assume algumas premissas importantes, listadas abaixo.

i Adota uma área de serviço onde as células possuem location probability igual ou superior a 70\%, sendo esta a área protegida para o serviço primário.

ii Considera que, na prática, não sejam utilizadas transmissões co-canais entre os sistemas WSD e DTT, ou seja, um WSD não transmite em um canal de frequência ocupado por um transmissor DTT dentro da sua área de serviço.

iii Um valor máximo de potência de transmissão de $36 \mathrm{dBm}$ é utilizado para todas as classes, tipos e localizações dos WSD.

iv O planejamento do sistema DTT é feito para utilização de antenas externas, sendo os parâmetros da metodologia ajustados para este tipo de antena. 
v Considera como premissa de cálculo que apenas um WSD irradiará por célula e por canal de frequência. Entretanto, reconhece que, na prática, um WSDB pode prover serviços para múltiplos WSD na mesma área geográfica e mesmo canal de frequência, resultando na agregação das potências interferentes. O regulamento informa no item 6.22 em [6] que tal agregação de interferência é improvável ser um problema à curto prazo.

\section{2}

\section{Bancos de Dados e Admissão}

O banco de dados geolocalizado WSDB é responsável por controlar a admissão e operação dos WSDs na faixa de frequência do sistema DTT. Para isso, o WSDB recebe informações do banco de dados da Ofcom, permitindo que o mesmo conheça os canais de frequência livres e calcule os limites de potência de transmissão em qualquer um destes canais nas células da região de sua atuação.

Um WSD master deve primeiro consultar uma lista de banco de dados WSDB provida no website da Ofcom. Após escolher um WSDB, o WSD deve enviar a ele sua localização e seus parâmetros (device parameters). O WSDB deve retornar parâmetros (operational parameters) com informações de canais livres que podem ser utilizados e respectivos limites da potência de transmissão entre outros. O WSD escolhe seu canal e informa seus parâmetros ao WSDB (channel usage parameters). A ocupação do canal de frequência selecionado é permitida apenas por um certo período de tempo (time period). Desta forma, o WSD deve retornar a comunicação com o WSDB em períodos de tempo regulares para revalidar sua ocupação. O procedimento de início de operação de um novo WSD não deve ser feito com transmissões dentro da faixa de frequência. Assim sendo, o WSD master deve possuir uma conexão internet. Este processo de descoberta do WSDB e admissão do WSD é ilustrado na Figura 2.2 obtida em [6].

O banco de dados da Ofcom proverá aos bancos de dados WSDB os conjuntos de dados relacionados ao sistema DTT listados abaixo.

DTT coexistence data são dados relacionados a potência de transmissão máxima que um WSD pode transmitir em cada célula.

Unschedule Adjustment data são dados revisados da potência de transmissão máxima para uma área geográfica particular.

Além disso, o banco de dados Ofcom se comunicará com os WSDB para obter informações para uma ferramenta de gerenciamento de interferência que 


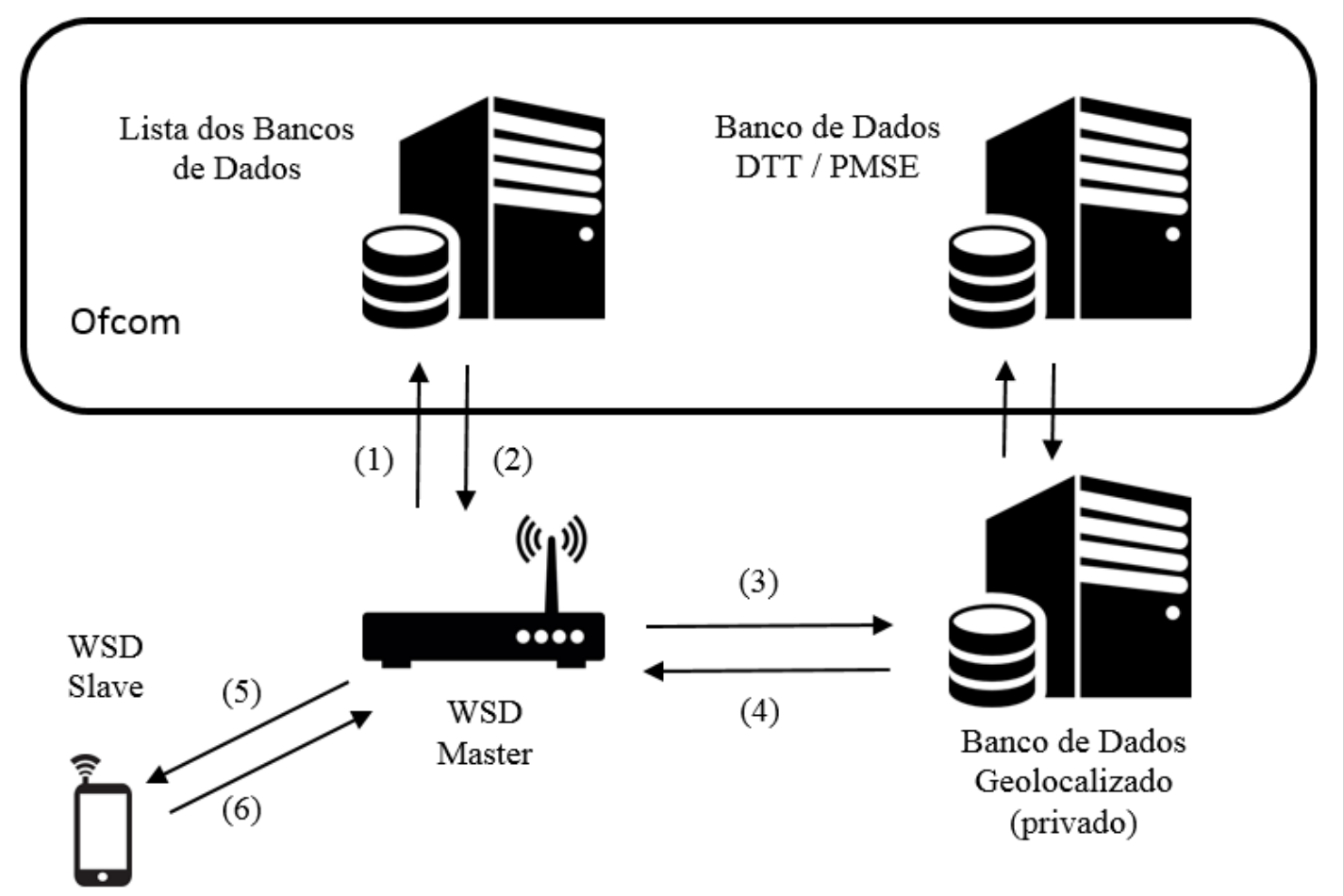

Figura 2.2: Busca pelo Banco de Dados e Admissão do WSD.

fará uma avaliação inicial dos casos de interferência. Assim, através de seu sistema de banco de dados, a Ofcom poderá:

(a) Requerer que um WSD específico desligue sua transmissão;

(b) Definir um novo conjunto de potências de transmissão máximas para uma região e canais de frequência específicos;

(c) Desligar alguns ou todos os serviços de um WSDB.

$\mathrm{Na}$ admissão do sistema, um WSD master requisita parâmetros operacionais genéricos de um WSDB. Estes são canais de frequência e potência de transmissão regulatória para um WSD slave genérico. O WSD slave pode continuar utilizando seus parâmetros operacionais genéricos ou prover ao WSD master informações adicionais, em especial de localização. Essas informações são transferidas para o WSDB que calcula parâmetros operacionais específicos para este WSD slave. O WSD master, também, deve informar os parâmetros do WSD slave (channel usage parameters) ao WSDB. 


\section{3}

\section{Potência Interferente Intersistema Máxima $Z$}

A metodologia de cálculo da potência de transmissão máxima regulatória de um WSD é definida a partir de uma potência interferente intersistema máxima $Z$ permissível em cada célula. Esta é calculada a partir de uma degradação máxima do parâmetro location probability que define a qualidade da cobertura de uma célula. O cálculo deste parâmetro, apenas para interferências intrasistema, é calculado como

$$
\begin{aligned}
q & =P\left(P_{S} \geq P_{S, \text { min }}+\sum_{k=1}^{n} r_{U, k} P_{U, k}\right) \\
& =P\left(P_{S} \geq P_{S, \min }+V\right) \\
& =P\left(P_{S} \geq U\right)
\end{aligned}
$$

onde

$P(x)$ é a probabilidade de $\mathrm{x}$;

$P_{S}$ é a potência de recepção do sinal DTT;

$P_{S, \min }$ é a sensibilidade do receptor DTT considerando apenas ruído;

$r_{U, k}$ é a taxa de proteção da k-ésima interferência;

$P_{U, k}$ é a potência de recepção da k-ésima interferência excedida $1 \%$ do tempo.

A variável $V$ representa o somatório das interferências $P_{U, k}$ dos transmissores DTT reduzidas pela taxa de proteção $r_{U, k}$ correspondente. A taxa de proteção representa a discriminação em frequência devido as características de seletividade do receptor e do espectro de transmissão interferente.

O cálculo da location probability $q$ de cada célula pode ser realizado por simulação Monte Carlo ou por um método analítico [14] [15] [16]. Para ambos, o planejamento do sistema DTT modela as potências $P_{S}$ e $U$ como variáveis aleatórias (v.a.) gaussianas caracterizadas por média e desvio padrão. Através do método analítico, pode-se desenvolver a expressão de $q$. 


$$
\begin{aligned}
q & =P\left(P_{S} \geq U\right) \\
& =P\left(\frac{P_{S}}{U} \geq 1\right) \\
& =P\left(P_{S(d B m)}-U_{(d B m)} \geq 0\right) \\
& =P\left(X_{(d B m)} \geq 0\right)
\end{aligned}
$$

Sendo

$$
X \sim N\left(m_{X}, \sigma_{X}\right) ; m_{X}=m_{S}-m_{U} ; \sigma_{X}=\sqrt{\sigma_{S}^{2}+\sigma_{U}^{2}}
$$

Utilizando as expressões

$$
\begin{gathered}
P(X>\alpha)=Q\left(\frac{\alpha-m_{X}}{\sigma_{X}}\right) \\
Q(-\alpha)=1-Q(\alpha)
\end{gathered}
$$

Conclui-se que é possível calcular a location probability $q$ em todos as células de uma região através de

$$
\begin{aligned}
& q=P(X \geq 0)=Q\left(\frac{-m_{X}}{\sigma_{X}}\right)=1-Q\left(\frac{m_{X}}{\sigma_{X}}\right) \\
& q=1-Q\left(\frac{m_{S}-m_{U}}{\sqrt{\sigma_{S}^{2}+\sigma_{U}^{2}}}\right)
\end{aligned}
$$

A soma das potências em dBm de $V, U$ e $X$ deve ser calculada no domínio linear como uma soma de variáveis aleatórias lognormal estatisticamente independentes. Esta soma não possui um resultado analítico e é calculada por um método de aproximação criado por Schwartz-Yeh [10], sendo o cálculo dos coeficientes simplificado como integrais numéricas por Ho [11]. A aproximação de Schwartz-Yeh e suas equações são descritas no Apêndice A.

Introduzindo uma potência interferente intersistema $Z$ em (2-1), a location probability é reduzida para um valor $q^{\prime}$ dado pela Equação (2-5).

$$
\begin{aligned}
& q^{\prime}=P\left(P_{S} \geq P_{S, \text { min }}+\sum_{k=1}^{n} r_{U, k} P_{U, k}+Z\right) \\
& q^{\prime}=P\left(P_{S} \geq U+Z\right)
\end{aligned}
$$

A diferença entre a location probability antes e depois da introdução de $Z$ define a degradação $\Delta q$. 


$$
\Delta q=q-q^{\prime}
$$

A metodologia Ofcom define a degradação máxima $\Delta q_{\max }$ em $7 \%$. Assim sendo, o valor da location probability $q$ para todas as células de uma região pode ser calculado usando (2-4). Então, o valor da location probability mínima pode ser calculada como $q^{\prime}=q-\Delta q_{\max }$ para estas células e, finalmente, calcula-se pela expressão (2-5) o valor máximo da potência interferente intersistema $Z$ para todas estas células.

O cálculo da máxima potência interferente $Z$ também pode ser realizado por simulação Monte Carlo ou pelo método analítico [14] [15] [16]. Para ambos, as potências $P_{S}, U$ e $Z$ são variáveis aleatórias (v.a.) gaussianas caracterizadas por média e desvio padrão. O método analítico permite desenvolver a expressão de $q^{\prime}$ conforme (2-7).

$$
\begin{aligned}
q^{\prime} & =P\left(P_{S} \geq U+Z\right) \\
& =P\left(1 \geq \frac{U}{P_{S}}+\frac{Z}{P_{S}}\right) \\
& =P(1 \geq A+B)=P(1 \geq Y) \\
& =P\left(0 \geq Y_{(d B m)}\right)
\end{aligned}
$$

Sendo

$$
\begin{aligned}
& Y \sim N\left(m_{Y}, \sigma_{Y}\right) ; m_{Y}=m_{A}+m_{B} ; \sigma_{Y}=\sqrt{\sigma_{A}^{2}+\sigma_{B}^{2}} \\
& A \sim N\left(m_{A}, \sigma_{A}\right) ; m_{A}=m_{U}-m_{S} ; \sigma_{A}=\sqrt{\sigma_{U}^{2}+\sigma_{S}^{2}} \\
& B \sim N\left(m_{B}, \sigma_{B}\right) ; m_{B}=m_{Z}-m_{S} ; \sigma_{B}=\sqrt{\sigma_{Z}^{2}+\sigma_{S}^{2}}
\end{aligned}
$$

O cálculo de $Y, A$ e $B$ deve ser realizada no domínio linear como soma de v.a. lognormal pelo método de aproximação Schwartz-Yeh [10], sendo o cálculo dos coeficientes simplificado como integrais numéricas por Ho [11]. A aproximação de Schwartz-Yeh e suas equações são descritas no Apêndice A.

Assim sendo, a location probability $q^{\prime}$ pode ser calculada utilizando as expressões em (2-3) de forma similar ao cálculo de $q$.

$$
\begin{aligned}
& q^{\prime}=P\left(0 \geq Y_{(d B m)}\right)=P(Y \leq 0)=1-P(Y>0) \\
& q^{\prime}=1-Q\left(\frac{-m_{Y}}{\sigma_{Y}}\right)=1-\left(1-Q\left(\frac{m_{Y}}{\sigma_{Y}}\right)\right) \\
& q^{\prime}=Q\left(\frac{m_{Y}}{\sigma_{Y}}\right)
\end{aligned}
$$

O método analítico para o cálculo da potência interferente máxima $Z$ de 
uma célula é desenvolvido utilizando o algoritmo iterativo mostrado abaixo. Neste um valor de tolerância $\epsilon$ é somado ao valor da degradação de $7 \%$ da location probability no teste do passo (5).

(1) Carrega-se um valor inicial para $Z \sim N\left(m_{Z}, \sigma_{Z}\right)$

(2) Calcula-se $Y \sim N\left(m_{Y}, \sigma_{Y}\right)$ pelas expressões obtidas em (2-7)

(3) Calcula-se $q^{\prime}$ pela Equação (2-8)

(4) Calcula-se $\Delta q=q-q^{\prime}$

(5) Se $\Delta q \in[0.07 \pm \epsilon]$, então o último $Z$ é solução. Caso contrário, incrementase ou decrementa-se o valor de $Z$ e retorna para passo (2).

\section{4}

\section{Máxima Emissão do WSD}

Uma vez calculada a máxima potência interferente intersistema $Z$ para todas as células de uma região, é possível calcular a máxima potência que um WSD pode transmitir em um canal de frequência e uma localização específica dentro desta região.

A metodologia de cálculo Ofcom define a potência máxima de transmissão do WSD como uma e.i.r.p. (equivalent isotropically radiated power) cuja potência interferente em uma célula qualquer que encontram-se ao redor dele (região de trabalho) deve satisfazer a máxima potência interferente $Z$ desta célula.

O cálculo das e.i.r.p. máximas de um WSD para um dado canal adjacente devem ser realizados até um raio de $2 \mathrm{~km}$ no entorno do WSD. Isto corresponde a 1257 células, ou seja, 1257 cálculos de e.i.r.p. máxima. A Figura 2.3 ilustra uma célula $k$ central, onde encontra-se o WSD, e uma célula $j$ dentro da área circular $\mathcal{S}_{k}$ com raio de $2 \mathrm{~km}$ utilizada para os cálculos das e.i.r.p. máximas.

O cálculo da potência máxima de transmissão do WSD na célula $k$ dentro da área $\mathcal{S}_{k}$ é calculado por

$$
E_{k j}=\frac{Z_{j}}{\rho(\Delta f) \cdot G_{k j}}
$$

O parâmetro $G_{k j}$ é conhecido como ganho de acoplamento e contabiliza o efeito de toda perda entre a antena do WSD e a entrada do receptor DTT. O parâmetro $\rho(\Delta f)$ é a taxa de proteção relativa a separação em frequência entre o canal DTT e WSD. 


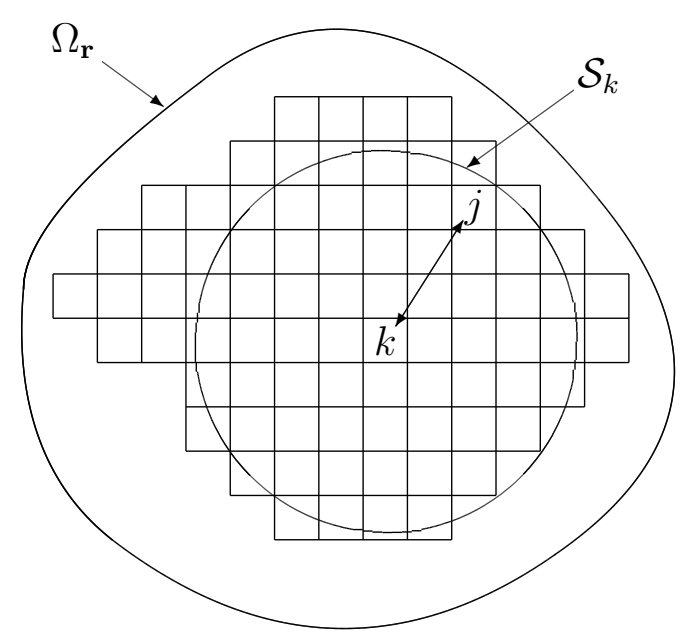

Figura 2.3: Diagrama para cálculo da (e.i.r.p. $)_{k j}$

Todas as informações necessárias para o cálculo da e.i.r.p. $E_{k j}$ estão disponíveis, uma vez que é conhecida a interferência intersistema máxima $Z$ de cada célula, a geolocalização do WSD e das células e os canais de frequência livres e ocupados na localização do WSD. Assim sendo, o primeiro passo é calcular os parâmetros listados abaixo, conforme ilustra a geometria da Figura 2.4 .

- A distância $r_{k j}$ e com ela a perda de propagação $L_{k j}$;

- O ângulo $\theta_{j}$ entre a direção de apontamento para o transmissor DTT e a direção do WSD e com ele o ganho da antena $g\left(\theta_{j}\right)$;

- A taxa de proteção $\rho(\Delta f)$ devido a diferença de frequência entre o canal do DTT e o canal do WSD.

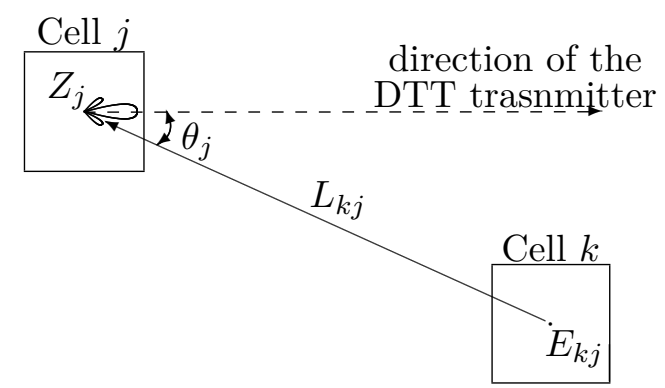

Figura 2.4: Geometria para o cálculo da e.i.r.p. $E_{k j}$

Um receptor DTT na célula $j$ será interferido por uma potência interferente $i_{k j}$ provocada por um WSD localizado na célula $k$, transmitindo com e.i.r.p. $E_{k j}$, conforme (2-10). Destacamos que a taxa de proteção possui valor negativo e por isso encontra-se com sinal positivo na equação.

$$
i_{k j}=E_{k j}+g\left(\theta_{j}\right)-L_{k j}+\rho(\Delta f)
$$


A perda de propagação $L_{k j}$ é calculada pelo modelo Hata extendido [17] e utiliza a distância $r_{k j}$ e a frequência central do canal DTT. Este modelo utiliza outras variáveis como o tipo de ambiente (clutter) e a altura das antenas. O clutter é classificado como urbano, suburbano ou área aberta, sendo definido conforme informações de banco de dados de mapas. A topografia do terreno não é considerada.

A altura da antena do DTT é fixada em 10m. A altura da antena do WSD deve ser informada pelo mesmo ao banco de dados WSDB, sendo aproximada para uma das 6 alturas mais próximas da sequência $\{1.5,5,10,15,20,30\}$. Caso o WSD não informe sua altura de antena, será utilizada a altura de $30 \mathrm{~m}$ para um WSD do tipo A e $1.5 \mathrm{~m}$ para um WSD do tipo B.

O WSD é classificado em tipo A (fixo outdoor) ou tipo B (portátil/móvel). Para os WSD tipo B com altura de antena maior que $2 \mathrm{~m}$, uma perda de $7 \mathrm{~dB}$ devido a penetração em prédios é adicionada no ganho de acoplamento.

O ganho da antena $g\left(\theta_{j}\right)$ é calculado pelo diagrama da antena ITU-R BT.419-3 [24]. O ganho máximo na direção de apontamento é de 9.15 dBi e já considera a perda do cabo. Não é considerada a discriminação por polarização. A Figura 2.5 mostra o diagrama da discriminação angular desta antena obtida em [7].

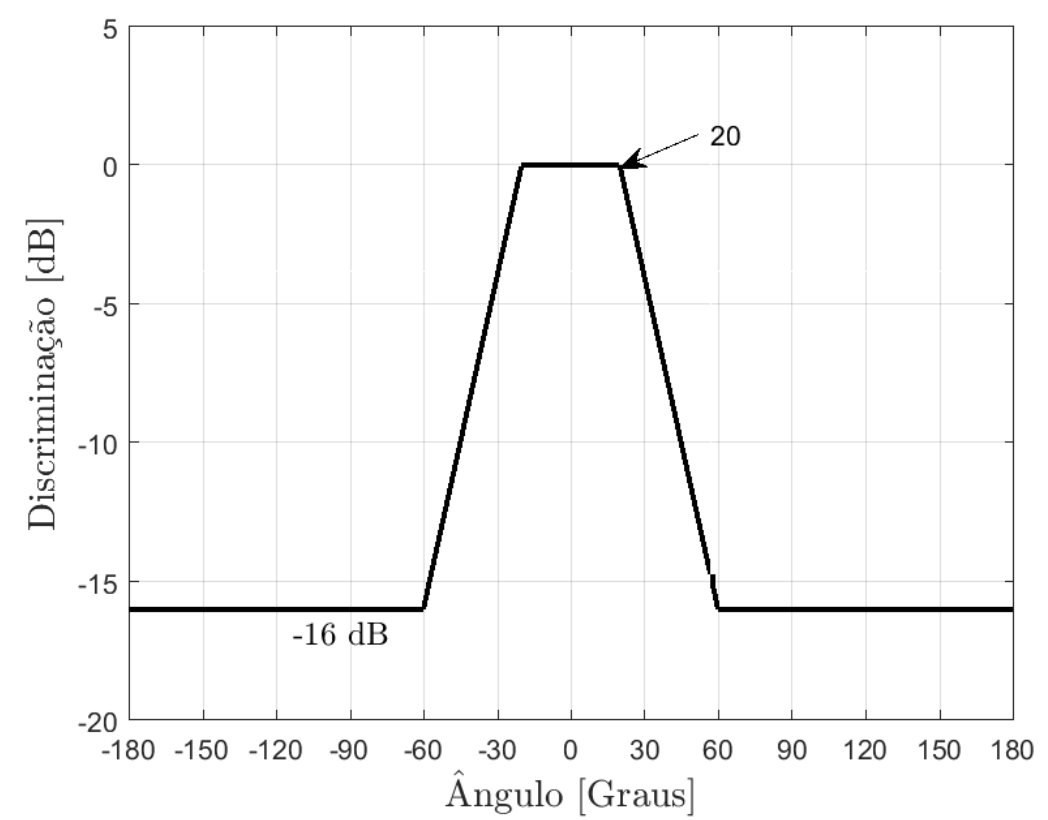

Figura 2.5: Diagrama da discriminação angular da antena ITU-R BT.419-3.

A taxa de proteção $\rho(\Delta f)$ é definida como a razão entre a potência de recepção do DTT e a potência de recepção do sinal interferente do WSD no 
ponto de falha do receptor DTT.

A taxa de proteção é tabelada em [7] através de medições realizadas em um grande número de receptores DTT de diferentes fabricantes. Os transmissores WSD são caracterizados nessas tabelas por 5 classes de emissões que são coerentes com o padrão ETSI Harmonised European Standard EN 301598 [33]. Os WSD da classe 1 possuem a melhor máscara de emissão do espectro de transmissão, enquanto a classe 5 possui a pior máscara de emissão.

Além da diferença em frequência, a taxa de proteção é função da potência de recepção mediana $m_{S}$ do DTT. Esta dependência é devido ao comportamento não linear do receptor DTT. Assim sendo, as tabelas são apresentadas como uma função $\rho\left(\Delta f, m_{S}\right)$.

A taxa de proteção, também, foi separada em 2 categorias: low e high. A categoria low corresponde aos WSD que apresentam transmissão contínua no tempo. Enquanto, a categoria high são para os WSD que apresentam transmissão descontínua no tempo. A taxa de proteção do receptor DTT apresenta uma significativa piora quando é interferido por tráfego descontínuo no tempo. Essa piora é refletida nas tabelas da categoria high.

Receptores DTT superheterodinos do padrão de TV digital DVB-T apresentam significativa piora da taxa de proteção na separação N+9 que corresponde a $72 \mathrm{MHz}$ de separação entre sinal desejado e interferente. Esta característica gerou a necessidade de introduzir linhas na tabela da taxa de proteção para considerar essa separação. Na Tabela 2.1 é mostrada uma das 10 tabelas de taxa de proteção obtida em [7].

Tabela 2.1: Taxa de proteção $\rho\left(\Delta F, m_{S}\right)$, em dB, para WSD categoria low classe 1.

\begin{tabular}{|c|c|c|c|c|c|c|c|}
\cline { 2 - 8 } \multicolumn{1}{c|}{} & \multicolumn{7}{c|}{$m_{S}(\mathrm{dBm})$} \\
\hline $\begin{array}{c}\text { Separação dos } \\
\text { Canais }\end{array}$ & $\leq-70$ & -60 & -50 & -40 & -30 & -20 & -12 \\
\hline$\Delta F= \pm 1$ & -36 & -37 & -36 & -32 & -29 & -23 & -15 \\
\hline$\Delta F= \pm 2$ & -42 & -41 & -42 & -36 & -31 & -23 & -15 \\
\hline$\Delta F= \pm 3$ & -46 & -45 & -43 & -37 & -31 & -23 & -15 \\
\hline$\Delta F= \pm 4$ & -48 & -46 & -44 & -38 & -31 & -23 & -15 \\
\hline$\Delta F= \pm 8$ & -55 & -52 & -47 & -40 & -32 & -23 & -15 \\
\hline$\Delta F=+9$ & -44 & -44 & -44 & -38 & -33 & -23 & -15 \\
\hline$\Delta F=-9$ & -57 & -54 & -48 & -40 & -32 & -23 & -15 \\
\hline$|\Delta F| \geq \pm 10$ & -57 & -54 & -48 & -40 & -32 & -23 & -15 \\
\hline
\end{tabular}

Utilizando os parãmetros e cálculos descritos, podemos calcular a e.i.r.p. máxima $E_{k j}$, fazendo $i_{k j}$ atender a condição da máxima potência interferente $Z$ da célula $j$, conforme Equação (2-11). 


$$
\begin{aligned}
& Z_{j} \geq i_{k j} \\
& Z_{j} \geq E_{k j}+g\left(\theta_{j}\right)-L_{k j}+\rho(\Delta f) \\
& E_{k j} \leq Z_{j}-g\left(\theta_{j}\right)+L_{k j}-\rho(\Delta f)
\end{aligned}
$$

A e.i.r.p. máxima regulatória $E_{k}^{R e g}$ é calculada para atender a todas as máximas potências interferentes $Z_{j}$ das células ao redor do WSD dentro da área $\mathcal{S}_{k}$. Assim sendo, a e.i.r.p. regulatória $E_{k}^{\text {Reg }}$ deve ser a menor de todas as e.i.r.p. máximas $E_{k j}$ dentro da área $\mathcal{S}_{k}$.

$$
E_{k}^{R e g}=\min _{j}\left(E_{k j}^{M a ́ x}\right)
$$

Nota-se que a e.i.r.p. regulatória $E_{k}^{R e g}$ foi definida por uma única célula que possui o menor valor das e.i.r.p. máximas $E_{k j}$. Caso o WSD aumentasse sua potência acima de $E_{k}^{R e g}$, esta célula seria a primeira a ter sua potência interferente máxima $Z$ ultrapassada. Por isso, chamaremos esta célula de célula mais vulnerável.

\section{5}

\section{Indeterminação da Localização do Receptor DTT}

A indeterminação da localização do receptor DTT introduz duas questões. A primeira é a distância entre WSD e o receptor DTT. A segunda é o ângulo da antena entre a direção de apontamento para o transmissor DTT e a direção do WSD. Para tratar essas questões as células foram classificadas em camadas, chamadas Tiers, ao redor do WSD, conforme Figura 2.6 obtida em [6].

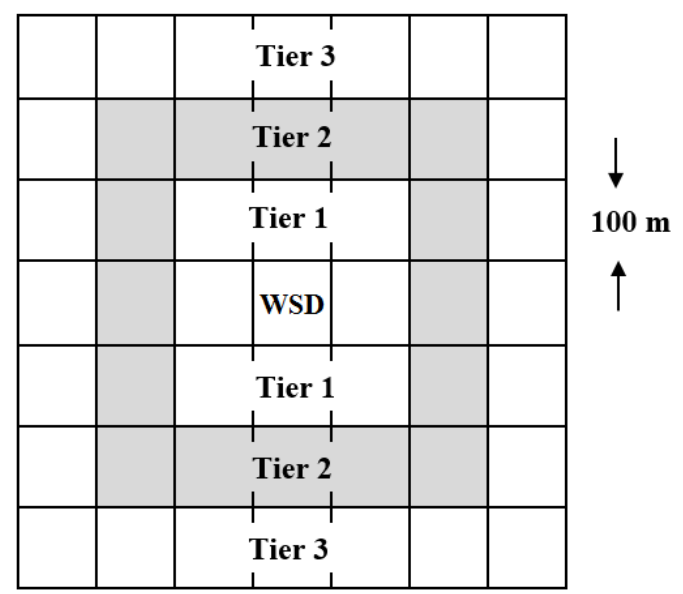

Figura 2.6: Tiers ao redor de um WSD. 
O Tier 0 é a célula em que o WSD se encontra. O Tier 1, 2, 3 e demais são as células vizinhas ao Tier imediatamente anterior. Utilizando este modelo de camadas, o problema da indeterminação da localização do DTT foi solucionado dividindo essas camadas em 3 conjuntos com métodos de cálculo distintos para distância e ângulo da antena.

\section{Tier 3 e demais $(m \geq 3)$}

Nestas células, a distância e ângulo da antena são calculados, utilizando o centro da célula como referência para a localização do DTT.

O cálculo mostrado na subseção 2.4 para a máxima emissão do WSD representa o método de cálculo do Tier 3 e demais, pois utiliza distância e ângulo da antena calculados pela aproximação do centro da célula.

Tier $2(m=2)$

Nestas células são utilizadas estatísticas apenas para distância. O ângulo da antena é calculado, utilizando o centro da célula como referência para a localização do DTT. Uma tabela é definida para ser utilizada como um dos fatores para o cálculo do ganho de acoplamento G. A geometria para Tier 2 é mostrada na Figura 2.7 obtida em [7].

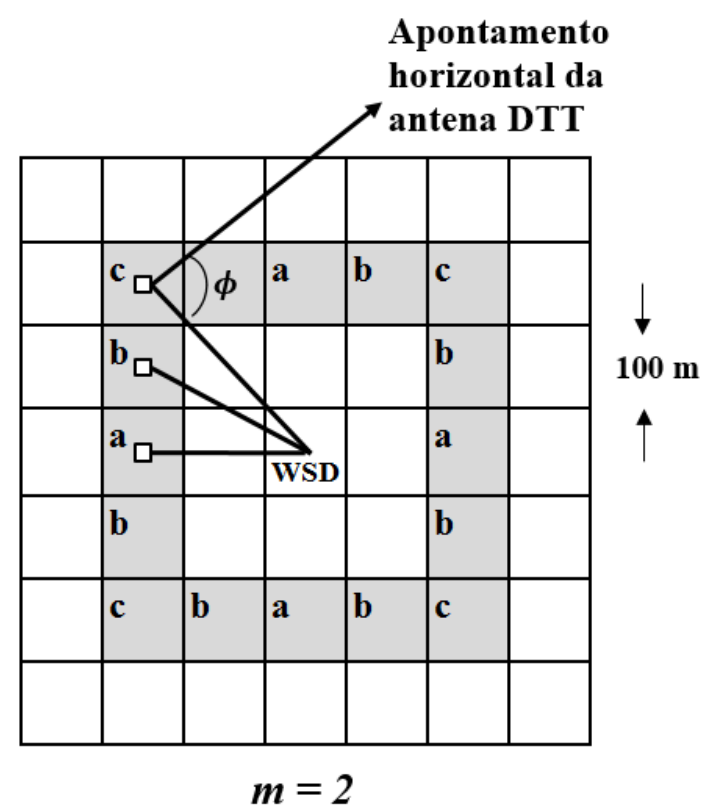

Figura 2.7: Geometria para Tier 2.

As células desta camada são divididas em 3 tipos $\{a, b, c\}$. A perda devido a distância é especificada através de um ganho de acoplamento de referência $G_{a}$, $G_{b}$ ou $G_{c}$, conforme o tipo da célula. Os valores são obtidos para um percentil de $90 \%$ para uma distribuição aleatória uniforme da localização do transmissor 
WSD e do receptor DTT nas células relevantes. O ganho de acoplamento de referência inclui o ganho máximo na direção de apontamento de 9.15 dBi. A Tabela 2.2, obtida em [7], apresenta os valores utilizados em função do tipo de célula, clutter e altura da antena.

Tabela 2.2: Ganho de acoplamento de referência para Tier 2.

\begin{tabular}{|c|c|c|c|c|c|c|c|c|c|}
\hline & \multicolumn{9}{|c|}{ Tier 2: Ganho de acoplamento (área aberta, suburbano, urbano) } \\
\hline & \multicolumn{3}{|c|}{ Célula tipo a } & \multicolumn{3}{|c|}{ Célula tipo b } & \multicolumn{3}{|c|}{ Célula tipo c } \\
\hline $\begin{array}{c}\text { Altura } \\
\text { Antena WSD }\end{array}$ & \multicolumn{3}{|c|}{$G_{a}(\mathrm{~dB})$} & \multicolumn{3}{|c|}{$G_{b}(\mathrm{~dB})$} & \multicolumn{3}{|c|}{$G_{c}(\mathrm{~dB})$} \\
\hline $1.5 \mathrm{~m}$ & -65 & -82 & -91 & -67 & -85 & -93 & -71 & -89 & -97 \\
\hline $5 \mathrm{~m}$ & -60 & -74 & -83 & -62 & -77 & -85 & -64 & -81 & -90 \\
\hline $10 \mathrm{~m}$ & -60 & -63 & -72 & -62 & -65 & -74 & -64 & -70 & -78 \\
\hline $15 \mathrm{~m}$ & -60 & -60 & -68 & -62 & -62 & -70 & -64 & -66 & -75 \\
\hline $20 \mathrm{~m}$ & -60 & -60 & -66 & -62 & -62 & -68 & -64 & -64 & -72 \\
\hline $30 \mathrm{~m}$ & -60 & -60 & -62 & -62 & -62 & -64 & -64 & -64 & -69 \\
\hline
\end{tabular}

O ganho de acoplamento $G$ é calculado adicionando o ganho de acoplamento de referência ao ganho (discriminação angular) da antena $g(\phi)$. Este último é calculado através do ângulo $\phi$ entre a direção de apontamento para o transmissor DTT e a direção do centro do Tier 0 . O cálculo de G, em dB, pode ser realizado como

$$
G=G_{x}+g(\phi) \quad \text { onde x=a, b ou c. }
$$

Os valores dos ganhos de acoplamento de referência $G_{a}, G_{b}$ e $G_{c}$ são tabelados para a frequência de $474 \mathrm{MHz}$. Os valores para uma frequência $\mathrm{F}$, frequência central do canal DTT em $\mathrm{MHz}$, pode ser calculado adicionando o valor da expressão.

$$
20 \log \left(\frac{474}{F}\right)
$$

Tier 0/1 $(m=0 / 1)$

Nestas células são utilizadas estatísticas para distância e ângulo da antena, resultando em uma tabela que será o próprio ganho de acoplamento $G$. Estas camadas são as mais afetadas pela indeterminação da localização do DTT, uma vez que o DTT está na mesma célula (Tier 0) ou em uma célula imediatamente adjacente (Tier 1 ) ao WSD, conforme mostra a Figura 2.8 obtida em [7].

O ganho de propagação $G$ é definido, exclusivamente, pelo percentil de $90 \%$ dos valores baseados em uma distribuição aleatória da localização dos receptores DTT ao redor de um WSD para as alturas de antena do WSD consideradas. A Tabela 2.3, obtida em [7], apresenta os valores do ganho de acoplamento de referência $G_{0}$ utilizado como ganho de acoplamento para os Tiers $0 / 1$. 

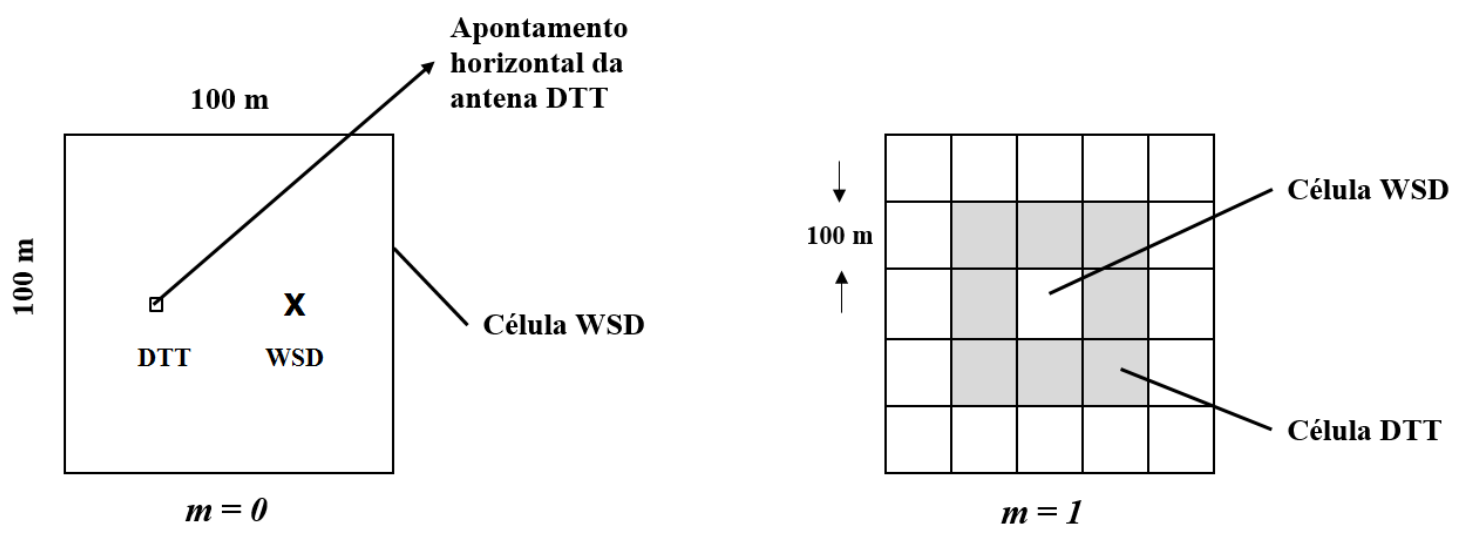

Figura 2.8: Geometria para Tier $0 / 1$.

Os valores do ganho de acoplamento de referência $G_{0}$ são tabelados para a frequência de $474 \mathrm{MHz}$. De forma idêntica a Tier 2, os valores para uma frequência F, frequência central do canal DTT em $\mathrm{MHz}$, pode ser calculado adicionando o valor da expressão (2-14).

Tabela 2.3: Ganho de acoplamento de referência para Tier 0/1.

\begin{tabular}{|c|c|}
\hline Altura Antena WSD & $\begin{array}{c}\text { Ganho de Acoplamento } G_{0}(\mathrm{~dB}) \\
\text { (área aberta, suburbano, urbano) }\end{array}$ \\
\hline $1.5 \mathrm{~m}$ & -49 \\
\hline $5 \mathrm{~m}$ & -45 \\
\hline $10 \mathrm{~m}$ & -43 \\
\hline $15 \mathrm{~m}$ & -45 \\
\hline $20 \mathrm{~m}$ & -50 \\
\hline $30 \mathrm{~m}$ & -56 \\
\hline
\end{tabular}

Média da e.i.r.p. para Tier $\mathbf{0 / 1}$ O procedimento adotado para as 9 células do Tier $0 / 1$ resulta em um valor de ganho de acoplamento único, logo para um par de canais de frequência livre (WSD) e ocupado(DTT), o valor calculado para as 9 máximas e.i.r.p. será o mesmo.

O cálculo de um único valor para a máxima e.i.r.p. em um dado canal de frequência para as 9 células do Tier $0 / 1$ distorce a minimização adotada para obter a célula mais vulnerável e com ele a máxima emissão do WSD.

Neste caso, calcula-se o valor médio, em dBm, da máxima e.i.r.p. para um dado canal de frequência de todas as 9 células do Tier $0 / 1$. Esta média é calculada considerando os canais de frequência ocupados dos transmissores $\operatorname{DTT}\left(F_{D T T}\right)$ como

$$
E_{k, 0 / 1}=\operatorname{mean}_{j \in \operatorname{Tier} 0 / 1}\left(E_{k j}\left(F_{D T T}\right)\right)
$$




\section{3 \\ Descrição Detalhada do Problema}

Neste capítulo é desenvolvido o detalhamento do problema da metodologia Ofcom, demonstrando a vulnerabilidade do receptor DTT à interferência agregada das emissões dos WSDs.

Um resumo da metodologia de cálculo é descrito na Seção 3.1. Os procedimentos de admissão Ofcom e ECC.186 são desenvolvidos nas seções 3.2 e 3.3. A diferença nas definições das potências interferentes intersistema $Z$ e intrasistema $P_{U, k}$ é apresentada na Seção 3.4. Por fim, a Seção 3.5 demonstra a ultrapassagem da potência interferente intersistema limite $Z$ pela potência interferente agregada das emissões de WSDs em uma mesma célula e em células diferentes.

\section{1}

\section{Aspectos Relevantes da Metodologia Ofcom}

A radiodifusão de TV digital é atualmente um serviço primário na faixa de freqüências de 470-790 MHz e deve ser protegida de interferências que prejudiquem a operação do sistema. No Brasil, uma parte da faixa, conhecida como faixa de $700 \mathrm{MHz}(698-806 \mathrm{MHz})$ foi leiloada para serviços móveis de tecnologia $4 \mathrm{G}$ em setembro de 2014.

O método de planejamento da cobertura das redes de radiodifusão de TV é o ponto de partida para definição de limites para a interferência produzida por sistemas secundários que utilizem a mesma faixa de frequência. Conhecendose a maneira pela qual o sistema de TV digital (DTT) limita sua própria interferência, é possível definir limites para interferência de um dispositivo que utilize os canais livres, operando como um serviço secundário na faixa.

O relatório ECC.186 [5], emitido em 2013, descreveu a metodologia de planejamento das redes de TV aplicado na definição da limitação de interferências intersistemas. Metodologia similar foi apresentada no regulamento Implementing TV white spaces [6] emitido, em 2015, pela agência reguladora Ofcom do reino unido.

A metodologia Ofcom foi apresentada no Capítulo 2. Abordaremos aqui alguns aspectos do que foi apresentado naquela seção para descrição do problema de que trata esta tese. 
A área total de cobertura de uma rede de radiodifusão de TV é, geralmente, subdividida em unidades de área que denominaremos células, tipicamente com tamanho de $100 \mathrm{~m}$ x $100 \mathrm{~m}$. O nível do sinal recebido varia com a localização do receptor dentro desta célula. A qualidade de cobertura de uma célula, usualmente conhecida como location probability, é definida como a fração da célula onde a potência na entrada do receptor DTT é superior a um valor de potência mínimo requerido $P_{\text {lim }}$. Assim, dada uma célula com location probability $q$, podemos escrever

$$
q=P\left(P_{S} \geq P_{\text {lim }}\right)
$$

onde $P()$ denota probabilidade, $P_{S}$ é a potência recebida no receptor DTT e $P_{\text {lim }}$ é uma potência mínima requerida pelo receptor.

As interferências no receptor DTT são dependentes do tempo, devido a fenômenos de propagação que ocorrem conforme as condições atmosféricas. Os efeitos dos fenômenos de propagação são contabilizados no planejamento, utilizando-se a disponibilidade no tempo dos sinais desejado e interferente. A recomendação ITU-R P.1546 fornece curvas de propagação para 1\% e 50\% do tempo. A curva de $\mathrm{x} \%$ fornece um valor de campo elétrico que é excedido $\mathrm{x} \%$ do tempo.

No planejamento dos sistemas DTT os sinais interferentes são calculados com base nas curvas para $1 \%$ do tempo, enquanto sinais desejados são calculados com base nas curvas para 50\% do tempo [5]. Quando o sistema DTT opera sozinho na faixa, existem apenas interferências intrasistema e a potência limite é geralmente definida como

$$
P_{l i m}=P_{S, \min }+\sum_{k=1}^{n} r_{U, k} P_{U, k}
$$

sendo $P_{S, \text { min }}$ a sensibilidade do receptor DTT considerando-se apenas ruído, e $P_{U, k}$ a potência de recepção interferente do $k$-ésimo transmissor DTT (potência excedida $1 \%$ do tempo). Ainda em (3-1), $r_{U, k}$ é a taxa de proteção, associada ao $k$-ésimo transmissor DTT, devida à discriminação em frequência resultante da seletivid,ade do receptor em função da separação em frequência de seus canais.

A introdução de uma interferência externa adicional, resulta em uma redução da location probability planejada para o sistema DTT. Esta degradação da location probability é uma métrica adequada para especificar limites máximos para a interferência de sistemas secundários compartilhando a mesma faixa de frequências. Caso uma célula esteja sujeita a uma interferência externa adicional, a potência requerida $P_{\text {lim }}$ para a operação do receptor DTT é dada 
por

$$
P_{l i m}=P_{S, \min }+\sum_{k=1}^{n} r_{U, k} P_{U, k}+Z
$$

onde o parâmetro $Z$ é a potência interferente intersistema na célula.

Consequentemente, a location probability desta célula é degradada para um valor $q^{\prime}$ dado por

$$
q^{\prime}=P\left(P_{S} \geq P_{S, \min }+\sum_{k=1}^{n} r_{U, k} P_{U, k}+Z\right)
$$

Note que o valor de $Z$ deve ser limitado para garantir uma degradação máxima aceitável $\epsilon$ da location probability. O valor desta degradação máxima está associada a uma perda de cobertura aceitável para o sistema DTT e deve ser definida pelo órgão regulador do país que venha a adotar essa metodologia.

$$
\Delta q=q-q^{\prime} \leq \epsilon
$$

Uma vez especificado o valor da degradação máxima $\epsilon$ e conhecido o valor inicial $q$ da location probability para todas as células da região, o valor mínimo de $q^{\prime}$ pode ser calculado em (3-4) para todas as células e, através de (3-3), pode-se calcular o valor máximo de $Z$, também, para todas as células. O método analítico deste cálculo foi desenvolvido na Seção 2.3.

Conhecido os valores de $Z$ para todas as células da região, é possível determinar um valor máximo de potência de transmissão para um WSD em uma localização qualquer dentro desta região. Isto é feito garantindo que a potência interferente produzida pelo WSD em uma célula seja inferior aos valores de $Z$ associados as células da região.

A partir de uma certa distância, a potência interferente do WSD terá seu valor muito reduzido, sendo por isso desprezada em comparação aos demais parâmetros do cálculo da location probability. Assim sendo, é possivel traçar uma área circular $\mathcal{S}_{k}$ ao redor do WSD onde encontram-se as células que serão consideradas no cálculo. A Figura 3.1 (repetida da Figura 2.3) ilustra uma célula $k$ onde encontra-se o WSD e uma célula $j$ dentro da área circular $\mathcal{S}_{k}$.

A partir desta geometria o cálculo da potência de transmissão do WSD localizado em $k$ pode ser efetuado pela equação (3-5).

$$
E_{k j}=\frac{Z_{j}}{\rho(\Delta f) G_{k j}}
$$

Onde $E_{k j}$ é a potência de transmissão do WSD localizado na célula $k$ devida a máxima potência interferente $Z_{j} ; G_{k j}$ é conhecido como ganho de acoplamento e contabiliza o efeito conjunto da perda de propagação devido a distância entre a célula $k$ e a célula $j$ e do ganho da antena associado ao ângulo de chegada da interferência em relação a direção de apontamento da antena DTT e $\rho(\Delta f)$ é a taxa de proteção relativa a separação em frequência $\Delta f$ 


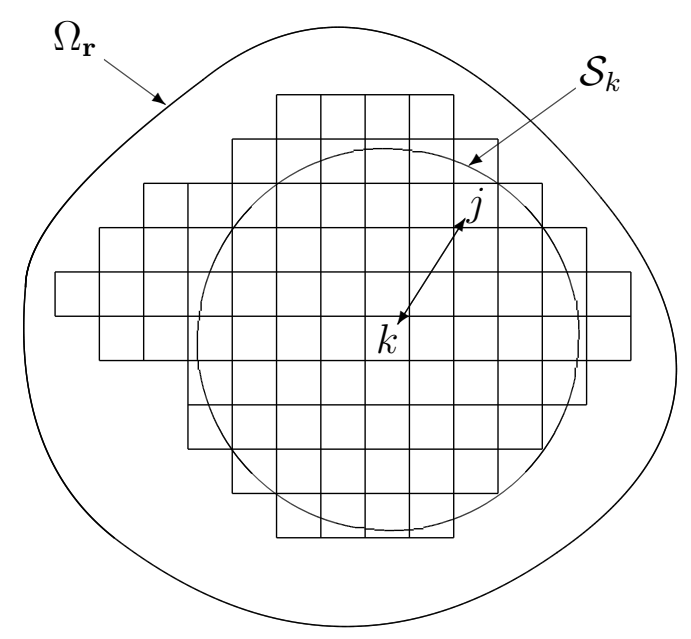

Figura 3.1: Diagrama para cálculo da potência de transmissão $E_{k j}$

entre os canais de frequência do DTT e do WSD. A Equação (3-5) é utilizada para calcular as potências máximas de transmissão do WSD devido as células existentes em $\mathcal{S}_{k}$.

O cálculo do ganho de acoplamento $G_{k j}$ considera variáveis como perda de propagação e ganho da antena quando a distância entre a célula $j$ e a célula $k$ é uma boa aproximação da distância entre o receptor DTT e o transmissor WSD. Entretanto, quando a célula $j$ é a mesma ou adjacente a célula $k$, a aproximação da distância não é mais adequada dada a curta distância entre as células e a indeterminação da localização do receptor DTT. Neste caso, o ganho de acoplamento $G_{k j}$ é calculado a partir de uma geometria de referência entre o receptor DTT e o transmissor WSD.

Idealmente, esta geometria de referência leva em conta a menor separação possível, dentro das condições reais de operação, para garantir que a interferência no receptor DTT não seja significativa. Neste caso, o ganho de acoplamento é determinado através de uma tabela cujos valores são calculados por avaliações estatísticas e medições da geometria de referência mais adequada.

Após o cálculo de todos $E_{k j}$, calcula-se a potência máxima de transmissão regulatória da célula $k$, selecionando o menor dos $E_{k j}$ máximos.

$$
E_{k}=\min _{j}\left(E_{k j}^{\max }\right)
$$

É possível notar que a metodologia Ofcom que define a máxima emissão do WSD utiliza uma abordagem single entry. Ou seja, a potência máxima de transmissão regulatória é definida pelo valor máximo de potência interferente $Z$ de uma única célula, mais especificamente, ao valor de $Z$ associado à célula mais vulnerável dentro da área $\mathcal{S}_{k}$. 
Esta potência máxima de transmissão regulatória é definida como uma e.i.r.p. (equivalent isotropically radiated power) máxima da célula para um dado canal de frequência e é informada pelo banco de dados WSDB ao WSD em processo de admissão no sistema.

A Figura 3.2 ilustra de forma simplificada a comunicação entre o WSDB e o WSD em processo de admissão.

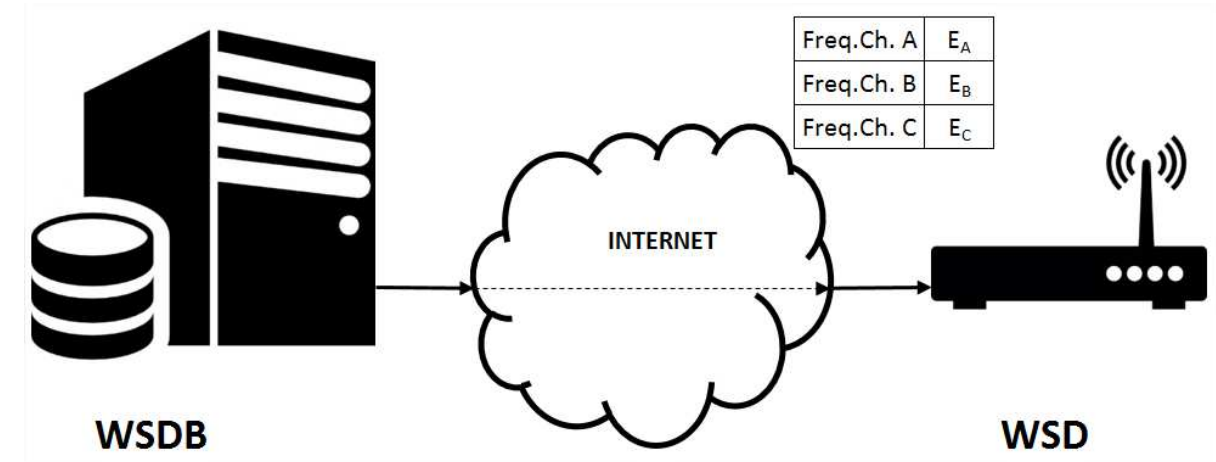

Figura 3.2: WSDB informa canais e potências máximas permitidas ao WSD em processo de admissão.

O WSD seleciona o canal de frequência que irá operar e retorna ao WSDB esta informação. O WSD inicia a contagem do período de tempo permitido para ocupar o canal de frequência selecionado. No final deste tempo de retorno máximo $(\Delta)$, o WSD deve reiniciar o procedimento de admissão para continuar no mesmo ou selecionar outro canal de frequência, recebendo neste processo novos parâmetros.

Três questões importantes não foram abordadas pela metodologia Ofcom. A primeira está relacionada a mudança no tratamento dado a interferência intersistema quando comparada a interferência intrasistema, esta questão é abordada na Seção 3.4. As duas outras questões estão relacionadas a não limitação da interferência agregada de WSDs operando simultaneamente no mesmo canal de frequência, estas questões são abordadas na Seção 3.5.

\section{2}

\section{Procedimento de Admissão Ofcom}

A metodologia de cálculo Ofcom considera que, em geral, os WSDs utilizam uma e.i.r.p. menor que a e.i.r.p. máxima regulatória informada pelo banco de dados WSDB. Isto ocorre devido ao uso de tecnologias adaptativas que controlam os parâmetros de transmissão conforme o estado do enlace rádio. Esta premissa permite modelar a potência de transmissão do WSD admitido no sistema como uma variável aleatória. 
A restrição fundamental da metodologia Ofcom é a e.i.r.p. regulatória de uma célula que não deve ser ultrapassada. Esta premissa permite definir que a soma das e.i.r.p. dos WSDs em operação dentro de uma mesma célula está limitada à e.i.r.p. regulatória desta célula.

Apesar da metodologia de cálculo Ofcom não apresentar como o banco de dados WSDB vai garantir a restrição da e.i.r.p. regulatória da célula, é possível utilizar as duas premissas acima para definir a metodologia Ofcom para admissão de WSDs, mostrada na Figura 3.3.

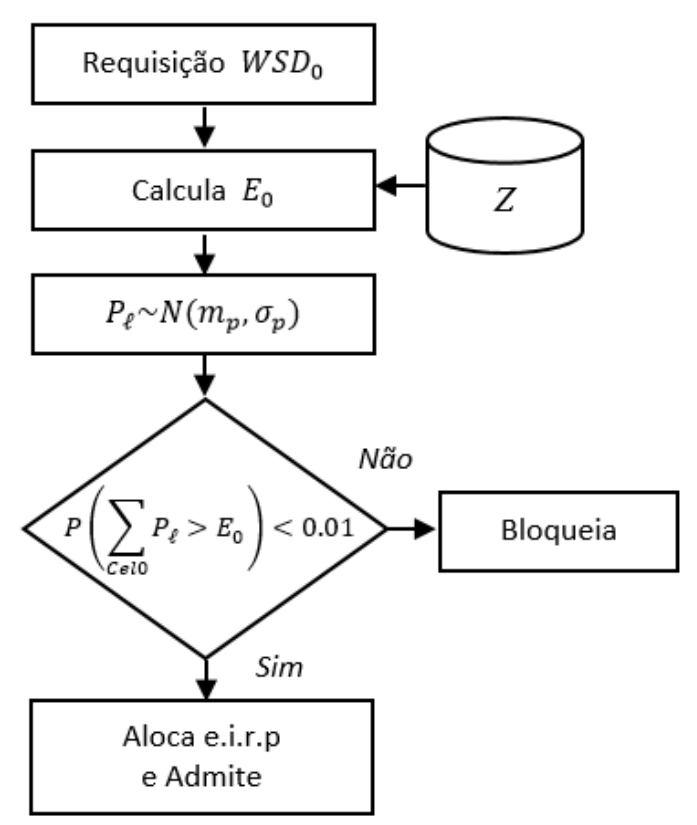

Figura 3.3: Procedimento de admissão baseado na metodologia Ofcom.

O procedimento inicia com a requisição de admissão do novo WSD $\left(\mathrm{WSD}_{0}\right)$ e o cálculo da e.i.r.p. máxima regulatória $E_{0}$ da célula em que o $\mathrm{WSD}_{0}$ está localizado. Este cálculo utiliza a base de dados da potência interferente intersistema $Z$.

O critério de admissão deve limitar o somatório das e.i.r.p. $P_{\ell}$ de todos os WSDs que se encontram dentro da mesma célula do $\mathrm{WSD}_{0}$. O limite deste somatório é a e.i.r.p. máxima regulatória $E_{0}$ desta célula, nomeada como Célula 0 (Cel0). Modelando as potências de transmissão $P_{\ell}$ como variáveis aleatórias estatísticamente independentes, então o somatório das $P_{\ell}$ também é uma variável aleatória e o critério de admissão pode ser avaliado limitando a probabilidade do somatório das $P_{\ell}$ de ser maior que $E_{0}$ a um valor baixo. Assim, o critério de admissão Ofcom é escrito como

$$
P\left(\sum_{C e l 0} P_{\ell}>E_{0}\right)<p
$$


onde $p$ é o limite do critério de admissão cujo valor adotado neste trabalho é 0.01 .

Caso o critério de admissão seja atendido, o $\mathrm{WSD}_{0}$ é admitido. Caso contrário, o $\mathrm{WSD}_{0}$ é bloqueado. Neste último caso, o novo WSD deve buscar outro canal de frequência em cujo número de WSDs dentro da sua célula atenda ao critério de admissão.

\section{3}

\section{Procedimento de Admissão Ecc.186}

Uma alternativa para garantir a restrição da e.i.r.p. regulatória de uma célula é dividir esta e.i.r.p. máxima entre os WSDs que estão dentro da célula. Esta abordagem foi descrita no relatório ECC.186 [5] através de 3 possíveis soluções.

A primeira solução divide igualmente a e.i.r.p. regulatória, utilizando o número potencial de WSDs na mesma célula. Neste caso, enquanto o número potencial de WSDs não for atingido, a e.i.r.p. regulatória é subutilizada.

A segunda solução divide igualmente a e.i.r.p. regulatória, utilizando o número de WSDs ativos na mesma célula. Neste caso, a única subutilização seria a diferença entre a e.i.r.p. definida pelo WSDB e a e.i.r.p. real utilizada pelos WSDs ativos.

A terceira solução avalia a e.i.r.p. real do WSD e divide a e.i.r.p. regulatória de acordo com as necessidades de cada dispositivo que se encontra na mesma célula. Neste caso, o WSDB terá um maior custo computacional e de comunicação devido ao aumento do tráfego de informações.

Um procedimento de admissão de WSDs foi desenvolvido nesta tese, utilizando a segunda solução do relatório ECC.186 e por isso nomeada como Ecc.186, conforme mostra o diagrama da Figura 3.4.

O objetivo na utilização do procedimento de admissão Ecc.186 é ter uma referência para o critério de admissão de WSDs na qual o somatório das e.i.r.p. $P_{\ell}$ nunca ultrapassa a e.i.r.p. regulatória, uma vez que as mesmas são definidas deterministicamente pela divisão da e.i.r.p. regulatória.

O processo se inicia com a requisição de admissão do $\mathrm{WSD}_{0}$ e o cálculo da e.i.r.p. máxima regulatória $E_{0}$ de forma idêntica ao procedimento de admissão Ofcom. A e.i.r.p. $P_{\ell}$ de cada WSD é calculada dividindo a e.i.r.p. máxima regulatória $E_{0}$ pelo número total $n$ de WSDs que se encontram na mesma célula do $\mathrm{WSD}_{0}$, nomeada como Célula 0 . Este valor de $P_{\ell}$, em dBm, é calculado por

$$
P_{\ell}=E_{0}-10 \log (n)
$$

A redução da potência de transmissão do WSD pode implicar na redução 


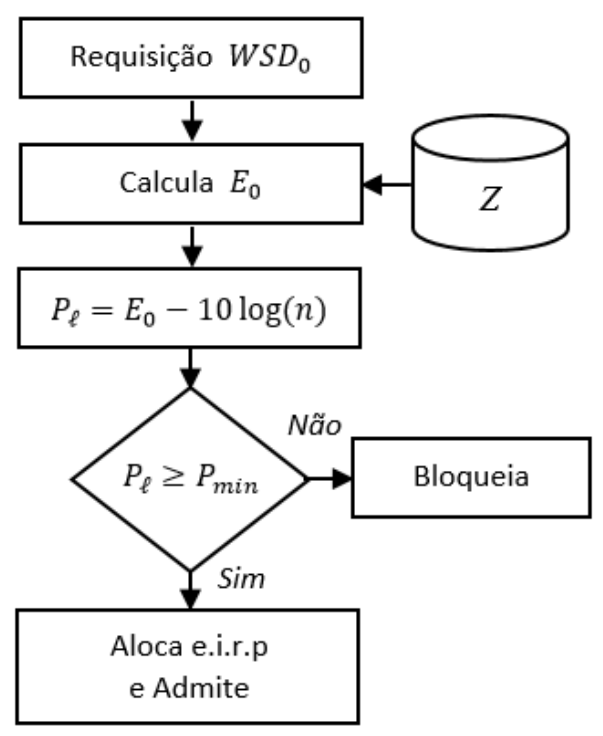

Figura 3.4: Procedimento de admissão baseado na metodologia Ecc.186.

da taxa de transmissão, logo uma e.i.r.p. mínima de trabalho $P_{\min }$ é definida para que o WSD possa operar com uma taxa de transmissão adequada.

O critério de admissão ECC.186 é avaliado comparando $P_{\ell}$ e $P_{\text {min }}$, como mostrado em (3-9). Caso $P_{\ell}$ não tenha sido reduzida abaixo do valor mínimo, então $\mathrm{WSD}_{0}$ é admitido. Caso contrário, $\mathrm{WSD}_{0}$ é bloqueado.

$$
P_{\ell} \geq P_{\min }
$$

Um custo associado ao procedimento de admissão Ecc.186 é o maior tempo de admissão quando existir outros WSDs operando na Célula 0. Neste caso, os WSDs em operação na Célula 0 devem reduzir suas e.i.r.p. antes que o $\mathrm{WSD}_{0}$ possa iniciar sua operação, representando um atraso adicional na admissão. Este procedimento é necessário para que a soma das e.i.r.p. dos WSDs na Célula 0 não ultrapasse a e.i.r.p. máxima $E_{0}$ ainda que temporariamente. Note que quando o $\mathrm{WSD}_{0}$ encontra a Célula 0 sem WSDs operando, ele pode ser admitido sem atraso adicional.

Este custo de admissão é avaliado pelo tempo médio de admissão de um WSD no procedimento de admissão Ecc.186. Considere dois eventos associados a admissão do $\mathrm{WSD}_{0}$ como mostrado na Figura 3.5. O evento $E$ (Empty) representa a chegada do $\mathrm{WSD}_{0}$ no sistema quando o número de WSDs operando na Célula 0 é igual a zero, enquanto o evento $\bar{E}$ representa a chegada do $\mathrm{WSD}_{0}$ no sistema quando o número de WSDs operando na Célula 0 é diferente de zero.

O tempo de admissão do $\mathrm{WSD}_{0}$ na Célula 0 é uma variável aleatória (v.a.) que pode ser calculada através da regra da partição do espaço amostral 


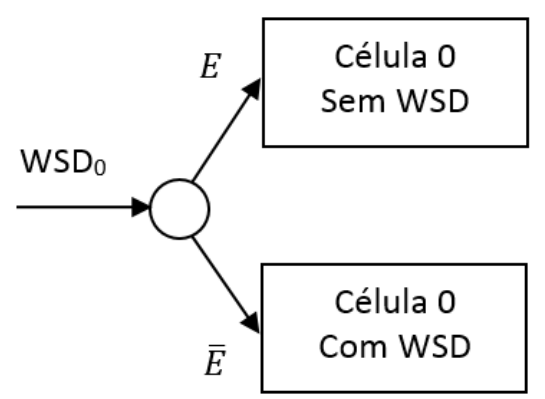

Figura 3.5: Eventos associados a admissão do $\mathrm{WSD}_{0}$ no procedimento de admissão Ecc.186.

aplicada a sua função densidade de probabilidade (fdp).

$$
p_{t}(T)=p_{t \mid E}(T) \cdot P(E)+p_{t \mid \bar{E}}(T) \cdot P(\bar{E})
$$

onde $p_{t}(T)$ é a fdp do tempo de admissão não condicional, $p_{t \mid E}(T)$ é a fdp do tempo de admissão dado que o evento $E$ ocorreu, $p_{t \mid \bar{E}}(T)$ é a fdp do tempo de admissão dado que o evento $\bar{E}$ ocorreu, sendo $P(E)$ e $P(\bar{E})$ as probabilidades dos eventos $E$ e $\bar{E}$, respectivamente.

A fdp $p_{t \mid E}(T)$ pode ser modelada como um impulso na origem, pois não existe atraso quando o $\mathrm{WSD}_{0}$ encontra a Célula 0 vazia, ou seja

$$
p_{t \mid E}(T)=\delta(T)
$$

Quando ocorre o evento $\bar{E}$ e o critério de admissão é satisfeito, então o $\mathrm{WSD}_{0}$ somente poderá iniciar operação no sistema após a redução das potências dos WSDs em operação localizados na mesma Célula 0. Seja $\tau_{i}$ o tempo até o retorno da comunicação do $\mathrm{WSD}_{i}$ com o banco de dados WSDB, contado a partir da chegada do $\mathrm{WSD}_{0}$, conforme Figura 3.6.

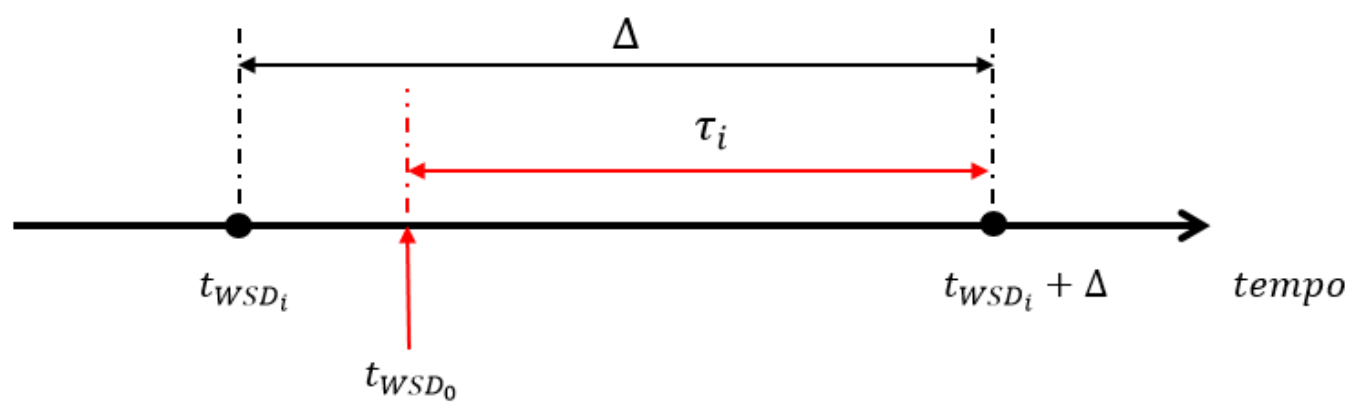

Figura 3.6: Tempo de retorno $\tau_{i}$ contado do instante de chegada do $\mathrm{WSD}_{0}$ até o retorno da comunicação do $\mathrm{WSD}_{i}$ com o banco de dados WSDB.

Nesta Figura, o tempo $t_{W S D_{i}}$ é o instante de admissão do $\mathrm{WSD}_{i}$ no sistema e o tempo $t_{W S D_{0}}$ é o instante de chegada do $\mathrm{WSD}_{0}$, ou seja, o instante da requisição de admissão. O tempo de retorno máximo $\Delta$ é definido na Seção 
3.1, conforme regulamento Ofcom [6], sendo este parâmetro fixado pelo banco de dados WSDB para todos os WSDs do sistema. Assim sendo, o tempo de retorno $\tau_{i}$ é definido como o tempo entre o instante de chegada do $\mathrm{WSD}_{0}$ e o próximo instante de retorno da comunicação do $\mathrm{WSD}_{i}$ com o WSDB.

Assim, o tempo de admissão do $\mathrm{WSD}_{0}$ está associado ao tempo de retorno $\tau_{i}$ de cada WSD em operação na Célula 0 . Então, o tempo de admissão pode ser calculado como $t=\max \left(\tau_{i}\right)$, sendo $i=1 \ldots n$ e $n$ é o número de WSDs em operação na Célula 0.

O tempo de retorno pode ser modelado como uma v.a. independente e identicamente distribuídas (i.i.d.) com densidade de probabilidade uniforme entre 0 e o tempo de retorno máximo $\Delta$. Esta modelagem permite definir a função distribuição de probabilidade (FDP) da v.a. tempo de admissão $t$ como

$$
\begin{aligned}
F_{t \mid \bar{E}}(T) & =P(t \leq T \mid \bar{E}) \\
& =P\left(\tau_{1} \leq T, \tau_{2} \leq T, \ldots, \tau_{n} \leq T \mid \bar{E}\right) \\
& =\prod_{i=1}^{n} P\left(\tau_{i} \leq T \mid \bar{E}\right)
\end{aligned}
$$

A probabilidade no produtório é a FDP do tempo de retorno $\tau_{i}$, sendo a fdp de $\tau_{i}$ uniforme e i.i.d., então $F_{\tau_{i} \mid \bar{E}}(T)=T / \Delta$ para $0<T \leq \Delta$. Assim, a FDP do tempo de admissão pode ser escrita como

$$
F_{t \mid \bar{E}}(T)= \begin{cases}0 & ; T \leq 0 \\ \left(\frac{T}{\Delta}\right)^{n} & ; 0<T \leq \Delta \\ 1 & ; T>\Delta\end{cases}
$$

Derivando a distribuição $F_{t \mid \bar{E}}(T)$, obtemos a densidade $p_{t \mid \bar{E}}(T)$.

$$
p_{t \mid \bar{E}}(T)= \begin{cases}0 & ; T \leq 0 \\ \left(\frac{n}{\Delta^{n}}\right) T^{n-1} & ; 0<T \leq \Delta \\ 0 & ; T>\Delta\end{cases}
$$

Substituindo (3-11) e (3-14) em (3-10), teremos uma expressão para função densidade de probabilidade não condicional do tempo de admissão. O tempo médio de admissão $\left(T_{a d}\right)$ pode ser calculado como o valor esperado da v.a. tempo de admissão.

$$
\begin{aligned}
& E[t]=\int_{-\infty}^{\infty} T p_{t}(T) d T \\
& E[t]=P(E) \int_{-\infty}^{\infty} T \delta(T) d T+P(\bar{E}) \int_{0}^{\Delta} T\left(\frac{n}{\Delta^{n}}\right) T^{n-1} d T
\end{aligned}
$$


A integral com impulso na origem $\delta(T)$ em (3-15) vale zero, pois o valor de T na origem é zero.

$$
\begin{aligned}
E[t] & =P(\bar{E})\left(\frac{n}{\Delta^{n}}\right) \int_{0}^{\Delta} T^{n} d T \\
& =\left.P(\bar{E})\left(\frac{n}{\Delta^{n}}\right)\left(\frac{T^{n+1}}{n+1}\right)\right|_{0} ^{\Delta} \\
& =P(\bar{E})\left(\frac{n}{\Delta^{n}}\right)\left(\frac{\Delta^{n+1}}{n+1}\right) \\
T_{a d}=E[t] & =P(\bar{E})\left(\frac{n}{n+1}\right) \Delta
\end{aligned}
$$

O tempo médio de admissão $T_{a d}$ no procedimento de admissão Ecc.186 é definido em (3-16) utilizando o número $n$ de WSDs em operação localizados na Célula 0 , a probabilidade $P(\bar{E})$ da Célula 0 ter WSDs em operação na chegada do $\mathrm{WSD}_{0}$ no sistema e o tempo de retorno máximo $\Delta$.

\section{4}

\section{Incompatibilidade entre as Definições de $Z$ e $P_{U, k}$}

A metodologia Ofcom não definiu a potência interferente intersistema do WSD da mesma forma que a potência interferente intrasistema do DTT.

O método de planejamento da cobertura do sistema primário DTT foi utilizado para que o mesmo tratamento que limita a interferência intrasistema fosse utilizado para limitar a interferência intersistema e através desta limitação definir a potência de transmissão máxima do sistema secundário WSD.

O critério de planejamento do sistema DTT define que as potências interferentes intrasistema são calculadas com base nas curvas para $1 \%$ do tempo. Ou seja, elas representam a potência de recepção interferente excedida $1 \%$ do tempo. Entretanto, o método de cálculo da potência interferente $Z$ não adotou este critério. A potência interferente intersistema $Z$ é tratada como um limite para a potência interferente single-entry que não deve nunca ser excedida.

Ainda que se desejasse mudar o critério da potência interferente intersistema $Z$ de uma célula em relação ao critério da interferência intrasistema $P_{U, k}$, esta alteração deveria ter sido definida explicitamente. Assim, a potência interferente intersistema $Z$ poderia ser definida como a potência de recepção interferente excedida $\mathrm{K} \%$ do tempo.

A metodologia Iagg proposta estabelece o mesmo critério da potência interferente intrasistema $P_{U, k}$ para a potência interferente intersistema $Z$, conforme definição de $P_{U, k}$ em (2-1). 


\section{5}

\section{Múltiplos WSDs Excedem Interferência Limite}

A metodologia Ofcom assume como premissa de cálculo que somente um WSD irradiará por célula e por canal de frequência. Entretanto, reconhece que um WSDB pode prover serviços para múltiplos WSD na mesma área geográfica e no mesmo canal de frequência, resultando em uma agregação da interferência. O regulamento assume que a agregação de múltiplas entradas de interferência dos WSDs não será um problema a curto prazo.

Essa questão, não abordada pelo metodologia Ofcom, pode ser avaliada pela localização dos múltiplos WSDs que compartilham o mesmo canal de frequência: (1) quando os WSDs estão na mesma célula e (2) quando os WSDs estão em células diferentes.

A potência interferente agregada produzida por múltiplos WSDs localizados numa mesma célula, operando no mesmo canal de frequência, supera o limite de potência interferente intersistema $Z$ da célula mais vulnerável (CMV).

A metodologia Ofcom não estabelece como deve ser reduzida a potência de múltiplos WSDs cocanais que se encontram em uma mesma célula para que a soma das interferências desses WSDs na CMV associada não exceda o limite $Z$ da mesma. Este problema se estende, não só para CMV, mas também para outras células da região. A Figura 3.7 mostra esta situação para dois WSDs.

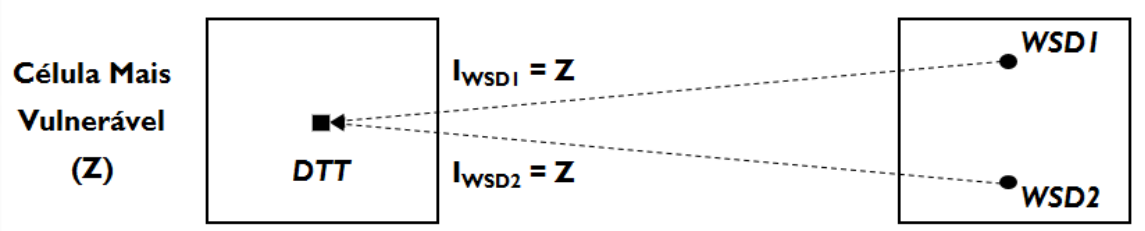

Figura 3.7: WSDs ocupam mesma célula e mesmo canal de frequência, irradiando com a potência de transmissão regulatória. Logo, cada um produz uma potência interferente $Z$ na célula mais vulnerável, logo a potência interferente agregada excede o limite $Z$ desta célula.

Note que a potência de transmissão regulatória de uma célula é calculada a partir da máxima potência interferente $Z$ de uma única CMV, conforme (36). Em outras palavras, a potência de transmissão regulatória de uma célula é aquela que produz uma potência interferente de valor $Z$ na CMV a ela associada.

Caso $N$ WSDs transmitam com a potência de transmissão regulatória numa mesma célula e no mesmo canal de frequência, a potência interferente agregada produzida na CMV a ela associada, ultrapassará o valor limite $Z$ da mesma. 
Considera-se nesta questão que os WSDs operam em subredes distintas independentes, o que gera situações nas quais os WSDs transmitem simultaneamente no mesmo canal de freqüência.

A potência interferente agregada produzida por múltiplos WSDs localizados em células diferentes, operando no mesmo canal de frequência, pode superar o limite de potência interferente intersistema $Z$ de uma célula da região.

Em outras palavras, WSDs cocanais em células diferentes, transmitindo com a potência de transmissão máxima regulatória podem gerar uma soma de interferências que excede os valores de $Z$ associados a algumas das células em sua vizinhança.

Esta questão evidencia-se em um cenário simples onde dois WSDs, localizados em células próximas e operando no mesmo canal de frequência, utilizam a potência máxima regulatória. Neste caso, as CMVs associadas a cada um desses WSDs, que já recebem a potência interferente máxima $Z$, terão uma interferência adicional devida ao outro WSD, conforme ilustra a Figura 3.8

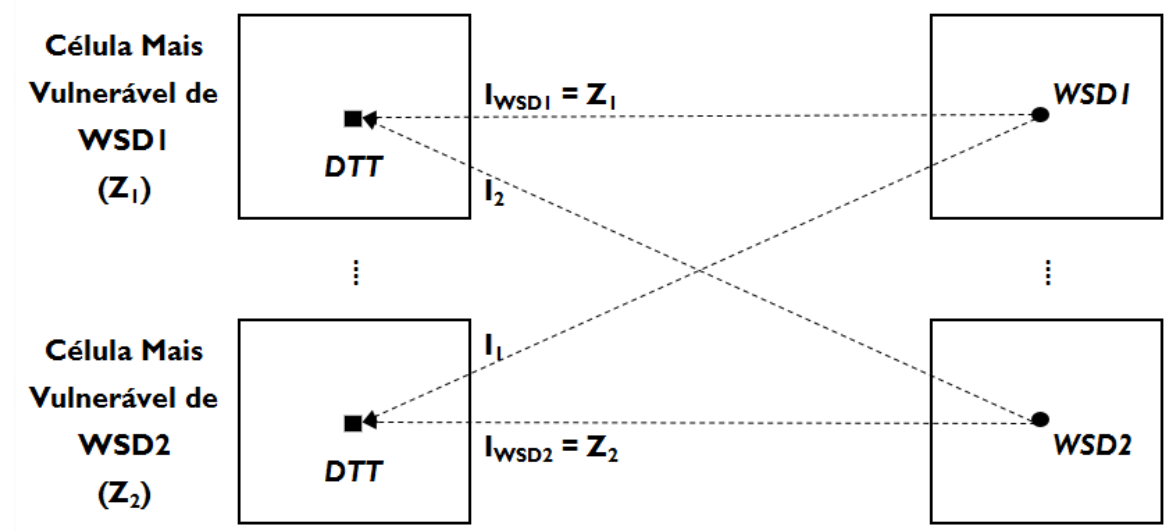

Figura 3.8: WSDs ocupam células próximas e mesmo canal de frequência, irradiando com a potência de transmissão regulatória. Logo, a potência interferente agregada na célula mais vulnerável de cada um dos WSD excede o limite de potência interferente $Z$ pelo valor da interferência do outro WSD.

O banco de dados WSDB poderia buscar solucionar esta questão fornecendo canais de frequência diferentes para WSDs que ocupem células próximas de forma a criar uma discriminação em frequência e reduzir a interferência agregada. Entretanto, isto limita o re-uso de frequências, tornando-se um gargalo em locais com alta densidade de WSDs, onde todos os canais de frequência disponíveis estejam ocupados.

A limitação do re-uso de canais de frequência reduz a eficiência espectral. A adoção de um modelo de acesso dinâmico ao espectro em uma faixa de frequência compartilhada tem a eficência espectral como principal motivação. 
O próprio conceito de rádio cognitivo está associado a melhoria da eficiência espectral. Assim sendo, o re-uso de canais de frequência é um aspecto importante para o sistema WSD.

Como exemplo, podemos citar os sistemas $4 \mathrm{G}$ que utilizam o padrão LTE (Long Term Evolution), estes são planejados como redes heterogêneas (HetNet) através da utilização de células menores (micro, pico e femto células). As HetNets já foram utilizadas no planejamento dos sistemas 2G que utilizam o padrão GSM (Global System for Mobile Communications), sendo as camadas de macro e micro células GSM separadas através do uso de diferentes canais de frequências. Esta solução também é possível nas redes LTE. Entretanto, as redes LTE utilizam, primordialmente, o re-uso de frequências para maximizar a utilização da faixa de frequência licenciada [26].

É interessante notar que as femto células são implementadas sem coordenação com as macro células, um cenário similar ao dos sistemas WSD independentes. Tal exemplo indica que as futuras redes WSD serão utilizadas buscando maximizar o re-uso de frequências, sendo o cenário de interferências cocanal uma realidade para este tipo de sistema.

O problema da metodologia Ofcom em relação a interferência agregada está na determinação da potência de transmissão regulatória por uma metodologia de cálculo que adota uma abordagem single-entry da interferência. Esta abordagem cria dificuldades em satisfazer o limite máximo de potência interferente $Z$ de uma célula quando múltiplas entradas de interferência cocanal são consideradas.

Órgãos reguladores, tradicionalmente, definem critérios máximos de interferência pelo modelo single-entry. Este tipo de critério é motivado, entre outras razões, pela falta de informação de um dispositivo sobre as características dos demais dispositivos ao seu redor. Entretanto, uma metodologia de cálculo que utilize múltiplas entradas de interferência para satisfazer o critério de interferência de uma célula é, plenamente, possível para um sistema de banco de dados geolocalizado que possui as informações de localização, de equipamento e de potência de todos os dispositivos admitidos no sistema.

Adotar uma metodologia de cálculo que considere múltiplas entradas de interferência e utilize a potência interferente agregada como parâmetro para avaliação do critério de interferência de uma célula se torna necessário para a real proteção do sistema DTT e, também, para aumentar a eficiência espectral e a capacidade do sistema WSD através do re-uso de canais de frequência. 


\section{4}

\section{Modelagem Matemática}

Este capítulo desenvolve a teoria que serve de base para a metodologia de cálculo proposta. Esta metodologia é aqui nomeada Metodologia Iagg como uma referência a seu objetivo central de limitar a potência interferente agregada $\left(i_{a g g}\right)$ para atender o critério de interferência.

O modelo matemático permite as definições do critério de interferência, da potência de transmissão máxima do WSD e da potência interferente agregada, conforme é apresentado nas seções 4.1 e 4.2. Por fim, a Seção 4.3 apresenta resultados preliminares que comprovam o não atendimento do critério de interferência pela interferência agregada na metodologia de cálculo Ofcom.

\section{1}

\section{Critério de Interferência e e.i.r.p. Máxima}

O relatório ECC.186 [5] define que o método de planejamento do sistema primário de TV digital é adotado para definir os limites de interferência de um sistema secundário. Ou seja, o critério a ser adotado para a interferência intersistema deve ser o mesmo adotado para interferência intrasistema. Assim sendo, adota-se nesta tese a potência interferente intersistema $Z$ como sendo aquela que é excedida $1 \%$ do tempo, de forma idêntica a interferência intrasistema $P_{U, k}$ da equação (2-1). Este conceito significa que em qualquer situação a potência interferente agregada que chega em uma célula $j\left(i_{a g g, j}\right)$ não deve ultrapassar o valor da potência interferente intersistema $Z$ associado a esta célula $\left(Z_{j}\right)$ com uma probabilidade superior a $1 \%$. Esta condição é chamada critério de interferência, conforme (4-1), e deve ser satisfeita para todas as células.

$$
P\left(i_{\text {agg, } j}>Z_{j}\right) \leq \epsilon
$$

onde $\epsilon=0.01$ representa o limite definido pelo planejamento do sistema DTT.

A partir do critério de interferência definido em (4-1) é calculada a e.i.r.p. (equivalent isotropically radiated power) máxima dos WSDs em uma célula $k$ utilizando a geometria ilustrada na Figura 4.1 (repetida da Figura 2.4). A potência interferente $i_{k j}$ que chega em uma célula $j$ devida a e.i.r.p $E_{k j}$ dos WSDs localizados em uma célula $k$ é calculada como 


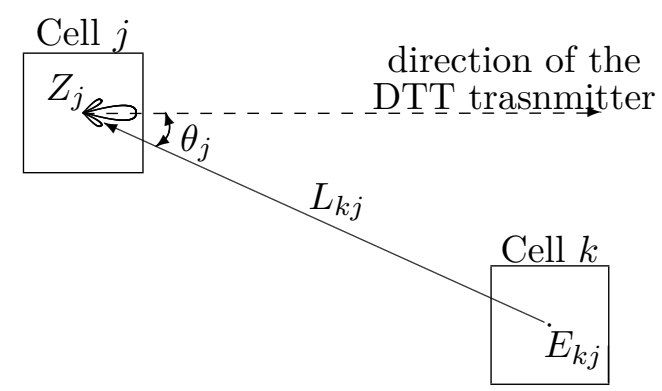

Figura 4.1: Geometria para cálculo da e.i.r.p. $E_{k j}$

$$
i_{k j}=E_{k j}+g\left(\theta_{j}\right)-L_{k j}+\rho(\Delta f)
$$

onde

$L_{k j}$ é a perda de propagação entre a célula $k$ e $j$

$g\left(\theta_{j}\right)$ é o ganho da antena DTT para o ângulo de chegada da interferência $\theta_{j}$ $\rho(\Delta f)$ é a taxa de proteção devido a separação de frequência $\Delta f$ entre os canais DTT e WSD

A perda de propagação $L_{k j}$ é dada pelo modelo Hata extendido [17], sendo expressa como uma variável aleatória com distribuição gaussiana, $L_{k j} \sim$ $N\left(m_{k j}, \sigma_{k j}\right)$. A relação linear em (4-2) indica que a potência interferente $i_{k j}$ é também uma variável aleatória gaussiana, $i_{k j} \sim N\left(m_{k j}^{\prime}, \sigma_{k j}^{\prime}\right)$, com média e desvio padrão calculados por

$$
m_{k j}^{\prime}=E_{k j}+g\left(\theta_{j}\right)-m_{k j}+\rho(\Delta f) \quad \text { e } \quad \sigma_{k j}^{\prime}=\sigma_{k j}
$$

A probabilidade expressa em (4-1) pode então ser reescrita através de uma função Q como

$$
P\left(i_{k j}>Z_{j}\right)=Q\left(\frac{Z_{j}-m_{k j}^{\prime}}{\sigma_{k j}^{\prime}}\right) \leq 0.01
$$

Note que exigir que uma função Q seja menor ou igual a 0.01 é equivalente a exigir que o argumento dela seja maior ou igual a 2.33. Assim, podemos substituir a média e desvio padrão de (4-3) e escrever a condição que a e.i.r.p. $E_{k j}$ deve satisfazer.

$$
\begin{gathered}
Q\left(\frac{Z_{j}-m_{k j}^{\prime}}{\sigma_{k j}^{\prime}}\right) \leq 0.01 \rightarrow \frac{Z_{j}-m_{k j}^{\prime}}{\sigma_{k j}^{\prime}} \geq 2.33 \\
E_{k j} \leq Z_{j}+m_{k j}-g\left(\theta_{j}\right)-\rho(\Delta f)-2.33 \sigma_{k j}
\end{gathered}
$$

De acordo com os anexos do regulamento Ofcom [7], para interferências de canal adjacente, a máxima e.i.r.p. permitida em uma célula $k$ deve satisfazer 
a condição limite de potência interferente $Z$ para todas as células em uma área circular de $2 \mathrm{~km}$ de raio ao redor da célula $k$. A Figura 4.2 (repetida da Figura 2.3) ilustra essa área circular.

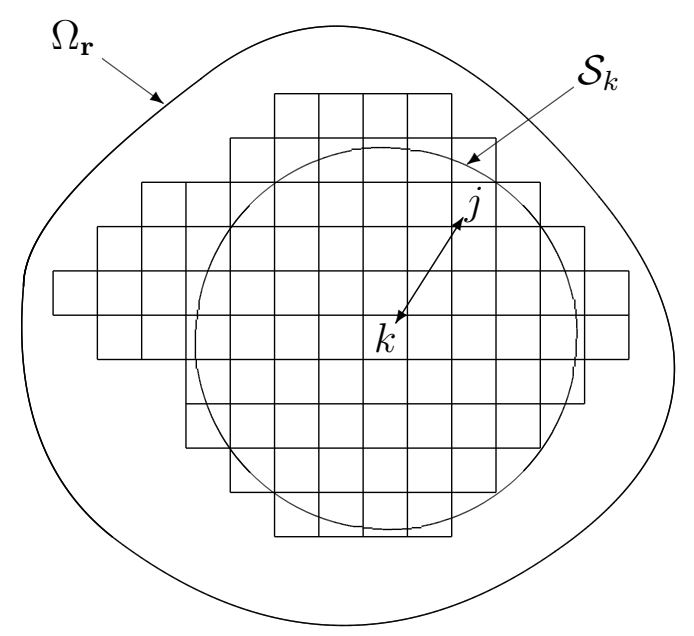

Figura 4.2: Área circular para cálculo da e.i.r.p. $E_{k j}$

A máxima e.i.r.p. $E_{k}$ permitida na célula $k$ é aquela que atende a potência interferente limite $Z$ de todas as células $j$ da área circular. Ela é definida pelo menor valor entre todos os valores máximos calculados para as e.i.r.p. $E_{k j}$, ou seja,

$$
E_{k}=\min _{j}\left(Z_{j}+m_{k j}-g\left(\theta_{j}\right)-\rho(\Delta f)-2.33 \sigma_{k j}\right)
$$

O cálculo da e.i.r.p. $E_{k j}$ dado pela equação (4-5) é aplicável as células das Tier 3 e maiores, enquanto o cálculo para as células das Tier 2 e 0/1 é realizada através da geometria de referência equivalente das tabelas de ganho de acoplamento $(G)$ da metodologia Ofcom. Isto ocorre porque as Tier 2 e 0/1 não utilizam a distância aproximada pela separação das células entre WSD e DTT devido a indeterminação da localização do receptor DTT.

Note que as e.i.r.p $E_{k j}$ e $E_{k}$ são calculadas por um modelo single-entry, ou seja, a potência interferente máxima $Z$ de apenas uma célula define o valor destas e.i.r.p. No caso de $E_{k}$, a célula que define seu valor é a célula mais vulnerável (CMV) da região circular. Em outras palavras, caso o valor de $E_{k}$ fosse ligeiramente maior que o definido pela equação (4-6), a CMV associada seria a primeira célula a ter sua potência interferente máxima Z ultrapassada.

\section{2}

\section{Interferência Agregada}

Nesta seção, o cálculo da potência interferente agregada é desenvolvido e os principais aspectos envolvidos na metodologia de cálculo Iagg são analisados. 
Um dos aspectos relevantes para o cálculo da potência interferente agregada é o modelo de distribuição espacial dos WSDs utilizado nas simulações, sendo este discutido na Subseção 4.2.1.

Outro aspecto importante é a determinação da célula vítima onde a potência interferente agregada é calculada, sendo tratada na Subseção 4.2.2.

O cálculo da potência interferente agregada é desenvolvido na Subseção 4.2.3. Este cálculo requer um algoritmo para a determinação da função densidade de probabilidade (fdp) da soma de variáveis aleatórias lognormais desenvolvido em 4.2.3.1. Por fim, uma expressão matemática de um critério de interferência equivalente a (4-1) para o caso particular em que as parcelas de interferência tem fdp lognormal é desenvolvido em 4.2.3.2.

\subsection{1}

\section{Distribuição Espacial dos WSDs}

O modelo matemático adotado para a distribuição espacial dos WSDs é o processo pontual de Poisson (PPP) desenvolvido pelo ramo da estatística conhecida como Geometria Estocástica.

Os processos pontuais permitem interpretar padrões de objetos como um sistema de pontos em um adequado espaço representativo, um ponto neste sistema representa um objeto particular no padrão original.

O processo pontual de Poisson possui um papel central na teoria dos processos pontuais por servir como uma hipótese nula para testes estatísticos de interação e, também, por ser um bloco de construção para muito outros processos.

O processo pontual de Poisson é um modelo que define padrões de pontos aleatórios cujo número de pontos é definido por uma distribuição de probabilidade de Poisson.

$$
P(\Phi(B)=m)=\frac{(\lambda \cdot|B|)^{m}}{m !} \exp (-\lambda \cdot|B|)
$$

sendo $\Phi$ o PPP, $\Phi(B)$ o número de pontos em uma região bidimensional $B$, $P(\Phi(B)=m)$ a probabilidade que o número de pontos seja $m, \lambda$ a densidade do PPP, $|B|$ a área de $B$.

Assim sendo, o número aleatório de pontos $\Phi(B)$ em uma área do espaço bidimensional $B$ tem uma distribuição de Poisson de média $\lambda \cdot|B|$ para um valor de densidade $\lambda$ de pontos por unidade de área.

Além da propriedade da distribuição de probabilidade do número de pontos, os processos pontuais de Poisson possuem uma segunda propriedade que é a completa aleatoriedade espacial. Em outras palavras, duas áreas disjuntas, $A$ e $B$, de um PPP possuem número de pontos, $\Phi(A)$ e $\Phi(B)$, que são 
variáveis aleatórias independentes como ilustra a Figura 4.3. Esta propriedade representa a ausência de interação entre os pontos de um PPP.

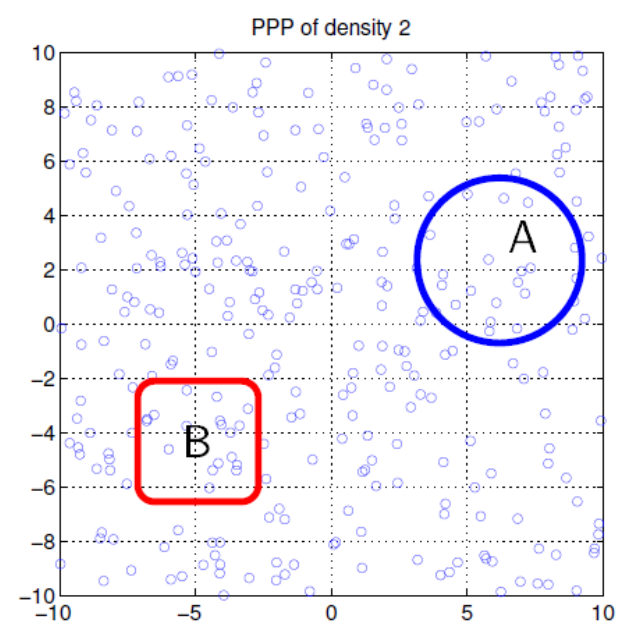

Figura 4.3: Completa aleatoriedade espacial do processo pontual de Poisson. $A \cap B=\emptyset$, então $\Phi(A) \perp \Phi(B)$

No caso específico da distribuição espacial de WSDs, a opção pelo processo pontual de Poisson é uma premissa de independência dos dispositivos que permite uma simulação não associada a uma tecnologia específica.

Uma revisão da teoria de processos pontuais da geometria estocástica é apresentada no Apêndice B. Esta revisão apresenta os conceitos principais que envolvem os processos pontuais de Poisson e sua simulação.

A simulação de uma amostra PPP é convertida do plano cartesiano para uma região geodésica do espaço através da associação da origem do plano à coordenada geográfica central da região onde será efetuada a simulação. Assim, as latitutes/longitudes dos WSDs podem ser calculadas utilizando azimutes e distãncias dos pontos da amostra PPP e a coordenada geográfica central da região.

\subsection{2}

\section{Conceito de Célula Mais Vulnerável}

A potência interferente agregada calculada para admissão de um novo WSD deve atender ao critério de interferência de todas as células da região no entorno do mesmo. Essa região de trabalho foi definida como um quadrado de $4 \mathrm{~km} \mathrm{x} 4 \mathrm{~km}$ que circunscreve o círculo com raio de $2 \mathrm{~km}$ definido pela metodologia Ofcom.

O cálculo da interferência agregada, $i_{\text {agg }}$, em uma região de $16 \mathrm{~km}^{2}$ com células de $0.1 \mathrm{~km} \times 0.1 \mathrm{~km}$, representa um total de 1600 células que devem 
ter seu critério de interferência (C.I.) avaliados. Isto representa um alto custo computacional e deve ser evitado para viabilidade da nova metodologia.

A e.i.r.p. regulatória da metodologia Ofcom é usada na nova metodologia Iagg como valor inicial máximo de potência do novo WSD $\left(\mathrm{WSD}_{0}\right)$ e para calculá-la é necessário encontrar a célula mais vulnerável (CMV) associada à célula em que o WSD se encontra, conforme indicado em (4-6).

A CMV é a primeira célula a ter seu limite de potência interferente $Z$ ultrapassado pela interferência da célula associada quando um WSD nesta célula ultrapassa a e.i.r.p. máxima $E_{k}$.

Caso a $i_{\text {agg }}$ na CMV associada a célula do novo WSD não exceda o limite de interferência da CMV, então todas as células da região de trabalho terão seus limites de interferência atendidos.

A metodologia de cálculo Iagg calcula a $i_{\text {agg }}$ na CMV associada ao WSD em processo de admissão para avaliar o atendimento do C.I. em toda a região de trabalho. Uma vez que atendendo o C.I. na CMV associada ao $\mathrm{WSD}_{0}$, todas as células da região de trabalho terão seus C.I. atendidos em relação a interferência adicional provocada pela e.i.r.p. do $\mathrm{WSD}_{0}$.

\subsection{3}

\section{Cálculo da Potência Interferente Agregada}

Uma vez calculado os valores das e.i.r.p. máximas $E_{k}$ de todas as células da área de trabalho, conforme detalhado na Seção 4.1, podemos detalhar o método utilizado para calcular a potência interferente agregada $i_{\text {agg }}$ na CMV associada ao novo WSD. A Figura 4.4 ilustra um ambiente envolvendo múltiplos WSDs interferindo em um receptor DTT.

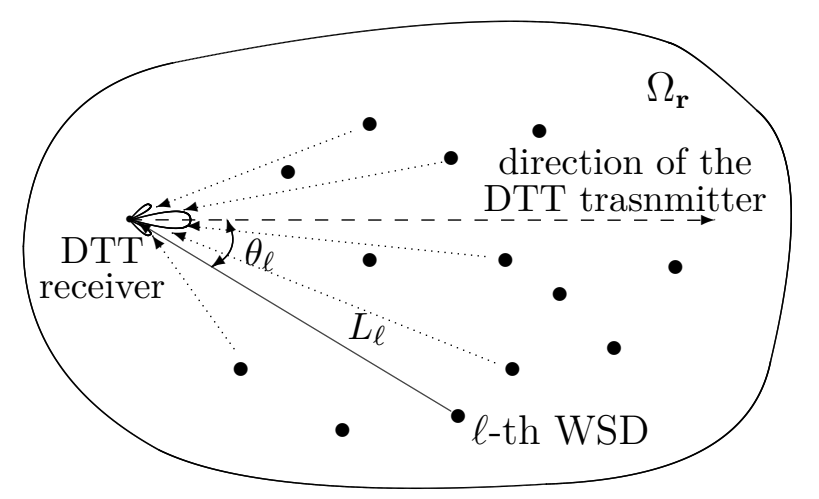

Figura 4.4: Múltiplos WSDs interferentes.

A potência interferente devido a um WSD pode ser escrita como

$$
i_{\ell}=P_{\ell}-L_{\ell}+g\left(\theta_{\ell}\right)+\rho(\Delta f)
$$


Onde

$P_{\ell}$ é a e.i.r.p. transmitida pelo WSD interferente,

$L_{\ell}$ é a perda de propagação,

$g\left(\theta_{\ell}\right)$ é o ganho da antena DTT para o ângulo de chegada da interferência $\theta_{\ell}$ $\rho(\Delta f)$ é a taxa de proteção devido a separação de frequência $\Delta f$ entre os canais de frequência do DTT e WSD.

De acordo com o modelo Hata extendido [17], a perda de propagação $L_{\ell}$, quando expressa em dB, é caracterizada por uma variável aleatória gaussiana. Consequentemente, a partir de (4-8), conclui-se que a potência interferente $i_{\ell}$ devida a um WSD é, também, uma v.a. gaussiana com média $m_{\ell}$ e desvio padrão $\sigma_{\ell}$ dadas, respectivamente, por

$$
m_{\ell}=P_{\ell}-m+g\left(\theta_{\ell}\right)+\rho(\Delta f)
$$

$\mathrm{e}$

$$
\sigma_{\ell}=\sigma
$$

onde $m$ e $\sigma$ representam a média e o desvio padrão da perda de propagação $L_{\ell}$, respectivamente.

Assumindo existirem N WSDs interferentes, a potência interferente agregada $i_{\text {agg }}$ chegando ao receptor DTT, em dBm, pode ser expressa como

$$
i_{\text {agg }}=10 \log \left(\sum_{\ell=1}^{N} 10^{i_{\ell} / 10}\right)
$$

Uma vez que a interferência $i_{\ell}$, em dBm, é modelada como uma variável aleatória gaussiana, então as entradas dessa interferência no somatório da equação (4-11), expressas em miliWatts, são modeladas por uma distribuição lognormal. Como consequência, a potência interferente agregada, expressa em miliWatts, corresponde a uma soma de variáveis aleatórias lognormal estatisticamente independentes.

\subsubsection{1}

\section{Soma de Variáveis Aleatórias com Distribuição Lognormal}

A potência de recepção média em um ambiente rádio terrestre é caracterizada por efeitos de sombreamento que define seu comportamento aleatório através de uma distribuição lognormal no domínio linear [32]. Assim sendo, a soma das potências interferentes representa uma soma de variáveis aleatórias (v.a.) com distribuição lognormal. 
Considerando a premissa de independência dos dispositivos WSDs, desenvolvida na Subseção 4.2.1, as parcelas de potência interferente são modeladas como v.a. lognormais estatisticamente independentes e a potência interferente agregada $i_{\text {agg }}$ resultante do somatório dessas parcelas é, também, uma variável aleatória.

Não existe uma expressão analítica para calcular a distribuição da soma de v.a. lognormal. Entretanto, diversos autores apresentaram aproximações e, em geral, essas aproximações modelam a soma de v.a. lognormal, também, como uma v.a. lognormal.

Uma v.a. lognormal apresenta a propriedade de seu logaritmo ter uma distribuição gaussiana, considere $L_{i}$ uma v.a. lognormal e $x_{i}$ o valor da mesma em dB $\left(x_{i}=10 \log _{10} L_{i}\right)$. Então, a densidade de probabilidade de $x_{i}\left(f_{x_{i}}\right)$ é dada por

$$
f_{x_{i}}(X)=\frac{1}{\sqrt{2 \pi \sigma_{x_{i}}^{2}}} \exp \left[-\frac{\left(X-m_{x_{i}}\right)^{2}}{2 \sigma_{x_{i}}^{2}}\right]
$$

Sendo $m_{x_{i}}$ e $\sigma_{x_{i}}$ a média e desvio padrão de $x_{i}$, respectivamente.

Uma questão importante na escolha de uma aproximação para a soma de v.a. lognormal é a faixa de valores do desvio padrão $\sigma_{x_{i}}$, conhecido também como dB spread, o seu valor em um ambiente rádio móvel na faixa de UHF varia de 6 a $12 \mathrm{~dB}$ dependendo da intensidade do sombreamento [13].

A aproximação de Schwartz-Yeh [10] é melhor aplicada para um desvio padrão entre 4 e $12 \mathrm{~dB}$ [12], sendo por isso uma boa opção para sistemas rádio na faixa de UHF.

O método de cálculo de Schwartz-Yeh foi melhorado por Ho [11] que manteve o procedimento de cálculo original, mas desenvolveu integrais para as diversas variáveis que podem ser calculadas numericamente com poucos passos por meio da regra do trapézio. No método original essas variáveis eram obtidas por funções erro erfc ponderadas que geravam erros de arredondamento quando um grande número de componentes participavam da soma.

A aproximação é desenvolvida, basicamente, para obter a distribuição da soma de duas v.a. e generalizada para um número qualquer de v.a. através de um procedimento recursivo que utiliza a v.a. da soma obtida no passo anterior como uma das componentes do passo seguinte. A aproximação de SchwartzYeh e suas equações são descritas no Apêndice A.

A aproximação de Schwartz-Yeh modela a soma, em miliWatts, também como uma distribuição lognormal. Logo, a potência interferente agregada $i_{\text {agg }}$, em dBm, é fornecida como uma variável aleatória gaussiana representada pela sua média e variância.

Note que $i_{a g g}$ é dependente da localização dos WSDs que é represen- 
tada neste trabalho como um vetor $\mathbf{r}$, onde cada elemento representa uma latitude/longitude de um WSD, conforme equação (4-13).

$$
\mathbf{r}=\left(\begin{array}{llll}
r_{1}^{T} & r_{2}^{T} & \cdots & r_{N}^{T}
\end{array}\right)^{T}
$$

Fornecidas as localizações geográficas de todos os WSDs interferentes, ou seja dado $\mathbf{r}=\mathbf{R}$, a função Schwartz-Yeh implementada fornece os parâmetros da gaussiana que representa a $i_{\text {agg }}$ em dBm como mostra as equações (4-14) e $(4-15)$.

$$
\begin{gathered}
m_{i_{a g g} \mid \mathbf{r}=\mathbf{R}}=E\left[i_{a g g} \mid \mathbf{r}=\mathbf{R}\right] \\
\sigma_{i_{a g g} \mid \mathbf{r}=\mathbf{R}}^{2}=E\left[\left(i_{a g g}-m_{i_{a g g} \mid \mathbf{r}}\right)^{2} \mid \mathbf{r}=\mathbf{R}\right]
\end{gathered}
$$

\subsubsection{2}

\section{Critério de Interferência para Caso Particular Lognormal}

A potência interferente agregada $i_{a g g}$ na célula mais vulnerável (CMV) é calculada para avaliar o critério de interferência (C.I.) definido pela expressão (4-16). Esta desigualdade indica que a probabilidade da $i_{\text {agg }}$ ser maior que a potência interferente intersistema máxima $Z_{0}$ da CMV não deve exceder $1 \%$ do tempo. Este é o mesmo critério utilizado para a interferência intrasistema do DTT e através dele é possível calcular a e.i.r.p. limite do WSD associado a CMV, conforme descrito na Seção 4.1.

$$
P\left(i_{\text {agg }}>Z_{0}\right) \leq 0.01
$$

É possível fazer a avaliação do C.I. para o caso particular da soma de v.a. lognormal, definindo um parâmetro $I_{0}$ como o nível de potência interferente agregada excedida $1 \%$ do tempo, ou seja, considera-se que $P\left(i_{\text {agg }}>I_{0}\right)=0.01$.

Assim sendo, pode-se avaliar o C.I. comparando $I_{0} \operatorname{com} Z_{0}$. Caso $I_{0}$ seja menor que $Z_{0}$, então o C.I. foi satisfeito. Caso contrário, a diferença $I_{0}-Z_{0}$ define quanto a potência interferente agregada $I_{0}$ deve ser reduzida para que o C.I. seja atendido. Esta redução da interferência agregada é uma função da redução das e.i.r.p. dos WSDs no entorno da CMV.

A Figura 4.5 mostra a função distribuição de probabilidade da interferência agregada, definida como $P\left(i_{\text {agg }}>I\right)$, que supera o valor de $Z_{0}$ na probabilidade de $1 \%$. O asterísco vermelho representa o valor de $I_{0}$ e a diferença $\Delta=I_{0}-Z_{0}$ representa o quanto $I_{0}$ deve ser reduzido para satisfazer o C.I.

A potência interferente agregada $I_{0}$ pode ser calculada, considerando a distribuição espacial dos WSDs $(\mathbf{r}=\mathbf{R})$ no momento em que o novo WSD $\left(\mathrm{WSD}_{0}\right)$ inicia seu processo de admissão no banco de dados geolocalizado 


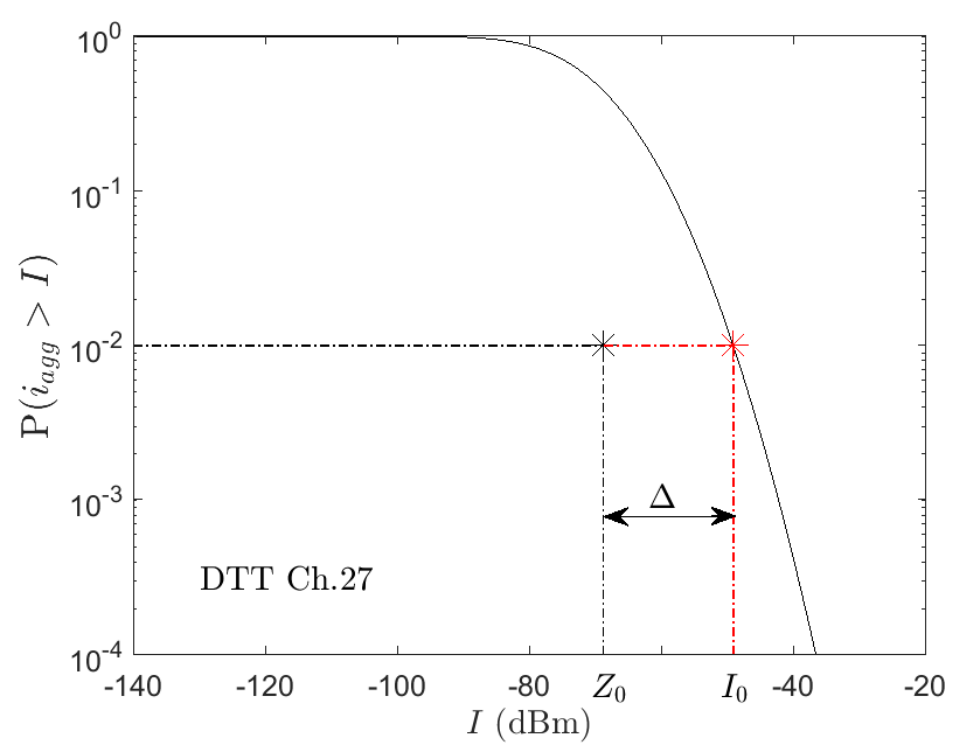

Figura 4.5: Curva da função distribuição de probabilidade da potência interferente agregada. Os asteríscos preto e vermelho representam os valores de $Z_{0}$ e $I_{0}$, respectivamente. $\Delta=I_{0}-Z_{0}$ representa o quanto $I_{0}$ deve ser reduzido para atender o C.I.

(WSDB).

A $i_{\text {agg }}$ na CMV é modelada como uma variável aleatória (v.a.) gaussiana com média e desvio padrão. Estes valores são conhecidos através da soma das potências interferentes dos WSDs utilizando a aproximação de Schwartz-Yeh $[10]$.

A expressão do C.I. em (4-16) pode então ser reescrita como uma função Q, utilizando $m_{i_{a g g} \mid \mathbf{r}=\mathbf{R}}$ e $\sigma_{i_{a g g} \mid \mathbf{r}=\mathbf{R}}$ como a média e desvio padrão da $i_{a g g}$ dado $\mathbf{r}=\mathbf{R}$.

$$
P\left(i_{a g g} \geq I \mid \mathbf{r}=\mathbf{R}\right)=Q\left(\frac{I-m_{i_{a g g} \mid \mathbf{r}=\mathbf{R}}}{\sigma_{i_{a g g} \mid \mathbf{r}=\mathbf{R}}}\right) \leq 0.01
$$

O valor de $I_{0}$ ( $i_{\text {agg }}$ que é excedida $1 \%$ do tempo) pode ser calculado, igualando a função Q ao limite superior 0.01.

$$
Q\left(\frac{I_{0}-m_{i_{a g g} \mid \mathbf{r}=\mathbf{R}}}{\sigma_{i_{\text {agg }} \mid \mathbf{r}=\mathbf{R}}}\right)=0.01
$$

Utilizando uma tabela da função Q podemos determinar o valor de seu argumento, pois $Q(x)=0.01 \rightarrow x=2.33$

$$
\frac{I_{0}-m_{i_{a g g} \mid \mathbf{r}=\mathbf{R}}}{\sigma_{i_{a g g} \mid \mathbf{r}=\mathbf{R}}}=2.33
$$

Logo, o valor de $I_{0}$ fica determinado como

$$
I_{0}=m_{i_{a g g} \mid \mathbf{r}=\mathbf{R}}+2.33 \sigma_{i_{a g g} \mid \mathbf{r}=\mathbf{R}}
$$


E o critério de interferência fica simplificado por

$$
I_{0} \leq Z_{0}
$$

\section{3}

\section{Resultados Preliminares Relativos à Interferência Agregada}

Esta seção desenvolve uma análise para comprovação do problema da metodologia Ofcom, descrito no Capítulo 3, demonstrando que a potência interferente agregada de WSDs excede o limite de interferência.

A Subseção 4.3.1 descreve a geração da base de dados da potência interferente intersistema $Z$ que define o limite'de interferência em uma célula. Por fim, a simulação e a análise dos resultados que demonstra que o critério de interferência não é atendido pela potência interferente agregada são desenvolvidos na Subseção 4.3.2.

\subsection{1}

\section{Construção da Base de Dados $Z$}

A primeira etapa do trabalho é o desenvolvimento de uma base de dados com a potência interferente intersistema $Z$ de cada célula dentro da área de serviço de um sistema de TV digital. A metodologia de cálculo do regulamento Ofcom [6] e seus anexos [7] foi utilizada para o cálculo da base de dados $Z$ conforme descrito na Seção 2.1. O diagrama de blocos da Figura 4.6 mostra as etapas da construção da base de dados $Z$.

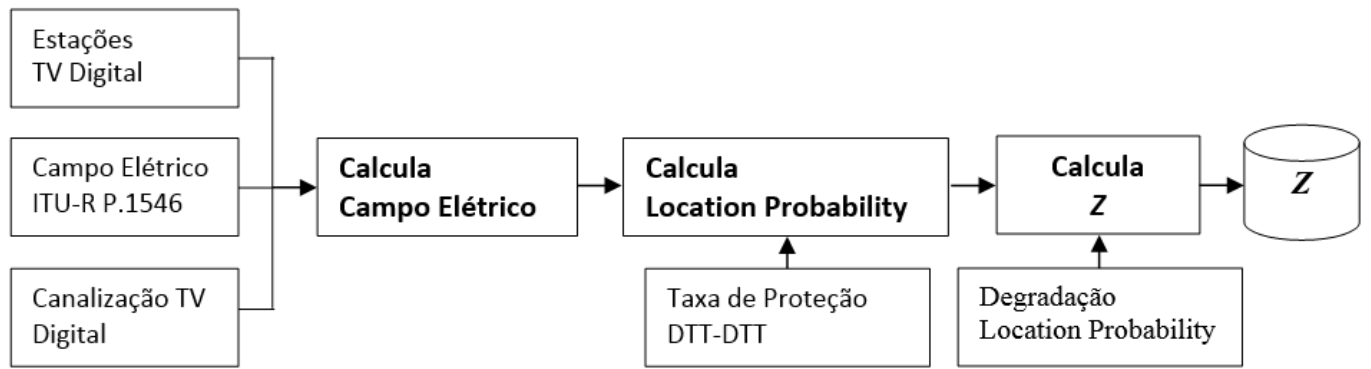

Figura 4.6: Diagrama de blocos da construção da base de dados $Z$

O cálculo do campo elétrico de cada célula na área de serviço utiliza 3 conjuntos de dados:

(a) Estações TV digital - Os dados de 3 estações de TV digital, localizadas no morro do Sumaré região metropolitana do Rio de Janeiro, foram obtidas do site da Anatel, sendo escolhidas as estações que possuiam os canais de frequência 24, 27 e 29. 
(b) Campo Elétrico ITU-R P.1546 - As tabelas de campo elétrico em função da distância para campo elétrico excedido 1\% e 50\% do tempo são obtidas da recomendação ITU-R P.1546 [23]. Os valores do campo elétrico na distância e frequência de cada célula são calculados por interpolação conforme anexo 5 da recomendação.

(c) Canalização TV digital - A tabela dos canais de frequências do sistema de TV digital com as frequências inicial e final de cada canal.

O cálculo da location probability de cada célula da área de serviço foi implementado utilizando as informações de campo elétrico e da taxa de proteção do sistema de TV digital, considerando a interferência intrasistema, ou seja, interferência de transmissores DTT em receptores DTT [25].

O cálculo da potência interferente intersistema $Z$ de cada célula da área de serviço é realizado utilizando a location probability e a degradação máxima da location probability definida pelo regulamento Ofcom como 0.07. Este cálculo é desenvolvido pelo algoritmo iterativo do método analítico descrito na Seção 2.3. A Figura 4.7 mostra $Z$, em dBm, na área de serviço do canal 24. Um conjunto de arquivos de dados da potência interferente intersistema $Z$ de

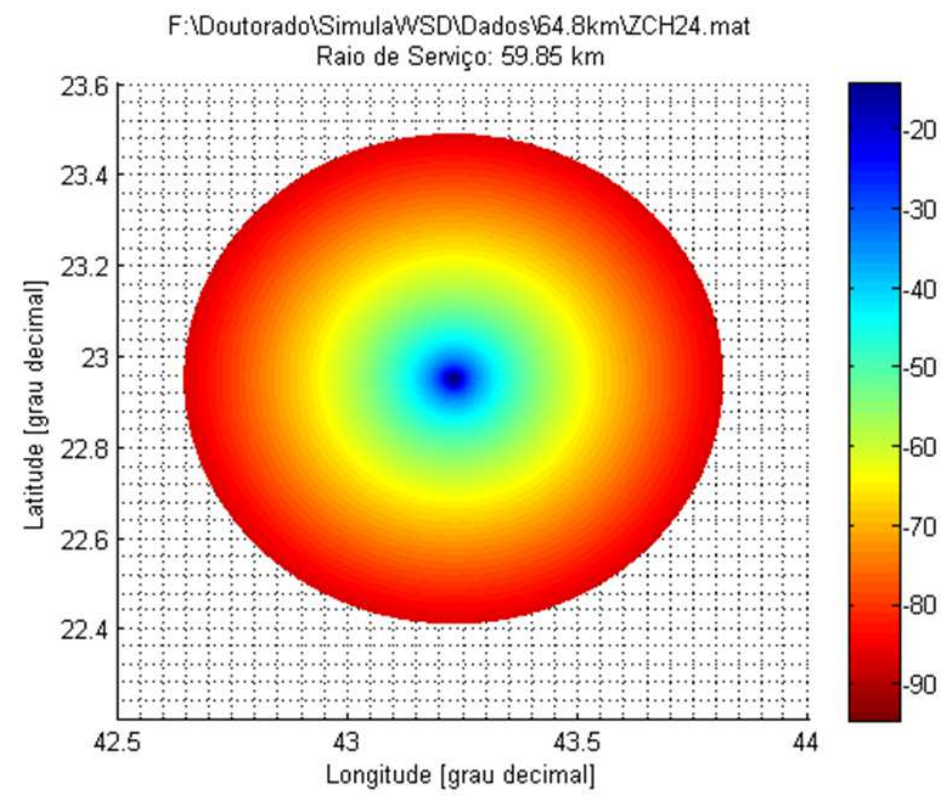

Figura 4.7: Potência interferente intersistema $Z$, em dBm, no canal de frequência 24

cada célula por canal de frequência é salvo para utilização nas simulações. 


\subsection{2}

\section{Análise da Interferência Agregada na Metodologia Ofcom}

A segunda etapa do trabalho é demonstrar que o critério de interferência em (4-1) não é atendido pela potência interferente agregada $\left(i_{\text {agg }}\right)$ de WSDs cujas e.i.r.p. são obtidas a partir da máxima e.i.r.p. definida pela metodologia de cálculo Ofcom. O diagrama de blocos para análise da $i_{a g g}$ na metodologia Ofcom é mostrado na Figura 4.8.

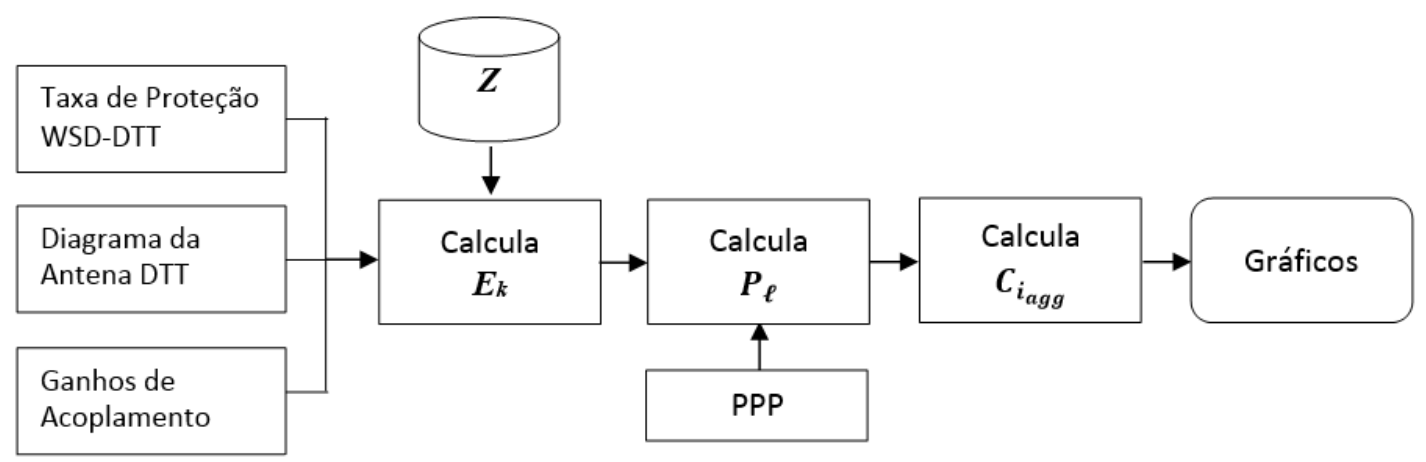

Figura 4.8: Diagrama de blocos da análise do comportamento estatístico da potência interferente agregada em relação ao critério de interferferência na metodologia Ofcom

A Seção 4.1 descreve o método de cálculo da e.i.r.p. $E_{k}$ aqui implementada. $O$ cálculo de $E_{k}$ para cada uma das células da região de trabalho utiliza a base de dados da potência interferente limite $Z$ e três conjuntos de dados obtidos do anexo 2 do regulamento Ofcom [7] como descritos abaixo.

(a) Taxa de Proteção WSD-DTT - A tabela da taxa de proteção low para WSDs da classe 1.

(b) Diagrama da antena DTT - O diagrama de irradiação da antena ITU-R BT.419-3 do receptor DTT com ganho máximo de 9.15 dBi.

(c) Ganhos de Acoplamento - As tabelas de ganhos de acoplamento para as Tiers 2 e $0 / 1$.

Para efetuar o cálculo da e.i.r.p. $E_{k}$ de uma célula é necessário selecionar ao redor desta célula todas as células em um círculo com $2 \mathrm{~km}$ de raio. As células deste círculo são classificadas como Tiers maiores ou igual a 3 (Tiers 3+), Tier 2, Tier 1 e Tier 0. A figura 4.9 ilustra em azul as células da região de trabalho, sendo a célula com menor latitude/longitude da região de trabalho utilizada como exemplo para seleção e classificação das células no círculo ao redor da mesma, as cores das células do círculo representam as camadas do Tier 3+, Tier 2, Tier 1 e Tier 0 . Esta seleção e classificação das células se repete para 
o cálculo de $E_{k}$ de cada uma das células da área quadrada em azul. Observe que para realizar o cálculo de $E_{k}$ das células da região de trabalho de $4 \mathrm{~km} \mathrm{x}$ $4 \mathrm{~km}$ é necessário ter o valor de $Z$ de uma região de $8 \mathrm{~km}$ x $8 \mathrm{~km}$ no entorno da célula central.

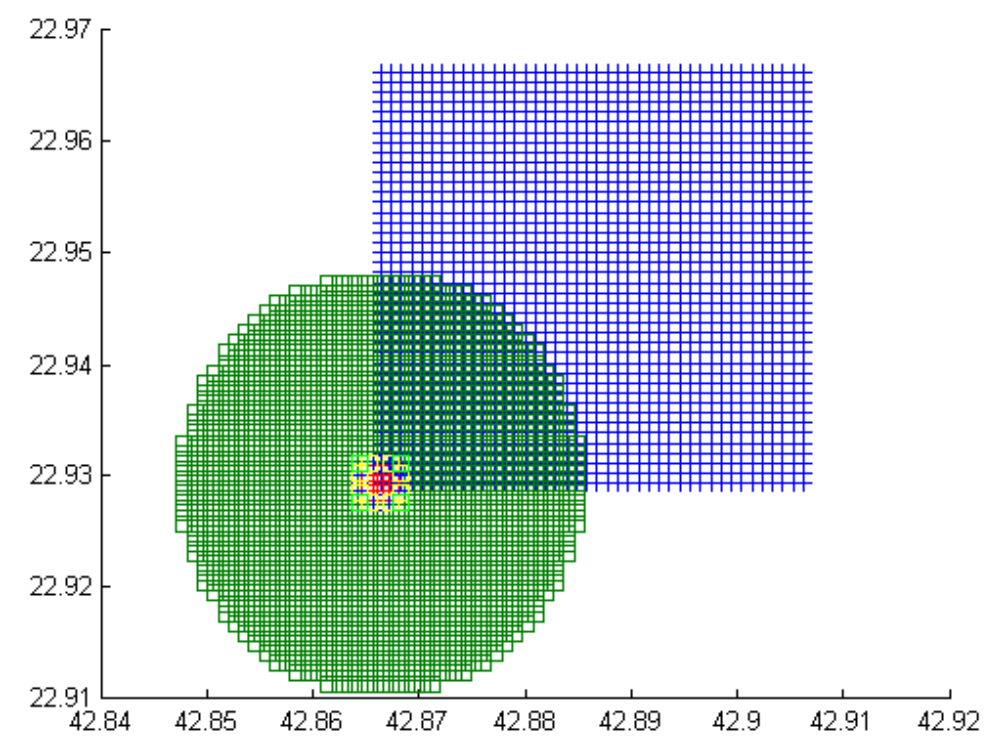

Figura 4.9: Representação das células da região de trabalho em azul e das células selecionadas para cálculo da e.i.r.p. $E_{k}$ na célula de menor latitude/longitude da região de trabalho.

A e.i.r.p. $P_{\ell}$ do WSD é utilizada no cálculo da potência interferente individual $i_{\ell}$ cujo somatório define o valor da $i_{a g g}$ como foi mostrado em (4-8) e (4-11). O relatório ECC.186 [5] sugere que os valores da e.i.r.p. $P_{\ell}$ sejam determinados dividindo-se a e.i.r.p. regulatória $E_{k}$ de uma célula entre os WSDs localizados dentro da mesma. Assim, o método utilizado para a determinação de $P_{\ell}$ divide a e.i.r.p. regulatória $E_{k}$ igualmente entre os WSDs ativos na célula, conforme procedimento de admissão Ecc.186 descrito na Seção 3.3. Este método foi utilizado na obtenção dos resultados no artigo [8]. Assim sendo, a e.i.r.p. $P_{\ell}$ é calculada por

$$
P_{\ell}=E_{k}-10 \log \left(N_{k}\right) \quad \text { Se } r_{\ell} \in \text { Célula } k
$$

onde $E_{k}$ é a e.i.r.p. máxima da célula $k, N_{k}$ é o número de WSDs na célula $k$ e $r_{\ell}$ é a localização do $\ell$-ésimo WSD $\left(\mathrm{WSD}_{\ell}\right)$.

Os WSDs são distribuídos espacialmente de acordo com um processo pontual de Poisson (PPP) homogêneo e bidimensional [18] [19] [20] [21] [22]. Uma simulação Monte Carlo é desenvolvida para cada densidade através de 1000 amostras PPP geradas dentro da região de trabalho. Verificou-se que a utilização de 1000 amostras PPP no método Monte Carlo é suficiente para 
o cálculo da $i_{\text {agg }}$ mesmo para baixas densidades. A utilização de um número maior de amostras PPP, praticamente, não altera o resultado obtido com 1000 amostras PPP. Adota-se que o receptor DTT vítima está localizado na célula central da região de trabalho, sendo o cálculo da $i_{\text {agg }}$ realizado para esta célula central denominada neste trabalho como Célula 0 .

O método de cálculo da $i_{\text {agg }}$ foi desenvolvido na Seção 4.2 onde foi visto que dadas as localizações geográficas $\mathbf{r}$ dos WSDs interferentes dentro da região de trabalho, ou seja, dado $\mathbf{r}=\mathbf{R}$, o método de Schwartz-Yeh fornece a média e a variância da função densidade de probabilidade condicional da potência interferente agregada $p_{i_{a g g \mid \mathbf{r}=\mathbf{R}}}$. Considerando-se que as posições dos WSDs, dadas pelo vetor $\mathbf{r}$, são aleatórias, então a função densidade de probabilidade da potência interferente agregada $p_{i_{a g g}}$ pode ser escrita como

$$
p_{i_{a g g}}(I)=\int_{\Omega_{\mathbf{r}}} p_{i_{a g g \mid \mathbf{r}=\mathbf{R}}}(I) p_{\mathbf{r}}(\mathbf{R}) d \mathbf{R}
$$

onde $p_{\mathbf{r}}(\mathbf{R})$ denota a função densidade de probabilidade do vetor $\mathbf{r}$ e $\Omega_{\mathbf{r}}$ a região de trabalho no entorno do receptor DTT vítima.

A função distribuição de probabilidade complementar da variável aleatória $i_{a g g}$ é então dada por

$$
C_{i_{a g g}}(I)=P\left(i_{a g g}>I\right)=\int_{\Omega_{\mathbf{r}}} p_{\mathbf{r}}(\mathbf{R}) \int_{I}^{\infty} p_{i_{a g g} \mid \mathbf{r}=\mathbf{R}}(u) d u d \mathbf{R}
$$

A função densidade de probabilidade condicional em (4-24) é uma gaussiana com média e variância dadas respectivamente por (4-14) e (4-15), assim sendo obtém-se

$$
C_{i_{a g g}}(I)=\int_{\Omega_{\mathbf{r}}} p_{\mathbf{r}}(\mathbf{R}) Q\left(\frac{I-m_{i_{a g g \mid \mathbf{r}=\mathbf{R}}}}{\sigma_{i_{a g g \mid \mathbf{r}=\mathbf{R}}}}\right) d \mathbf{R}
$$

O comportamento estatístico da $i_{a g g}$ afetando um receptor DTT vítima na Célula 0 é obtido utilizando-se (4-25) que é determinado para diferentes densidades de WSDs.

Um cenário particular foi analisado e os parâmetros utilizados são mostrados na Tabela 4.1. Neste cenário três transmissores DTT colocalizados, operando nos canais de frequência 27, 24 e 29, compartilham a faixa de frequência com um sistema WSD que ocupa o canal de frequência 26. Observe que os canais de frequências 27, 24 e 29 do sistema DTT são o primeiro, segundo e terceiro canal adjacente do canal de frequência 26 do sistema WSD.

Para fins de comparação, o ponto que corresponde ao critério de interferência (4-1) na Célula 0 é mostrado como um asterisco nas figuras e a potência interferente intersistema correspondente a este ponto é denominada $Z_{0}$. A Figura 4.10 ilustra as curvas das funções distribuição de probabilidade complementar condicionais da $i_{\text {agg }}$ que afetam o canal 24 do receptor DTT. Estas 
Tabela 4.1: Parâmetros do Cenário para Análise da $i_{a g g}$ na Metodologia Ofcom

\begin{tabular}{|l|c|}
\hline Parâmetro & Valor \\
\hline Número de transmissores DTT & 3 \\
\hline Canais de frequência DTT & $24,27,29$ \\
\hline Canal de frequência WSD & 26 \\
\hline Método de cálculo campo elétrico DTT & ITU-R P.1546-5 [23] \\
\hline Distância receptor DTT vítima & $35 \mathrm{~km}$ \\
\hline Azimute receptor DTT vítima & 270 graus \\
\hline Diagrama de radiação da antena DTT & ITU-R BT.419-3 [24] \\
\hline Tabela protection rate & low - classe 1 \\
\hline Método - perda de propagação & Hata extendido $[17]$ \\
\hline Clutter - perda de propagação & urbano \\
\hline Método de distribuição espacial WSD & PPP $[22]$ \\
\hline Número de amostras PPP por densidade & 1000 \\
\hline Dimensões região de trabalho & $4 \mathrm{~km} \mathrm{x} 4 \mathrm{~km}$ \\
\hline Altura antena DTT & $10 \mathrm{~m}$ \\
\hline Altura antena WSD & $30 \mathrm{~m}$ \\
\hline
\end{tabular}

curvas são obtidas das 1000 amostras PPP com densidade $\lambda$ de 1 WSD $/ \mathrm{km}^{2}$. A curva da função distribuição de probabilidade complementar incondicional $C_{i_{a g g}}$ está traçada em azul. Note que o atendimento ao critério de interferência requer que as curvas passem abaixo do asterisco, assim o critério de interferência não é satisfeito para parte das amostras PPP.

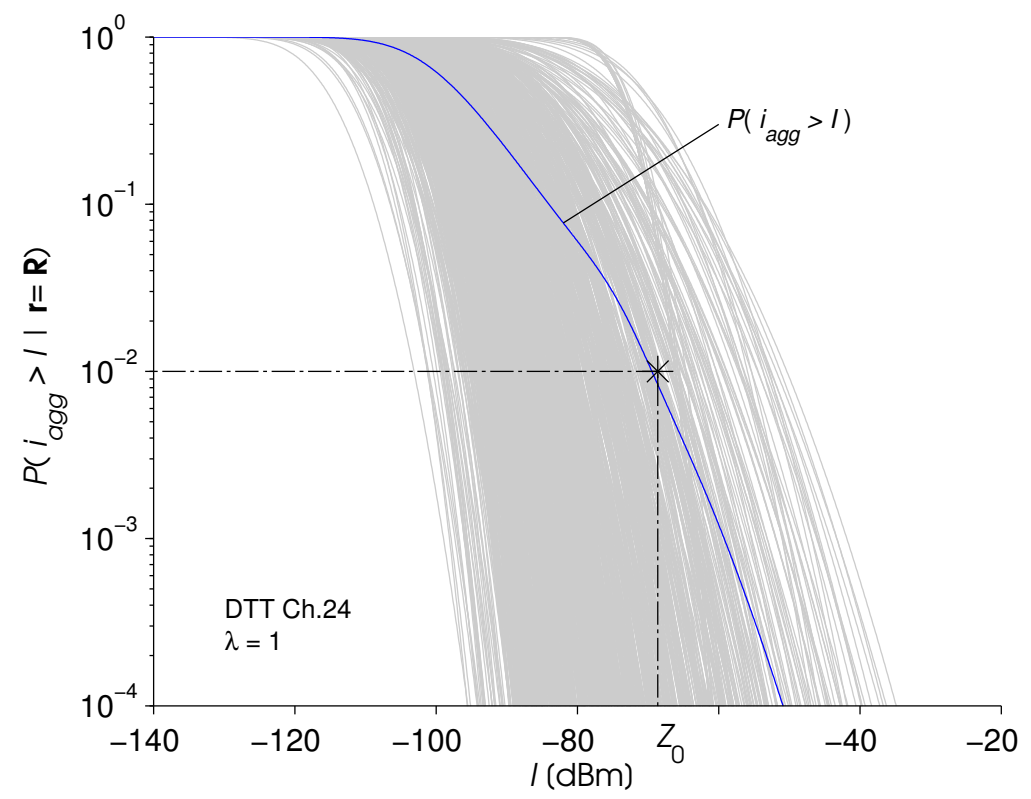

Figura 4.10: Funções distribuição de probabilidade complementar condicionais e incondicional da potência interferente agregada afetando o canal 24 para 1000 amostras PPP com densidade $\lambda=1 \mathrm{WSD} / \mathrm{km}^{2}$.

As figuras 4.11 e 4.12 mostram as funções distribuição de probabilidade complementar da $i_{\text {agg }}$ que afetam o receptor DTT na Célula 0 nos ca- 
nais 27 e 24, respectivamente. Foram utilizadas diferentes densidades $\lambda$ de WSDs variando de 0.1 a 100 dispositivos por $\mathrm{km}^{2}$. As densidades utilizadas são $\lambda=\{0.1,0.215,0.464,1.0,2.15,4.64,10.0,21.5,46.4,100\}$, sendo diferentes cores utilizadas para corresponder a diferentes densidades. Note que o cálculo

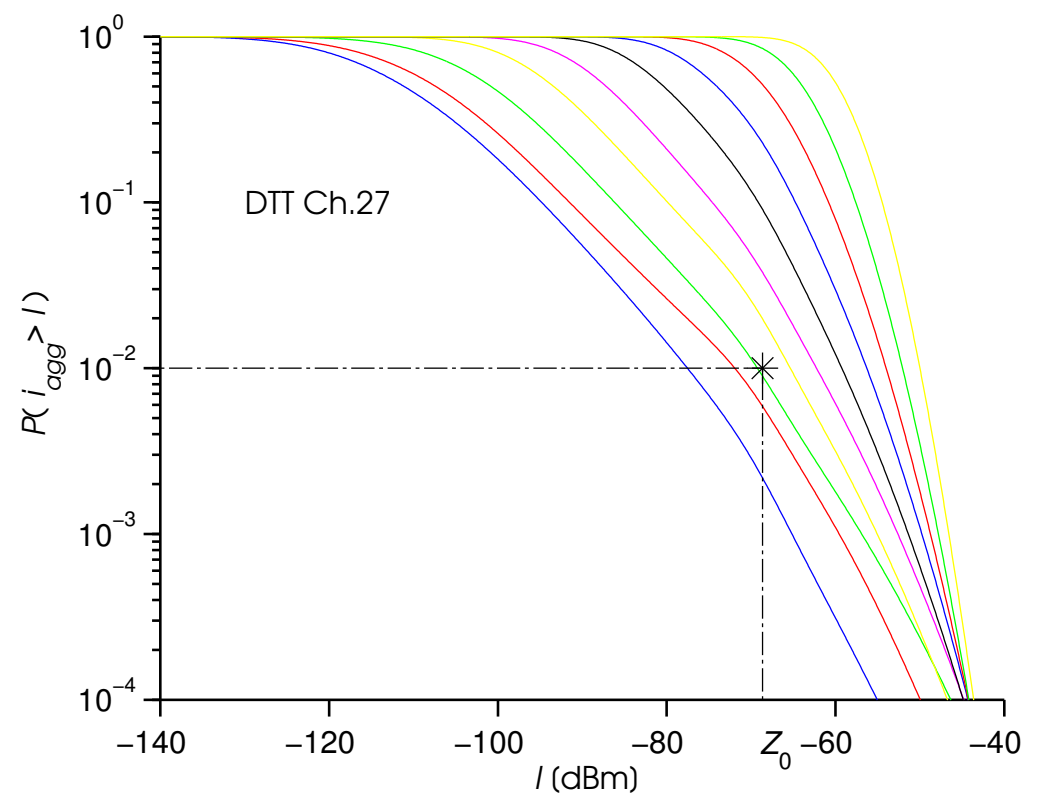

Figura 4.11: Funções distribuição de probabilidade complementar da potência interferente agregada afetando canal 27 do receptor DTT, devido aos WSDs operando no canal 26 para densidades variando de 0.1 a 100 .

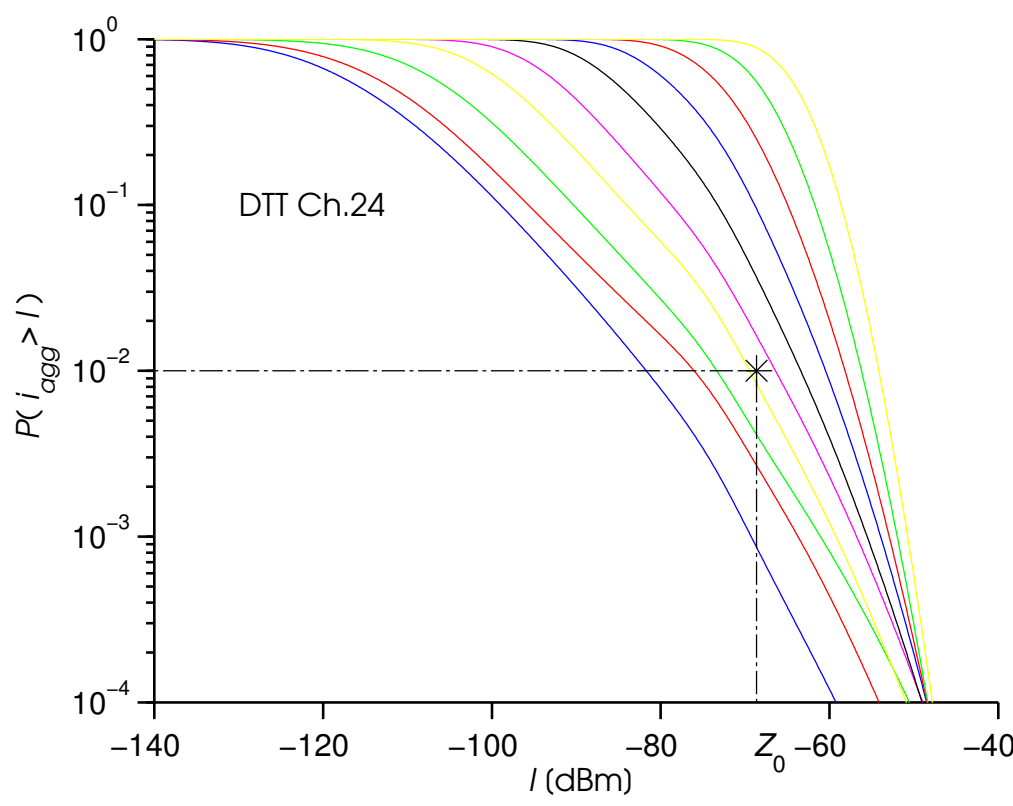

Figura 4.12: Funções distribuição de probabilidade complementar da potência interferente agregada afetando canal 24 do receptor DTT, devido aos WSDs operando no canal 26 para densidades variando de 0.1 a 100. 
da máxima e.i.r.p. pelo modelo single-entry da metodologia Ofcom é otimista para várias densidades, uma vez que várias curvas estão acima do asterisco, não satisfazendo o critério de interferência.

A Figura 4.13 mostra a probabilidade da $i_{a g g}$, afetando o receptor DTT na Célula 0 , exceder o valor de referência $Z_{0}$ para cada um dos três canais de frequências do sistema DTT. A linha tracejada mostra o limite $\epsilon=0.01$ do critério de interferência. Observe na Figura 4.13 que, para os canais de

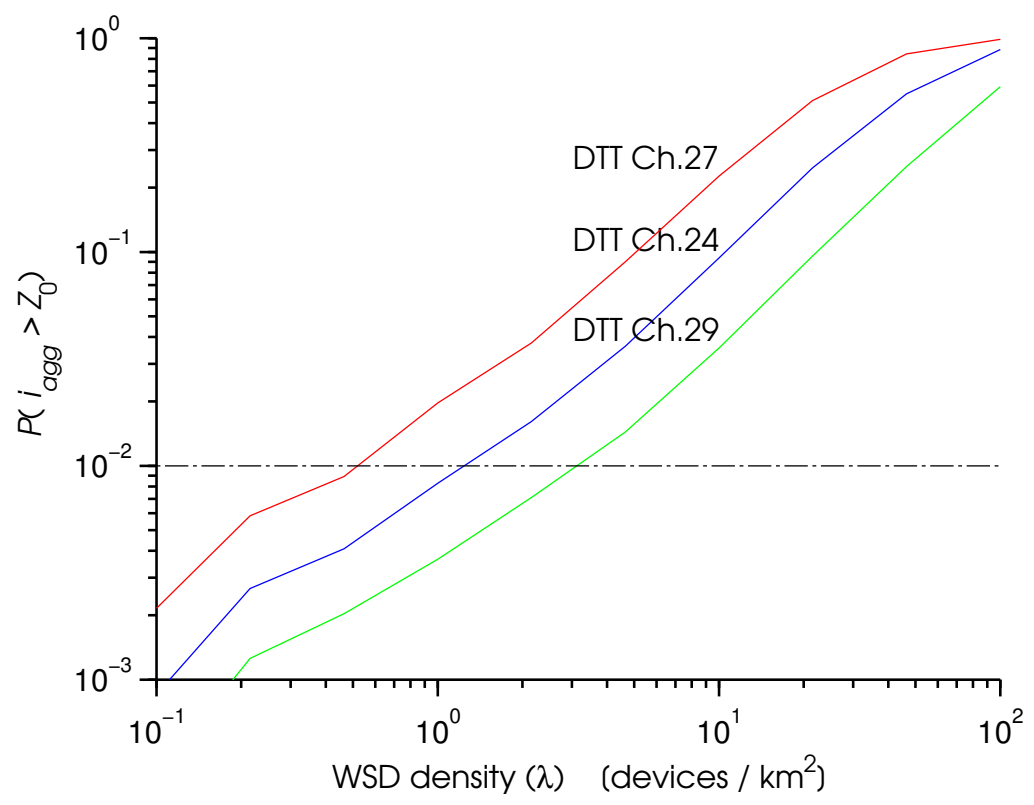

Figura 4.13: Probabilidade da potência interferente agregada exceder o valor de referência $Z_{0}$ para cada um dos três canais de frequências do sistema DTT.

frequências 27, 24 e 29, a máxima e.i.r.p. é otimista para densidades superiores a $0.5,1.2$ e 3.1, respectivamente, uma vez que o critério de interferência não é satisfeito acima desses valores de densidade. Assim sendo, a análise deste cenário demonstra que, quando os WSDs utilizam a e.i.r.p. determinada pelo modelo de interferência single-entry da metodologia Ofcom, o critério de interferência somente é satisfeito para baixos valores de densidade.

Uma vez que não há no regulamento Ofcom uma limitação para múltiplas interferências, ou para o somatório delas, é possível que o receptor DTT venha a experimentar uma degradação da location probability superior ao limite regulatório. Em outras palavras, o máximo valor da e.i.r.p. que pode ser transmitido pelo WSD em uma dada célula não garante que o receptor DTT está protegido contra a interferência agregada. 


\section{5}

\section{Novo Procedimento de Admissão}

Este capítulo desenvolve um procedimento de admissão, nomeado Iagg, cujo critério de admissão está vinculado ao critério de interferência, sendo a potência interferente agregada utilizada para avaliação deste critério.

O novo procedimento de admissão Iagg é apresentado na Seção 5.1, enquanto as funções de otimização, tempo médio de admissão e máscara de otimização necessárias para a implementação do procedimento de admissão Iagg são desenvolvidas na Seção 5.2.

\section{1}

\section{Procedimento de Admissão lagg}

Os procedimentos de admissão Ofcom e Ecc.186, tratados nas seções 3.2 e 3.3, respectivamente, possuem como objetivo satisfazer a restrição da máxima e.i.r.p. regulatória da célula, ou seja, a soma das e.i.r.p. de todos os WSDs dentro de uma mesma célula deve se limitar a e.i.r.p. regulatória desta célula. Entretanto, esta restrição não garante que o limite de interferência do sistema primário seja satisfeito conforme descrito no Capítulo 3.

O procedimento de admissão Iagg é proposto com o objetivo de garantir a proteção do sistema de TV digital (DTT) e dar solução para os problemas identificados na metodologia Ofcom. A solução destes problemas torna-se essencial para a real proteção do sistema DTT, uma vez que a metodologia Ofcom não garante que o limite de potência interferente $Z$ seja atendido em cenários onde múltiplos WSDs operam em um mesmo canal de frequência. Além disso, adotar uma metodologia que permita aos WSDs, localizados em células próximas, utilizar o mesmo canal de frequência conduz a uma maior eficiência espectral e, consequentemente, a uma maior capacidade do sistema WSD.

Torna-se clara pela descrição detalhada do problema, nas seções 3.4 e 3.5, a necessidade de adotar uma metodologia de cálculo que considere múltiplas entradas de interferência e utilize este agregado como parâmetro para avaliação da interferência limite, considerando $Z$ como a potência interferente intersistema excedida $1 \%$ do tempo. 
A proposta é que o processo de admissão de um novo WSD inclua uma função que verifique se o critério de interferência em (4-21) é satisfeito. Para os WSDs que não conseguem satisfazer este critério, uma solução de otimização das potências de transmissão dos WSDs será utilizada em uma tentativa de possibilitar a admissão do novo WSD. Assim, caso a interferência agregada satisfaça o critério de interferência, o novo WSD é admitido no canal de frequência que está sendo analisado com a potência de transmissão regulatória. Caso a interferência agregada não satisfaça o critério de interferência, um processo de otimização é utilizado para determinar a redução das potências de transmissão dos WSDs de modo a satisfazer o critério de interferência, permitindo a admissão do novo WSD no canal de frequência que está sendo analisado. Um diagrama do procedimento de admissão proposto é apresentado na Figura 5.1.

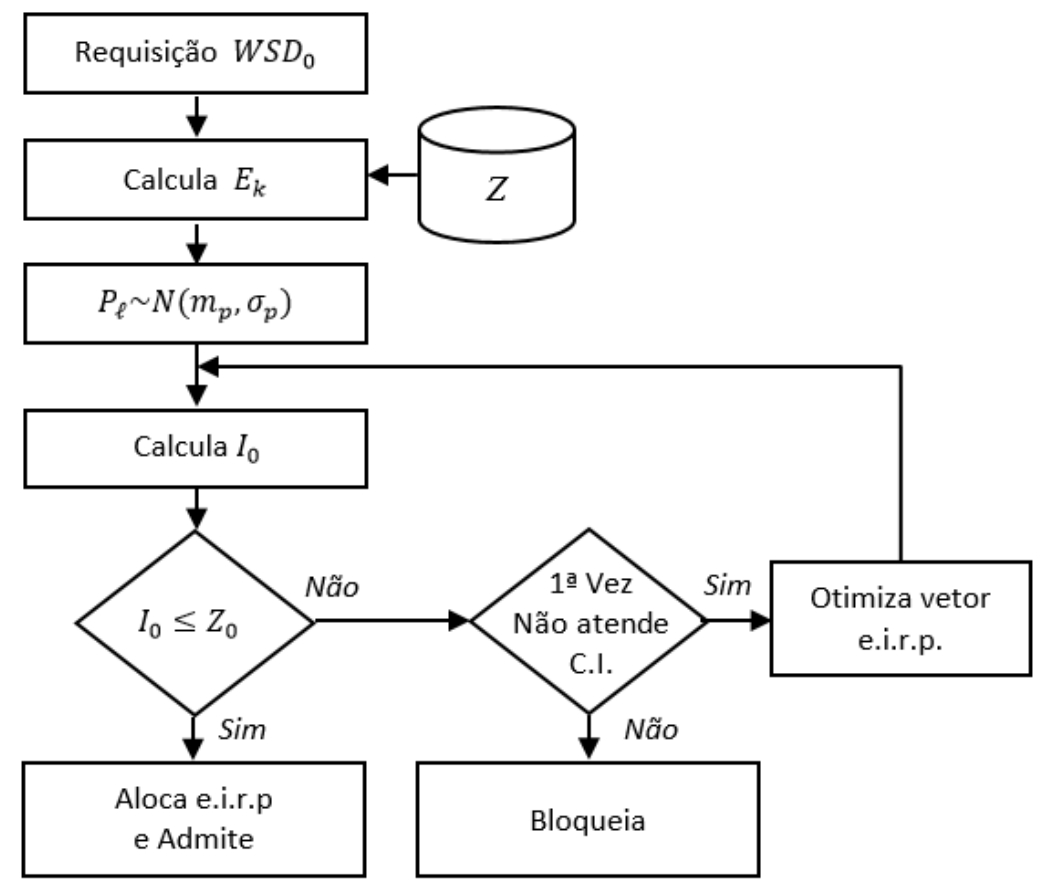

Figura 5.1: Procedimento de admissão da metodologia Iagg.

De acordo com este diagrama, o procedimento se inicia com a requisição de admissão do novo WSD $\left(\mathrm{WSD}_{0}\right)$ e o cálculo da e.i.r.p. máxima $E_{k}$ das células da região de trabalho através da base de dados da potência interferente intersistema $Z$. O valor da média e desvio padrão são atribuídas para a e.i.r.p. $P_{\ell}$ do $\mathrm{WSD}_{0}$.

A potência interferente agregada excedida $1 \%$ do tempo $I_{0}$ é calculada e o critério de interferência (C.I.) avaliado. Caso o C.I. seja satisfeito, a e.i.r.p. é alocada para o $\mathrm{WSD}_{0}$ e o mesmo é admitido. Caso o C.I. não seja satisfeito, uma otimização do vetor e.i.r.p. é realizada, $I_{0}$ é recalculada e o C.I. é avaliado 
novamente. Se o C.I. for satisfeito, as e.i.r.p. são alocadas para os WSDs que foram otimizados e o $\mathrm{WSD}_{0}$ é admitido. Se o C.I. não for satisfeito nesta $2^{a}$ avaliação, então o $\mathrm{WSD}_{0}$ é bloqueado. Neste último caso, o $\mathrm{WSD}_{0}$ deve buscar outro canal de frequência cuja configuração espacial dos WSDs permita a sua admissão.

Para utilizar o canal de frequência que necessita da redução das e.i.r.p. de WSDs em operação, o banco de dados geolocalizado WSDB deve primeiro reduzir estas e.i.r.p. antes de admitir o novo WSD no sistema. Este procedimento é necessário para que o critério de interferência não seja excedido ainda que temporariamente. Obviamente, haverá um atraso na admissão do novo WSD, este atraso representa um custo de entrada neste canal de frequência devido ao não atendimento ao critério de interferência. A análise deste atraso é realizada na Subseção 5.2.2.

É importante notar que a redução da potência de transmissão de WSDs em operação pode implicar na redução da taxa de transmissão. Assim sendo, para preservar um desempenho adequado, a metodologia proposta deve considerar uma e.i.r.p. mínima de trabalho $P_{\min }$ para os WSDs que participam da otimização.

O desafio de desenvolver uma metodologia que otimize as potências de transmissão para atender ao critério de interferência durante a admissão de um WSD está em minimizar o impacto desta admissão nos WSDs em operação, reduzir o tempo de espera do WSD em processo de admissão e diminuir o custo computacional e de comunicação do sistema de banco de dados.

\section{2}

\section{Otimização das e.i.r.p.}

Esta seção detalha como foi desenvolvida a redução das e.i.r.p. dos WSDs no entorno da célula mais vulnerável para atendimento ao critério de interferência durante a admissão de um novo WSD. Além disso, alguns aspectos importantes para esta redução são detalhados.

O problema e o método de solução utilizado na redução das e.i.r.p. é descrito na Subseção 5.2.1. A formulação matemática do atraso médio na admissão é desenvolvida na Subseção 5.2.2. Por fim, a seleção da região com os WSDs de maior impacto no cálculo da potência interferente agregada é desenvolvido na Subseção 5.2.3. 


\subsection{1}

\section{Redução das e.i.r.p.}

A redução das e.i.r.p. será feita considerando um problema de otimização com restrição convenientemente definido.

O critério de interferência (C.I.) pode ser avaliado verificando se a potência interferente agregada $I_{0}$ é menor ou igual a potência interferente intersistema limite $Z_{0}$ ambas calculadas na célula mais vulnerável $\left(\mathrm{CMV}_{0}\right)$ associada a célula onde o novo WSD $\left(\mathrm{WSD}_{0}\right)$ se encontra. Nesta condição o $\mathrm{WSD}_{0}$ pode ser admitido sem atraso.

Por outro lado, se $I_{0}$ for superior a $Z_{0}$, a potência interferente agregada na $\mathrm{CMV}_{0}$ não atende o C.I. Neste caso, a nova metodologia de admissão Iagg define que alguns WSDs no entorno da $\mathrm{CMV}_{0}$ reduzam suas e.i.r.p. para satisfazer o C.I. e permitir a entrada do $\mathrm{WSD}_{0}$. Neste caso, o $\mathrm{WSD}_{0}$ experimenta um atraso na sua admissão, pois somente iniciará sua operação após a redução das e.i.r.p. de todos os WSDs em operação afetados pelo processo de redução das e.i.r.p.

A redução seletiva das e.i.r.p. para atender o C.I. é desenvolvida através de uma otimização matemática aplicada as e.i.r.p. dos WSDs que estão dentro de uma área ao redor da $\mathrm{CMV}_{0}$. Esta área, nomeada como máscara de otimização, visa selecionar os WSDs que são os maiores ofensores para a potência interferente agregada, reduzindo o número de WSDs que serão otimizados e com isto diminuindo o o atraso na admissão e o custo computacional do banco de dados WSDB.

As e.i.r.p. dos WSDs que estão dentro da máscara de otimização são tratadas como um vetor $\mathbf{e}$

$$
\mathbf{e}=\left(\begin{array}{c}
e_{1} \\
e_{2} \\
\vdots \\
e_{N}
\end{array}\right)
$$

onde $N$ é o número de WSDs dentro da máscara de otimização.

A otimização do vetor e é obtida através da minimização de uma função denominada $f(\mathbf{e})$ (função objetivo).

$$
f(\mathbf{e})=\left(I_{0}(\mathbf{e})-Z_{0}\right)^{2}
$$

Note que buscamos que a diferença $I_{0}-Z_{0}$ seja reduzida até zero, ou seja, até que $I_{0}$ seja igual a $Z_{0}$. Para isto, utilizamos como função objetivo uma função quadrática sobre essa diferença que apresenta seu mínimo em $Z_{0}$.

A potência interferente agregada excedida $1 \%$ do tempo, $I_{0}$, é escrita como uma função do vetor e, uma vez que as componentes do vetor e são usadas 
para calcular, através de (4-8), a potência interferente individual de cada WSD na $\mathrm{CMV}_{0}$ e estas potências são somadas pela aproximação da Schwartz-Yeh [10] em uma potência interferente agregada $i_{\text {agg }}$ que é usada para calcular $I_{0}$ através de (4-20).

Obviamente, a redução da e.i.r.p. é limitada por um valor mínimo de trabalho estabelecido para garantir que os WSDs afetados pela otimização possam continuar operando e, também, por um valor máximo definido pela e.i.r.p. máxima regulatória da célula onde o WSD se encontra.

O problema de otimização matemática pode, então, ser escrito como

$$
\begin{array}{rl}
\min _{\mathbf{e}} & f(\mathbf{e}) \\
\text { sujeito a } & e_{j, \min } \leq e_{j} \leq e_{j, \max }, \quad j=1, \ldots, N
\end{array}
$$

onde $e_{j, \min }$ e $e_{j, \max }$ representam os valores mínimo e máximo da e.i.r.p. do WSD da posição $j$ do vetor e.i.r.p. e.

A função objetivo $f(\mathbf{e})$ é uma função não linear, devido a função $I_{0}$, enquanto as restrições são todas lineares. A solução deste problema de otimização não linear foi obtida utilizando-se o método da região de confiança (trust region) descrito em [28] [29] [30] [31].

Note que é possível que algumas otimizações não atinjam o mínimo $f(\mathbf{e})=0$ devido à restrição da e.i.r.p. mínima de trabalho. Isto ocorre quando, durante uma otimização, as e.i.r.p. dos WSDs são reduzidas até a e.i.r.p. mínima, porém o C.I. ainda não foi atendido. Neste caso, o $\mathrm{WSD}_{0}$ será bloqueado e deverá buscar outro canal de frequência onde a configuração espacial dos WSDs seja mais favorável para uma otimização, caso ela seja necessária.

\section{2 .2}

\section{Tempo Médio de Admissão}

Um custo associado a metodologia Iagg proposta é o maior tempo de admissão quando for necessária a otimização de WSDs em operação.

O tempo médio de admissão $\left(T_{a d}\right)$ de um novo WSD $\left(\mathrm{WSD}_{0}\right)$ pode ser calculado, observando que a admissão do $\mathrm{WSD}_{0}$ pode ser dividida pelos eventos de atendimento $(A)$ e não atendimento $(\bar{A})$ do critério de interferência (C.I.), conforme Figura 5.2.

A regra da partição do espaço amostral permite escrever:

$$
p_{t}(T)=p_{t \mid A}(T) \cdot P(A)+p_{t \mid \bar{A}}(T) \cdot P(\bar{A})
$$

Sendo $p_{t}(T), p_{t \mid A}(T)$ e $p_{t \mid \bar{A}}(T)$ a função densidade de probabilidade (fdp) do 


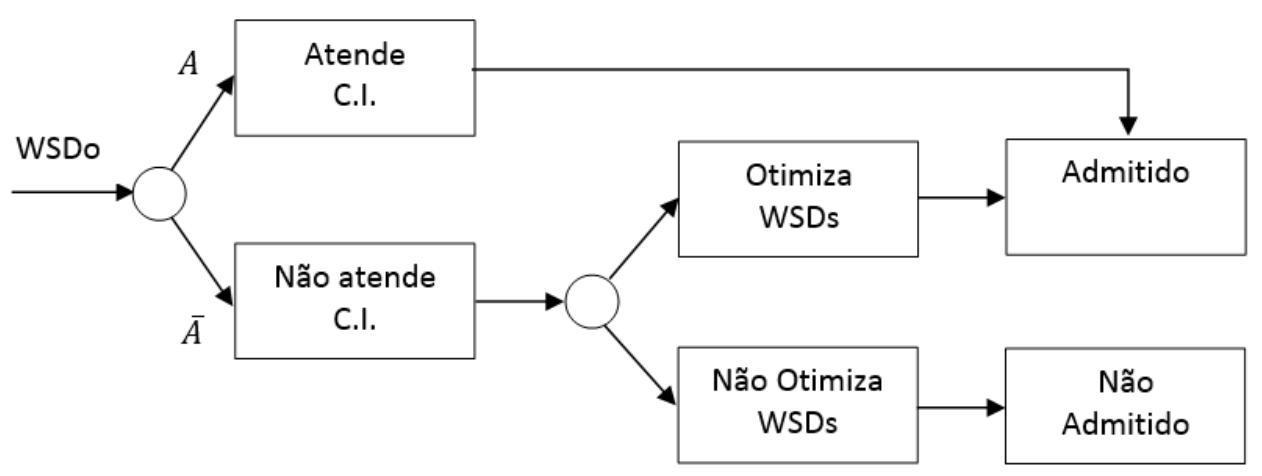

Figura 5.2: Eventos associados a admissão do novo WSD na metodologia Iagg.

tempo de admissão não condicional, condicional dado que o C.I. foi atendido e condicional dado que o C.I. não foi atendido, respectivamente. Enquanto, $P(A)$ e $P(\bar{A})$ são as probabilidades de atendimento e não atendimento do C.I, respectivamente.

A densidade $p_{t \mid A}(T)$ pode ser modelada como um impulso na origem, pois não existe atraso quando o $\mathrm{WSD}_{0}$ atende o critério de interferência.

$$
p_{t \mid A}(T)=\delta(T)
$$

Quando ocorre o evento $\bar{A}$ e a otimização é viável, então o $\mathrm{WSD}_{0}$ somente poderá iniciar operação no sistema após a redução das potências dos WSDs em operação otimizados. Seja $\tau_{i}$ o tempo até o retorno da comunicação do $\mathrm{WSD}_{i}$ com o banco de dados WSDB, contado a partir da chegada do $\mathrm{WSD}_{0}$, conforme Figura 5.3 (repetida da Figura 3.6).

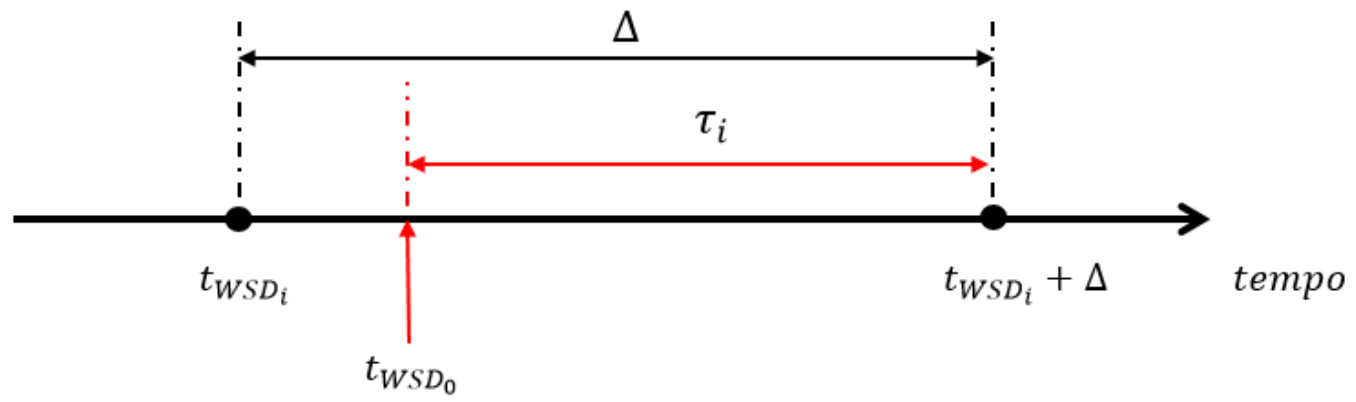

Figura 5.3: Tempo de retorno $\tau_{i}$ contado do instante de chegada do $\mathrm{WSD}_{0}$ até o retorno da comunicação do $\mathrm{WSD}_{i}$ com o banco de dados WSDB.

Na Figura 5.3, considere o tempo $t_{W S D_{i}}$ como o instante de admissão do $\mathrm{WSD}_{i}$ no sistema e o tempo $t_{W S D_{0}}$ como o instante de chegada do $\mathrm{WSD}_{0}$, ou seja, o instante da requisição de admissão, sendo o tempo de retorno máximo $\Delta$, definido conforme Seção 3.1, fixado pelo banco de dados WSDB para todos os WSDs do sistema. Assim sendo, o tempo de retorno $\tau_{i}$ é definido como o 
tempo entre o instante de chegada do $\mathrm{WSD}_{0}$ e o próximo instante de retorno da comunicação do $\mathrm{WSD}_{i}$ com o WSDB.

Assim, o tempo de admissão do $\mathrm{WSD}_{0}$ está associado ao tempo de retorno $\tau_{i}$ de cada WSD em operação na Célula 0. Então, o tempo de admissão pode ser calculado como $t=\max \left(\tau_{i}\right)$, sendo $i=1 \ldots N$ e $N$ é o número de WSDs em operação otimizados.

Esta modelagem permite definir a função distribuição de probabilidade (FDP) da v.a. tempo de admissão $t$ como

$$
\begin{aligned}
F_{t \mid \bar{A}}(T) & =P(t \leq T \mid \bar{A}) \\
& =P\left(\tau_{1} \leq T, \tau_{2} \leq T, \ldots, \tau_{N} \leq T \mid \bar{A}\right) \\
& =\prod_{i=1}^{N} P\left(\tau_{i} \leq T \mid \bar{A}\right)
\end{aligned}
$$

A probabilidade no produtório é a FDP do tempo de retorno $\tau_{i}$, a densidade de probabilidade de $\tau_{i}$ é modelada como uniforme e i.i.d., então $F_{\tau_{i} \mid \bar{A}}(T)=T / \Delta$ para $0<T \leq \Delta$. Assim, a FDP do tempo de admissão pode ser descrita conforme (5-7).

$$
F_{t \mid \bar{A}}(T)= \begin{cases}0 & ; T \leq 0 \\ \left(\frac{T}{\Delta}\right)^{N} & ; 0<T \leq \Delta \\ 1 & ; T>\Delta\end{cases}
$$

Derivando a distribuição $F_{t \mid \bar{A}}(T)$, obtemos a densidade $p_{t \mid \bar{A}}(T)$.

$$
p_{t \mid \bar{A}}(T)= \begin{cases}0 & ; T \leq 0 \\ \left(\frac{N}{\Delta^{N}}\right) T^{N-1} & ; 0<T \leq \Delta \\ 0 & ; T>\Delta\end{cases}
$$

Substituindo (5-5) e (5-8) em (5-4), teremos uma expressão para função densidade de probabilidade não condicional do tempo de admissão. O tempo médio de admissão pode ser calculado como o valor esperado da v.a. tempo de admissão.

$$
\begin{aligned}
& E[t]=\int_{-\infty}^{\infty} T p_{t}(T) d T \\
& E[t]=P(A) \int_{-\infty}^{\infty} T \delta(T) d T+P(\bar{A}) \int_{0}^{\Delta} T\left(\frac{N}{\Delta^{N}}\right) T^{N-1} d T
\end{aligned}
$$

A integral com impulso na origem $\delta(T)$ em (5-9) vale zero, pois o valor 
de T na origem é zero.

$$
\begin{aligned}
E[t] & =P(\bar{A})\left(\frac{N}{\Delta^{N}}\right) \int_{0}^{\Delta} T^{N} d T \\
& =\left.P(\bar{A})\left(\frac{N}{\Delta^{N}}\right)\left(\frac{T^{N+1}}{N+1}\right)\right|_{0} ^{\Delta} \\
& =P(\bar{A})\left(\frac{N}{\Delta^{N}}\right)\left(\frac{\Delta^{N+1}}{N+1}\right) \\
T_{a d}=E[t] & =P(\bar{A})\left(\frac{N}{N+1}\right) \Delta
\end{aligned}
$$

O tempo médio de admissão na metodologia Iagg é definido em (5-10) utilizando o número $N$ de WSDs otimizados, a probabilidade $P(\bar{A})$ de não atendimento do C.I. e o tempo de retorno máximo $\Delta$.

\section{2 .3}

\section{Máscara de Otimização}

A otimização das e.i.r.p. dos WSDs para atendimento ao critério de interferência pode ser realizada considerando os WSDs de toda a região de trabalho de $4 \mathrm{~km} \times 4 \mathrm{~km}$ no entorno da célula mais vulnerável associada ao WSD em processo de admissão. Entretanto, um grande número de WSDs em operação pode ser incluído na otimização, aumentando o tempo de admissão e o custo computacional do banco de dados geolocalizado WSDB.

Além disso, os WSDs mais afastados da célula mais vulnerável (CMV) podem ter suas e.i.r.p. reduzidas de valores pequenos, envolvendo, desnecessariamente, estes WSDs no processo de redução das suas e.i.r.p. .

Por outro lado, reduzir demais o número de WSDs em operação que são considerados na otimização pode resultar em falso atendimento ao critério de interferência (C.I.), basta observar que a interferência agregada é reduzida à medida que diminuimos o número de WSDs que participam do seu cálculo. Assim, uma otimização pode atender o C.I. para um certo número de WSDs que participam da otimização, entretanto a mesma otimização pode não atender o C.I. se mais WSDs fossem considerados.

O número de WSDs selecionados para participar da otimização $(N)$ possui uma relação de compromisso entre atendimento do C.I. e tempo de admissão. Para restringir $N$ e atender esta relação de compromisso, uma região limite no entorno da CMV chamada de máscara de otimização foi desenvolvida.

A máscara de otimização é a região do espaço onde todos os WSDs possuem um nível de interferência na CMV acima de um certo valor e este valor está referenciado a potência interferente limite $Z_{0}$ da CMV. Assim 
sendo, a máscara de otimização representa uma região de interferências mais significativas na $C M V$.

A borda da máscara de otimização corresponde as posições geográficas onde um WSD provoca na CMV uma potência interferente correspondente a $Z_{0}$ subtraído de um valor constante decremental, em dB, chamado dec. Um WSD localizado na região interior à borda da máscara de otimização tem uma potência interferente na CMV superior ao valor da potência interferente de borda. Assim sendo, a potência interferente de WSDs dentro da máscara de otimização, incluindo a borda, possui seu valor dado em 5-11.

$$
I_{W S D \rightarrow C M V} \geq Z_{o}-d e c
$$

A Figura 5.4 mostra as máscaras de otimização para alguns valores do parâmetro de redução da interferência de borda dec.

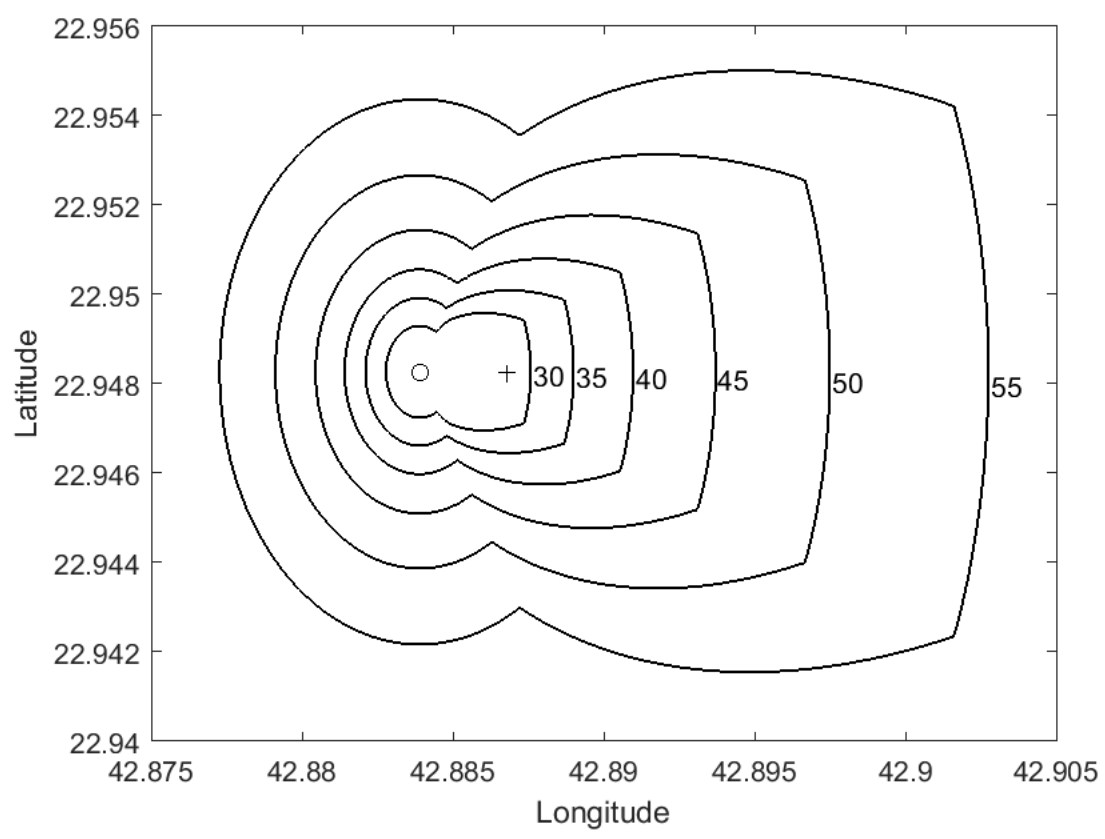

Figura 5.4: Máscaras de otimização em função do parâmetro dec variando de 30 a 55 dB. O círculo indica a posição da CMV e a cruz a posição do $\mathrm{WSD}_{0}$.

Nota-se que o parâmetro dec varia entre 30 e 55 dB. Estes extremos foram definidos avaliando a maior distância da CMV até a borda da máscara de otimização. A Figura 5.5 permite avaliar esta distãncia em função do parâmetro dec.

O valor mínimo de dec é definido de forma que a maior distância da CMV até a borda da máscara de otimização permita incluir o $\mathrm{WSD}_{0}$, pois a interferência do novo WSD deve sempre ser incluída na otimização. Nota-se na 


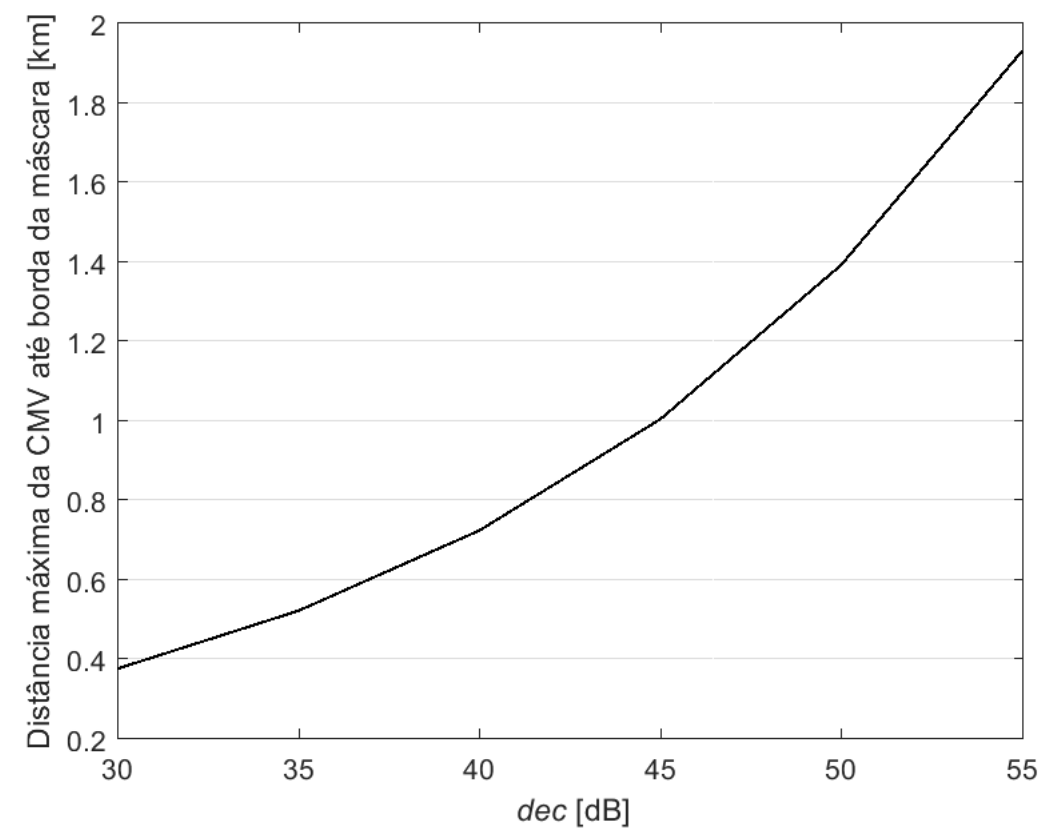

Figura 5.5: Distância máxima da CMV até borda da máscara em função da redução da interferência de borda (dec).

Figura 5.4 que o valor $30 \mathrm{~dB}$ para dec é, aproximadamente, um valor mínimo para inclusão do $\mathrm{WSD}_{0}$.

O valor máximo de dec é definido considerando o centro da região de trabalho de $4 \mathrm{~km}$ x 4km. Logo, uma distância máxima da CMV até a borda da máscara de otimização em torno de $2 \mathrm{~km}$ seria suficiente para abranger todos os WSDs relevantes para a otimização.

$\mathrm{Na}$ Figura 5.5, observa-se que o parãmetro dec no valor de $55 \mathrm{~dB}$ corresponde a uma distãncia máxima da CMV até a borda da máscara de otimização próxima a $2 \mathrm{~km}$, enquando no valor de $30 \mathrm{~dB}$ a distância máxima é inferior a 400m.

Considerando que a diminuição do número de WSDs implica na redução da potência interferente agregada $\left(i_{\text {agg }}\right)$ na CMV e que a máscara de otimização não deve excluir WSDs cujas potências interferentes na CMV sejam significativas no cálculo da $i_{\text {agg }}$, então a máscara de otimização deve ser selecionada de forma a reduzir a $i_{\text {agg }}$ de um valor pequeno.

O critério adotado para seleção da máscara de otimização foi utilizar o parâmetro dec que reduz $1 \mathrm{~dB}$ da $i_{\text {agg }}$ máxima na CMV. A Figura 5.6 mostra o gráfico que exemplifica esta seleção.

As máscaras de otimização são selecionadas por densidade através de simulação Monte Carlo com 1000 redes WSD onde é calculada a $i_{\text {agg }}$ média para cada valor do parâmetro dec. Considera-se a maior máscara de otimização, $d e c=55 \mathrm{~dB}$, como referência para o valor máximo da $i_{\text {agg }}$, sendo a máscara 


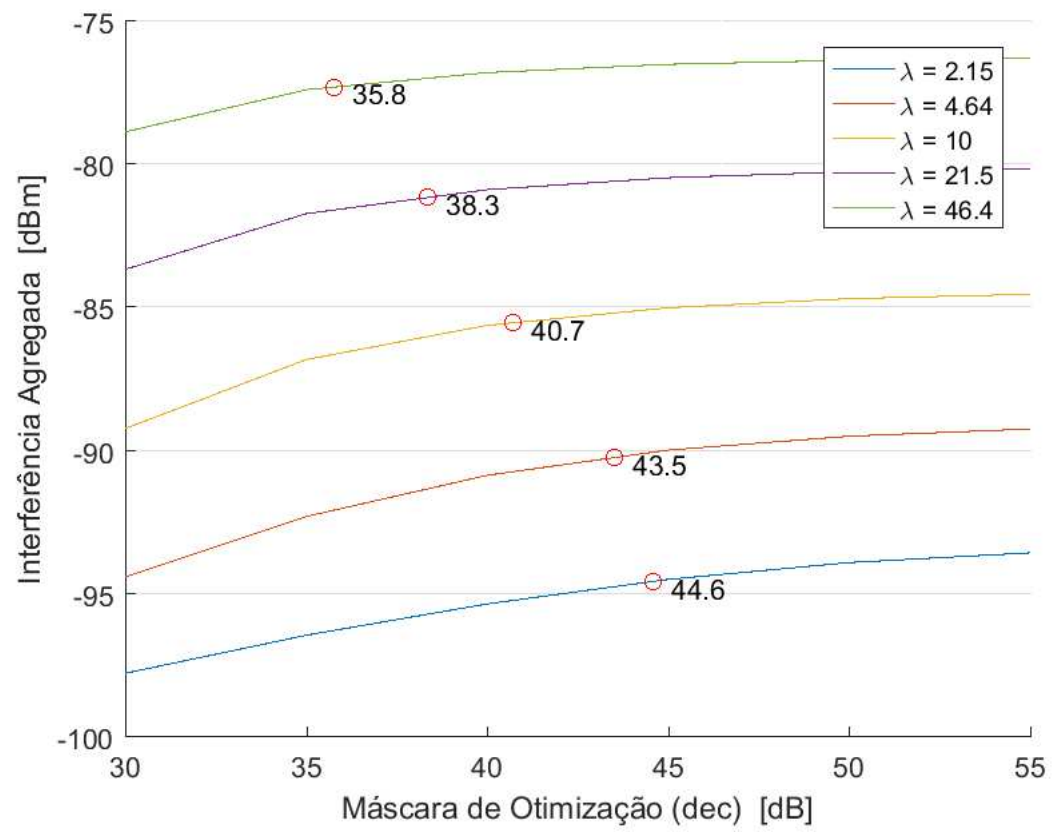

Figura 5.6: Máscaras de otimização selecionadas pelo valor de dec correspondente a $1 \mathrm{~dB}$ abaixo da $i_{\text {agg }}$ máxima de cada densidade $\lambda$. Os valores selecionados estão indicados por um círculo.

de otimização selecionada pelo valor do parâmetro dec interpolado na curva com $1 \mathrm{~dB}$ abaixo do valor máximo da $i_{\text {agg }}$. O gráfico da Figura 5.6 mostra os valores de $d e c$ selecionados por um círculo para cada densidade $\lambda$. 


\section{6 \\ Resultados Numéricos}

Este capítulo realiza uma análise comparativa das metodologias Ecc.186, Ofcom e Iagg. As definições das premissas e parâmetros utilizados na análise são desenvolvidas na Subseção 6.1. A Subseção 6.2 descreve a simulação conjunta dos procedimentos de admissão Ecc.186, Ofcom e Iagg realizada para obter os parâmetros de desempenho que serão utilizados na comparação das metodologias. Uma análise do atendimento ao critério de interferência é realizada na Subseção 6.3. Por fim, uma análise de desempenho através da taxa de atendimento ao critério de interferência é avaliada na Subseção 6.4.

\section{1}

\section{Premissas e Parâmetros}

A simulação dos procedimentos de admissão foi desenvolvida utilizando o mesmo cenário da Seção 4.3.2. Desta forma, a Tabela 4.1 define parte dos parâmetros da simulação. Os parâmetros adicionais são definidos nesta seção a partir das premissas adotadas.

Densidade $\boldsymbol{\lambda}$ A metodologia Ofcom foi avaliada na Seção 4.3 .2 com o objetivo de caracterizar a ocorrência de violação do critério de interferência pela potência interferente agregada quando os WSDs utilizam todo o recurso disponível da rede. Devido a isso, a determinação da e.i.r.p. (equivalent isotropically radiated power) do WSD foi realizada utilizando a metodologia nomeada aqui como Ecc.186. Naquela avaliação ficou demonstrado que a potência interferente agregada satisfaz o critério de interferência apenas em densidades baixas. Assim sendo, os valores de densidade $\lambda$ considerados nesta simulação são tomados a partir do valor $2.15 \mathrm{WSD} / \mathrm{km}^{2}$, visando avaliar as metodologias em densidades mais altas.

e.i.r.p. $\boldsymbol{P}_{\boldsymbol{\ell}}$ Uma das características do compartilhamento da faixa de frequência de TV digital com o sistema WSD é a definição de um ambiente de competição entre os dispositivos WSD. Esta competição resulta em uma maior agressividade dos dispositivos na utilização da potência de transmissão. 
Observe que o ambiente de interferência co-canal degrada a relação sinal ruído-interferência o que reduz a taxa de transmissão, desta forma o dispositivo tende a aumentar sua potência de transmissão para compensar esta redução. Consequentemente, ocorre um aumento do nível de interferência no ambiente rádio que reforça este comportamento do dispositivo. Este comportamento de utilização da máxima potência de transmissão é ainda mais intenso nas redes com mais alta densidade onde o nível de interferência no ambiente rádio é ainda maior. Esta característica dos dispositivos é confirmada em serviços de comunicação ad hoc como os das redes Wi-Fi conforme indica [34].

Pelo exposto, a premissa utilizada para definir os valores da e.i.r.p. $P_{\ell}$ dos WSDs foi adotar níveis de potência não muito distante da e.i.r.p. máxima da célula. O valor da e.i.r.p. mínima operacional $P_{\text {min }}$, também, deve adotar um valor não muito distante da e.i.r.p. máxima da célula $E_{0}$, porém, a faixa entre $P_{\text {min }}$ e $E_{0}$ deve ser larga o suficiente para uma avaliação de alguns valores de $P_{\ell}$. Considerando que no cenário definido pela Tabela 4.1 o valor da e.i.r.p. máxima $E_{0}$ é igual a $13.5 \mathrm{dBm}$, adotou-se para e.i.r.p. mínima operacional o valor $P_{\text {min }}=5 \mathrm{dBm}$, preservando uma faixa de $8.5 \mathrm{~dB}$ para os valores de $P_{\ell}$.

A metodologia Ecc.186 garante que os valores de $P_{\ell}$ estão dentro da faixa entre $P_{\text {min }}$ e $E_{0}$, uma vez que seu critério de admissão só admite o novo WSD se o valor calculado para $P_{\ell}$ não for inferior a e.i.r.p. mínima operacional $P_{\text {min }}$.

A definição dos valores mínimo e máximo adotados para as e.i.r.p. $P_{\ell}$ nas metodologias Ofcom e Iagg considera dois tipos de serviços de comunicação: o serviço de comunicação móvel que define o $P_{\ell}$ mínimo e o serviço de comunicação Wi-Fi que define o $P_{\ell}$ máximo.

Móvel. Nas metodologias Ofcom e Iagg, as e.i.r.p. $P_{\ell}$ são modeladas como variáveis aleatórias gaussianas estatisticamente independentes, sendo seus parâmetros média $m_{p}$ e desvio padrão $\sigma_{p}$ atribuídos conforme a característica do serviço de comunicação. Considere as restrições abaixo aplicadas para o serviço de comunicação móvel.

- O Item A11.50 do anexo 11 do regulamento Ofcom [7] e o documento ITU 5-6/81-E [35], indica que durante 90\% do tempo um dispositivo móvel em um ambiente urbano opera abaixo de $8 \mathrm{dBm}$, o que sugere a restrição

$$
P\left(P_{\ell}>8 \mathrm{dBm}\right)=0.1
$$

- a probabilidade de um WSD operar com uma e.i.r.p. inferior a $P_{\min }$ deve ser muito pequena, para isto adota-se o limite 0.01, ou seja,

$$
P\left(P_{\ell}<P_{\text {min }}\right)=0.01
$$


Considerando as restrições em (6-1) e (6-2), obtém-se os valores de $m_{p}$ e $\sigma_{p}$ da e.i.r.p. $P_{\ell}$, dados respectivamente por

$$
\begin{gathered}
m_{p}=5.16+0.35 P_{\min } \\
\sigma_{p}=2.22-0.28 P_{\min }
\end{gathered}
$$

Considerando o valor da e.i.r.p. mínima operacional $P_{\min }=5 \mathrm{dBm}$, obtem-se, a partir de (6-3) e (6-4), os valores de $m_{p}=6.9 \mathrm{dBm}$ e $\sigma_{p}=0.8$ dBm como os valores da média e desvio padrão da e.i.r.p. $P_{\ell}$ mais baixa da simulação.

Wi-Fi. A definição para o valor mais alto de $P_{\ell}$ utiliza como referência as característica do serviço de comunicação ad hoc do tipo Wi-Fi. Atualmente, na maioria das redes Wi-Fi em operação, praticamente, todos os nós transmitem na sua potência máxima [34]. Considerando esta característica das redes Wi-Fi e que a e.i.r.p. $P_{\ell}$ deve ter muito baixa probabilidade de ultrapassar a e.i.r.p. máxima da célula, adota-se a seguinte restrição.

$$
P\left(P_{\ell}>E_{0}\right)=0.01
$$

onde adotou-se o limite de 0.01 para garantir uma baixa probabilidade de ultrapassagem da e.i.r.p. máxima $E_{0}$.

Considerando o valor da e.i.r.p. máxima $E_{0}=13.5 \mathrm{dBm}$ e o desvio padrão $\sigma_{p}=0.8 \mathrm{dBm}$, calculado para e.i.r.p. $P_{\ell}$ mínima no serviço de comunicação móvel, obtém-se para a e.i.r.p. $P_{\ell}$ mais alta da simulação os valores de média e desvio padrão como $m_{p}=11.6 \mathrm{dBm}$ e $\sigma_{p}=0.8 \mathrm{dBm}$, respectivamente.

Limite $\epsilon$ O critério de interferência em (4-1) possui um limite $\epsilon$ que pode ser avaliado analisando a Figura 6.1. Esta Figura apresenta a e.i.r.p. regulatória na região de trabalho para cada valor do limite $\epsilon$. Assim, determinou-se entre as células da região de trabalho a e.i.r.p. regulatória com o maior valor, $E_{k, \max }$, e com o menor valor, $E_{k, \min }$, sendo o valor na célula central, $E_{k}$, dado como um valor intermediário entre estes extremos.

Note que existe um aumento de $6 \mathrm{~dB}$ no valor de $E_{k}$ entre os valores de $\epsilon=0.01$ e $\epsilon=0.05$. O aumento do limite $\epsilon$ gera uma maior e.i.r.p. regulatória nas células da região de trabalho, isto permite que os WSDs operem com níveis mais altos de e.i.r.p., consequentemente, ocorre um aumento da potência interferente agregada sobre um receptor DTT vítima localizado naquela região de trabalho. 


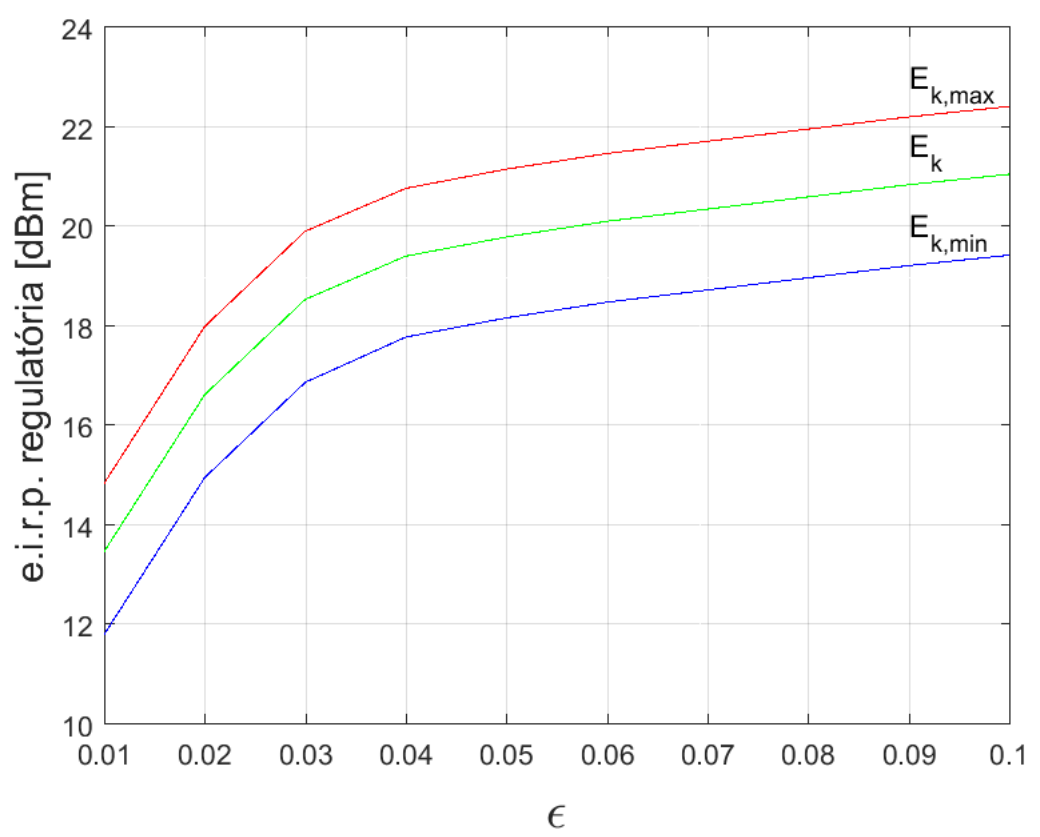

Figura 6.1: e.i.r.p regulatória máxima $E_{k, \max }$, média $E_{k}$ e mínima $E_{k, \text { min }}$ da região de trabalho em função do limite $\epsilon$.

Entretanto, a premissa utilizada é que o valor de $\epsilon$ deve seguir o critério estabelecido para o sistema primário de TV digital na faixa de frequência compartilhada, $\epsilon=0.01$, de forma a manter o mesmo limite de interferência, utilizado pelo sistema primário, para o sistema secundário.

A tabela 6.1 mostra um resumo dos parâmetros adicionais definidos para o cenário da simulação dos procedimentos de admissão.

Tabela 6.1: Parâmetros Adicionais do Cenário para Análise das Metodologias

\begin{tabular}{|l|c|}
\hline Parâmetro & Valor \\
\hline$\lambda$ & $2.15,4.64,10,21.5,46.4 \mathrm{WSD} / \mathrm{km}^{2}$ \\
\hline$P_{\min }$ & $5 \mathrm{dBm}$ \\
\hline$m_{p}$ & $6.9,8,9,10,11.6 \mathrm{dBm}$ \\
\hline$\sigma_{p}$ & $0.8 \mathrm{dBm}$ \\
\hline$\epsilon$ & 0.01 \\
\hline
\end{tabular}

\section{2}

\section{Simulação dos Procedimentos de Admissão}

O Capítulo 4 desenvolveu a modelagem matemática da metodologia Iagg como uma solução para os problemas da metodologia Ofcom descritos no Capítulo 3. Esta seção descreve a implementação de uma simulação que visa demonstrar a viabilidade da metodologia Iagg para solução dos problemas apontados. 
A Subseção 6.2.1 fornece uma visão geral da simulação implementada, permitindo distinguir os blocos que serão tratados nas subseções posteriores. A geração da base de dados das redes WSDs que são utilizadas na simulação é descrita na Subseção 6.2.2. As subseções 6.2.3, 6.2.4 e 6.2 .5 apresentam a implementação da simulação para os procedimentos de admissão Ecc.186, Ofcom e Iagg, respectivamente.

\subsection{1}

\section{Visão Geral da Simulação}

A simulação visa realizar a admissão de um novo WSD, denominado $\mathrm{WSD}_{0}$, no centro da região de trabalho dentro de uma rede de WSDs em operação. Este processo de admissão utiliza os procedimentos de admissão Ecc.186, Ofcom e Iagg implementados conforme descritos nas seções 3.3, 3.2 e 5, respectivamente. Os parâmetros de desempenho de cada metodologia são obtidos repetindo o processo de admissão conforme método de Monte Carlo. O diagrama de blocos da Figura 6.2 mostra uma visão geral de como a simulação foi implementada.

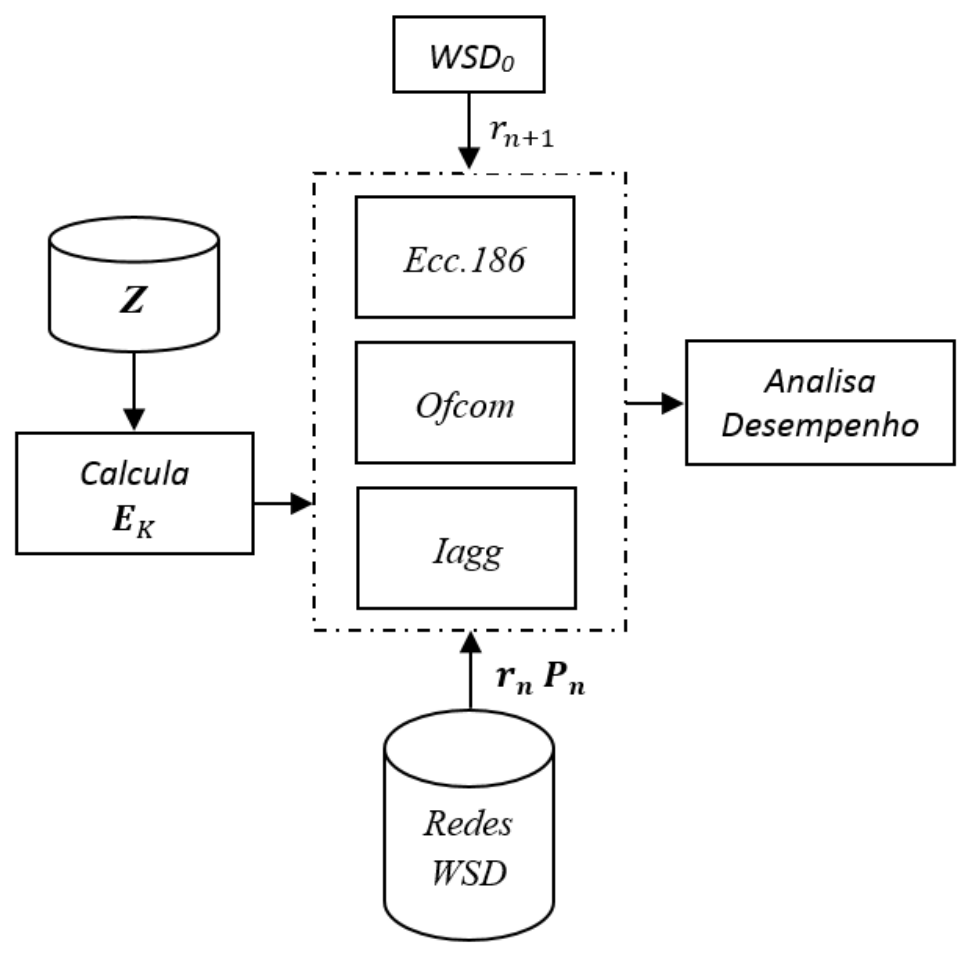

Figura 6.2: Diagrama de blocos da visão geral da simulação dos procedimentos de admissão Ecc.186, Ofcom e Iagg.

O diagrama inicia com a base de dados $Z$ dos limites da potência interferente intersistema que foi implementada conforme Seção 4.3.1. As e.i.r.p. 
máximas $E_{k}$ de cada célula da região de trabalho é então calculada conforme descrito na Seção 4.1.

A admissão do $\mathrm{WSD}_{0}$ é avaliada, separadamente, pelos blocos "Ecc.186", "Ofcom" e "Iagg" que implementam os procedimentos de admissão. O WSD 0 é adicionado a uma distribuição espacial de WSDs denominada rede WSD definida para cada um dos blocos. A rede WSD é definida pelo vetor localização $\mathbf{r}_{n}$ e vetor e.i.r.p $\mathbf{P}_{n}$ dos WSDs localizados dentro da região de trabalho, sendo $n$ o número de WSDs. O $\mathrm{WSD}_{0}$ em processo de admissão possui uma localização $r_{n+1}$ na célula central da região de trabalho, sendo sua e.i.r.p. calculada de forma diferente de acordo com o procedimento de admissão. Por fim, cada metodologia avalia o critério de admissão e determina se o $\mathrm{WSD}_{0}$ é admitido ou bloqueado.

O procedimento de admissão é repetido para um número $N_{R}$ grande de amostras de rede WSD de uma densidade específica. Uma base de dados denominada "Redes WSD" foi gerada contendo três conjuntos de redes, sendo cada conjunto gerado para um procedimento de admissão específico.

O bloco "Analisa Desempenho" calcula parâmetros e gera gráficos de desempenho através dos dados armazenados durante a simulação.

Vale lembrar que as metodologias Ecc.186 e Ofcom possuem critérios de admissão que consideram apenas a não ultrapassagem da e.i.r.p. máxima da célula, enquanto o critério de admissão da metodologia Iagg é definido pelo critério de interferência. Assim sendo, um módulo de avaliação do critério de interferência é introduzido nos blocos de procedimento de admissão Ecc.186 e Ofcom para fins de comparação.

As avaliações do critério de admissão e do critério de interferência são feitas com base em quatro eventos principais:

- Evento A: Admissão do $\mathrm{WSD}_{0}$ por atender o critério de admissão da metodologia.

- Evento B: Bloqueio do $\mathrm{WSD}_{0}$ por não atender o critério de admissão da metodologia.

- Evento C: Atendimento ao Critério de Interferência com a admissão do $\mathrm{WSD}_{0}$.

- Evento N: Não atendimento ao Critério de Interferência com a admissão do $\mathrm{WSD}_{0}$.

Estes eventos são contabilizados para a obtenção de estatísticas dos parâmetros de desempenho em cada metodologia. Note que na metodologia Iagg os eventos A e C coincidem, bem como os eventos B e N, pois o critério de admissão é definido pelo próprio critério de interferência. 


\subsection{2}

\section{Geração de Redes WSD}

Um gerador de redes WSD cria uma base de dados com um conjunto de redes que é utilizada na simulação. A geração desta base de dados é implementada de forma que três amostras de rede WSD, uma de cada metodologia, são geradas a partir da mesma amostra de uma distribuição espacial de WSDs. Isto garante a comparabilidade dos parâmetros de desempenho de cada metodologia na simulação.

A geração de uma amostra de rede é realizada adicionando um WSD por vez a partir da amostra da distribuição espacial dos WSDs, sendo esta última modelada por um processo pontual de Poisson (PPP). O WSD adicionado pode ser admitido ou bloqueado pelo respectivo procedimento de admissão. Isto assegura que não existem na amostra de rede final WSDs que não poderiam ter sido admitidos naquela metodologia. A Figura 6.3 mostra um diagrama de blocos desta geração de redes WSD.

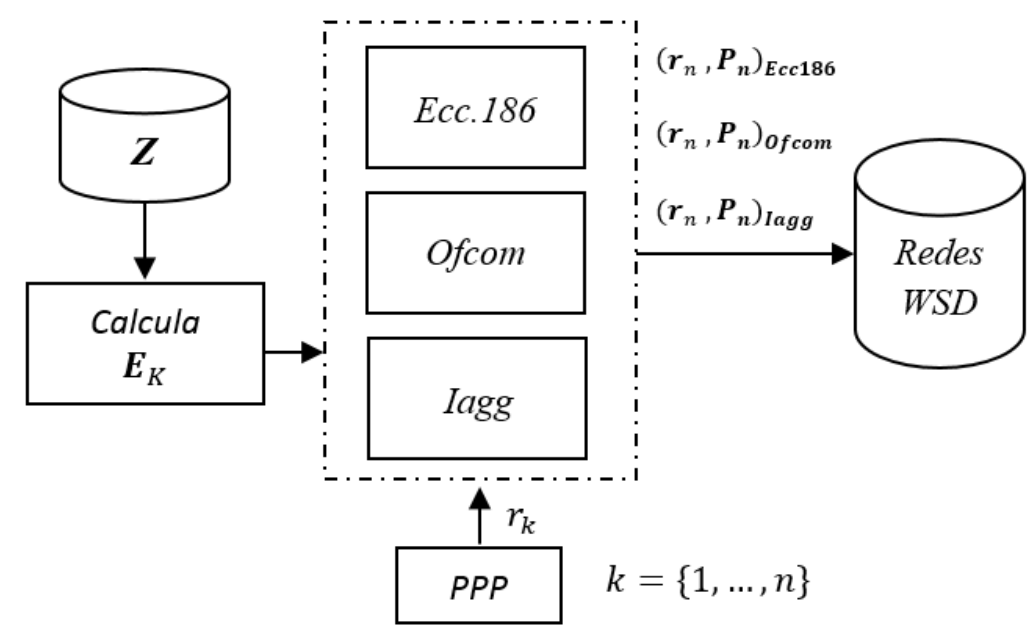

Figura 6.3: Diagrama de blocos da geração de redes WSD para os procedimentos de admissão Ecc.186, Ofcom e Iagg.

O diagrama inicia com a base de dados $Z$ dos limites da potência interferente intersistema e o cálculo das e.i.r.p. máximas $E_{k}$ de cada célula da região de trabalho.

O bloco "PPP" gera a amostra da distribuição espacial dos WSDs de uma dada densidade. A admissão de cada WSD é avaliada, separadamente, pelos blocos "Ecc.186", "Ofcom" e "Iagg" que implementam os procedimentos de admissão. O bloco "PPP" entrega aos blocos dos procedimentos de admissão a localização $r_{k}$ de um WSD por vez. O índice $k$ é incrementado até $n$ que é o número total de WSD da amostra. Cada WSD da amostra PPP terá sua e.i.r.p. calculada e sua admissão avaliada por cada um dos procedimentos de 
admissão. Caso o WSD não seja admitido, ele será excluído da amostra de rede. O conjunto das amostras de rede, constituídas pelos vetores localização e e.i.r.p. $\left(\mathbf{r}_{n}, \mathbf{P}_{n}\right)$, é armazenado na base de dados "Redes WSD". O procedimento de geração de redes WSD se repete para $N_{R}$ amostras PPP de cada densidade que será utilizada na simulação.

\section{2 .3}

\section{Simulação do Procedimento de Admissão Ecc.186}

O bloco "Ecc.186" na Figura 6.2 implementa o procedimento de admissão Ecc.186 definido, conforme a segunda solução do relatório ECC.186 [5]. Este procedimento de admissão divide a e.i.r.p. máxima da célula igualmente entre os WSDs ativos localizados dentro da mesma, desta forma o requisito de não ultrapassagem da e.i.r.p. máxima da célula é sempre satisfeito. O critério de admissão é definido para que a e.i.r.p. $P_{\ell}$ dos WSDs fique acima de um limite mínimo operacional $P_{\text {min }}$, evitando que a entrada de um novo WSD reduza a e.i.r.p. dos WSDs que estão na mesma célula abaixo de um nível mínimo de operação. Este procedimento de admissão foi descrito na Seção 3.3, sendo implementado como mostra o diagrama de blocos na Figura 6.4.

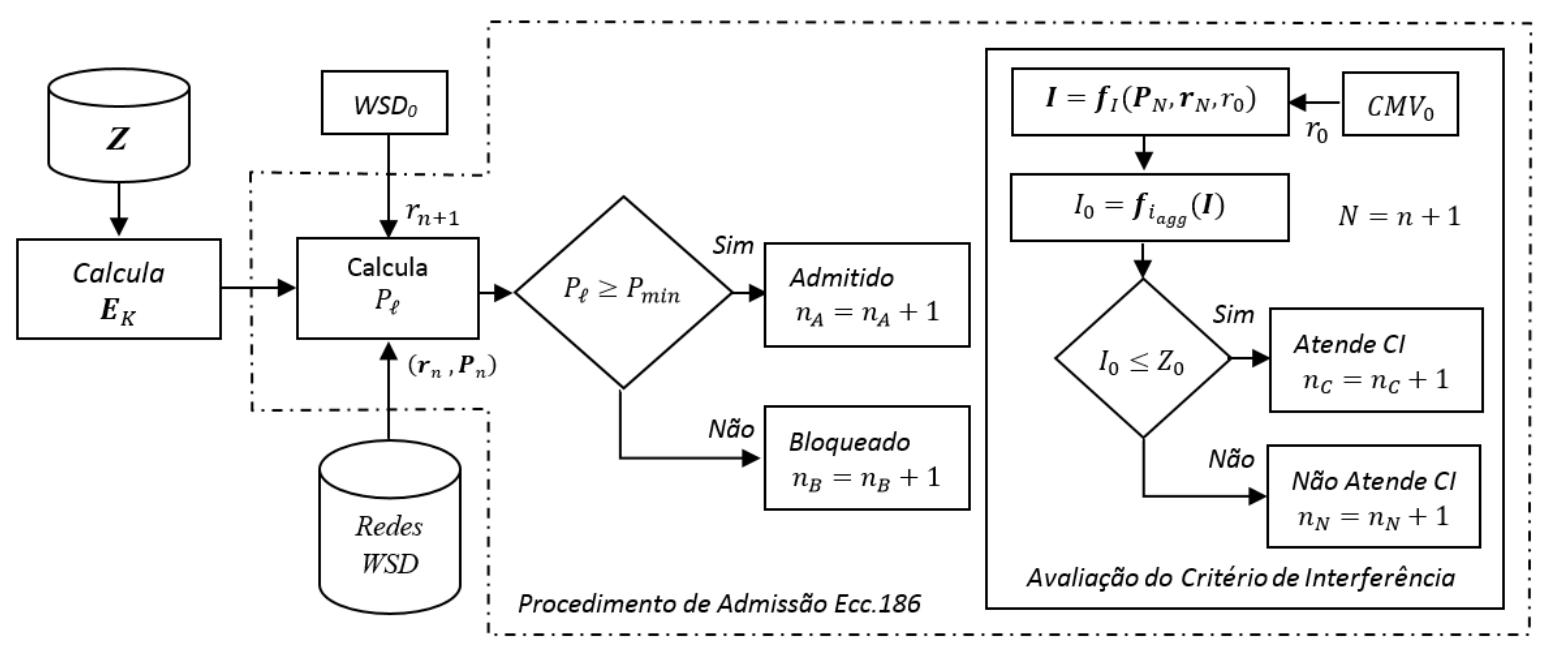

Figura 6.4: Diagrama de blocos do procedimento de admisssão Ecc.186 com avaliação do critério de interferência.

A admissão do $\mathrm{WSD}_{0}$ determina a mudança da e.i.r.p. $P_{\ell}$ de todos os WSDs que estão na mesma célula. A e.i.r.p. máxima $E_{0}$ da célula central (Célula 0), onde o $\mathrm{WSD}_{0}$ está localizado, é dividida igualmente para todos os $N_{0}$ WSDs localizados nesta célula. O bloco "Calcula $P_{\ell}$ " determina esta e.i.r.p., em dBm, através de (6-6).

$$
P_{\ell}=E_{0}-10 \log \left(N_{0}\right) \quad \text { Se } r_{\ell} \in \text { Célula } 0
$$


O critério de admissão é avaliado para o $\mathrm{WSD}_{0}$ que é admitido se o valor calculado para $P_{\ell}$ for maior ou igual a e.i.r.p. mínima operacional $P_{\min }$, a partir desta avaliação os eventos A e B são contabilizados. Assim, $n_{A}$ e $n_{B}$ indicam, respectivamente, o número de vezes que os eventos $\mathrm{A}$ e $\mathrm{B}$ ocorrem como mostra a Figura 6.4.

O módulo de avaliação do critério de interferência (C.I.) calcula a potência interferente agregada e testa o C.I. A célula vítima das interferências é a célula mais vulnerável $\left(\mathrm{CMV}_{0}\right)$ associada a célula do $\mathrm{WSD}_{0}$. A escolha da $\mathrm{CMV}_{0}$ como referência para a avaliação do C.I. é descrita na Subseção 4.2.2. A localização $r_{0}$ da $\mathrm{CMV}_{0}$ é fornecida pelo bloco "Calcula $E_{k}$ ".

Um vetor $\boldsymbol{I}$ com as potências interferentes individuais dos WSDs que estão dentro da máscara de otimização é calculado, sendo as máscaras de otimização definidas conforme a Subseção 5.2.3. A função $\boldsymbol{f}_{I}$ que calcula o vetor $\boldsymbol{I}$ utiliza como entradas o vetor das e.i.r.p. $\boldsymbol{P}_{N}$, o vetor das localizações $\boldsymbol{r}_{N}$ e a localização $r_{0}$ da $\mathrm{CMV}_{0}$, sendo $N=n+1$ o número de WSDs dentro da máscara de otimização. Este cálculo é detalhado na Subseção 4.2.3.

A potência interferente agregada $I_{0}$ excedida $1 \%$ do tempo é calculada utilizando o vetor $\boldsymbol{I}$, conforme descrito na Subseção 4.2.3.2. O critério de interferência é avaliado através da comparação de $I_{0}$ com a potência interferente intersistema $Z_{0}$ da $\mathrm{CMV}_{0}$. O resultado desta comparação permite contabilizar os eventos $\mathrm{C}$ e N. Assim, $n_{C}$ e $n_{N}$ indicam, respectivamente, o número de vezes que os eventos $\mathrm{C}$ e $\mathrm{N}$ ocorrem como mostra a Figura 6.4.

Além dos parâmetros $n_{C}$ e $n_{N}$, outros parâmetros são armazenados durante a simulação para serem utilizados na próxima função, "Analisa Desempenho". Os parâmetros $n$ (número de WSDs em operação localizados na Célula 0) e $P(\bar{E})$ (probabilidade do número de WSDs operando na Célula 0 ser diferente de zero) são armazenados para cálculo do tempo médio de admissão conforme (3-16). Outro exemplo, são os parâmetros média e desvio padrão da potência interferente agregada que são armazenados para cálculo da função distribuição de probabilidade complementar conforme (4-25).

\section{2 .4}

\section{Simulação do Procedimento de Admissão Ofcom}

O bloco "Ofcom" na Figura 6.2 implementa o procedimento de admissão Ofcom que segue as definições do regulamento Ofcom [6] e seus anexos [7]. O procedimento de admissão Ofcom também utiliza o requisito de não ultrapassagem da e.i.r.p. máxima da célula onde os WSDs se encontram. A diferença em relação ao procedimento de admissão Ecc.186 está no tratamento dado a e.i.r.p. $P_{\ell}$ dos WSDs que é modelada aqui como uma variável aleatória. 
Este procedimento de admissão foi descrito na Seção 3.2 e é implementado como mostra o diagrama de blocos na Figura 6.5.

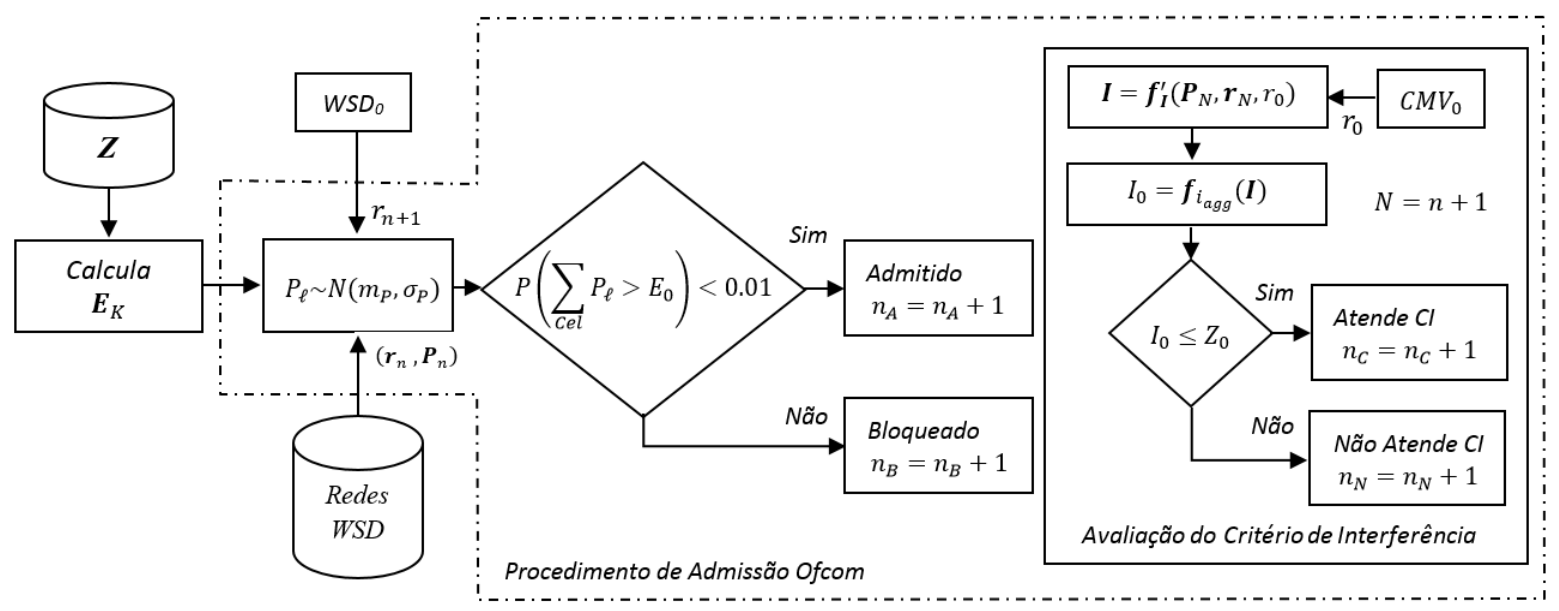

Figura 6.5: Diagrama de blocos do procedimento de admissão Ofcom com avaliação do critério de interferência.

De modo a possibilitar que o método de cálculo Schwartz-Yeh [10] continue sendo aplicado na determinação do comportamento estatístico da potência interferente agregada, modela-se por uma distribuição gaussiana as variáveis aleatórias $P_{\ell}$ dos WSDs. Isto se deve à restrição do método de Schwartz-Yeh onde as interferências $i_{\ell}$ no somatório em (4-11) são necessariamente v.a. gaussianas.

As e.i.r.p. $P_{\ell}$ dos WSDs são modeladas como variáveis aleatórias gaussianas estatisticamente independentes e o primeiro bloco do procedimento de admissão Ofcom inicia atribuindo os valores da média e desvio padrão da função densidade de probabilidade da e.i.r.p. do $\mathrm{WSD}_{0}, P_{\ell} \sim N\left(m_{p}, \sigma_{p}\right)$. Considera-se que o banco de dados já possua os valores de média e desvio padrão dos demais WSDs em operação. Nesta simulação, os valores de $m_{p}$ e $\sigma_{p}$ são definidos como valores constantes para todos os WSDs.

Note que esta atribuição de $m_{p}$ e $\sigma_{p}$ da e.i.r.p. $P_{\ell}$ do $\mathrm{WSD}_{0}$ é de fácil implementação, pois a comunicação periódica entre o WSD e o banco de dados WSDB no fim do tempo de retorno máximo permite que o WSDB obtenha as informações de média e desvio padrão da e.i.r.p. dos WSDs em operação e possa com estas informações aproximar os valores iniciais de $m_{p}$ e $\sigma_{p}$ da e.i.r.p. $P_{\ell}$ do $\mathrm{WSD}_{0}$.

Uma avaliação do critério de admissão é realizada considerando que a soma das e.i.r.p. dos $N_{0}$ WSDs na Célula 0 pode ultrapassar a máxima e.i.r.p. $E_{0}$ desta célula com uma probabilidade $p$ muito pequena, conforme expresso em

$$
P\left(\sum_{\ell=1}^{N_{0}} P_{\ell}>E_{0}\right)<p \quad \text { Se } r_{\ell} \in \text { Célula } 0
$$


Adota-se neste trabalho o valor $p=0.01$. Esta avaliação do critério de admissão permite contabilizar os eventos $\mathrm{A}$ e $\mathrm{B}$ através de $n_{A}$ e $n_{B}$ que indicam, respectivamente, o número de vezes que os eventos $\mathrm{A}$ e $\mathrm{B}$ ocorrem como mostra a Figura 6.5.

Uma avaliação do critério de interferência é realizada de forma similar a descrita no procedimento de admissão Ecc.186 da Subseção 6.2.3. Entretanto, o cálculo do vetor $\boldsymbol{I}$ deve considerar a mudança na definição da e.i.r.p. $P_{\ell}$ dos WSDs localizados dentro da máscara de otimização. Observe que o cálculo da potência interferente individual $i_{\ell}$ do WSD é realizado por (4-8) onde a e.i.r.p. $P_{\ell}$ é tratada como uma variável determinística, porém, a metodologia Ofcom define esta e.i.r.p. como uma variável aleatória.

De acordo com o modelo Hata extendido [17], a perda de propagação $L_{\ell}$, quando expressa em dB, é caracterizada por uma variável aleatória gaussiana. Da mesma forma, a e.i.r.p. $P_{\ell}$ é definida, também, como uma variável aleatória gaussiana. Consequentemente, a partir de (4-8), conclui-se que a potência interferente $i_{\ell}$ devida a um WSD é, também, uma v.a. gaussiana com média $m_{\ell}$ e desvio padrão $\sigma_{\ell}$ dadas, respectivamente, por

$$
m_{\ell}=m_{p}-m+g\left(\theta_{\ell}\right)+\rho(\Delta f)
$$

e

$$
\sigma_{\ell}=\sqrt{\sigma^{2}+\sigma_{p}^{2}}
$$

onde $m$ e $\sigma$ representam a média e o desvio padrão da perda de propagação $L_{\ell}$, respectivamente, e $m_{p}$ e $\sigma_{p}$ representam a média e o desvio padrão da e.i.r.p. $P_{\ell}$.

Esta alteração na função que calcula o vetor $\boldsymbol{I}$ é indicada como $\boldsymbol{f}_{I}^{\prime}$ na Figura 6.5. A potência interferente agregada $I_{0}$ excedida $1 \%$ do tempo é calculada, utilizando o vetor $\boldsymbol{I}$, e o critério de interferência é avaliado de forma idêntica ao que foi descrito no procedimento de admissão Ecc.186 na Subseção 6.2.3. A partir desta avaliação do critério de interferência, os eventos $\mathrm{C}$ e $\mathrm{N}$ são contabilizados através de $n_{C}$ e $n_{N}$ que indicam, respectivamente, o número de vezes que os eventos $\mathrm{C}$ e $\mathrm{N}$ ocorrem como mostra a Figura 6.5.

Além dos parâmetros $n_{C}$ e $n_{N}$, outros parâmetros são armazenados durante a simulação para serem utilizados na próxima função, "Analisa Desempenho", tais como, os parâmetros média e desvio padrão da potência interferente agregada que são armazenados para cálculo da função distribuição de probabilidade complementar conforme (4-25). 


\section{2 .5}

\section{Simulação do Procedimento de Admissão lagg}

O bloco "Iagg" na Figura 6.2 implementa o procedimento de admissão Iagg proposto para a solução dos problemas da metodologia Ofcom. A metodologia Iagg é desenvolvida utilizando a modelagem matemática descrita no Capítulo 4. A principal diferença deste procedimento de admissão Iagg em relação ao Ofcom está no requisito de não ultrapassagem do limite de interferência intersistema pela potência interferente agregada dos WSDs em operação. Este requisito define uma limitação para as e.i.r.p. associadas as múltiplas entradas de interferência, ao invés de limitar a e.i.r.p. associada a uma entrada simples de interferência como ocorre no procedimento de admissão Ofcom. Este procedimento de admissão é descrito no Capítulo 5 e é implementado como mostra o diagrama de blocos na Figura 6.6.

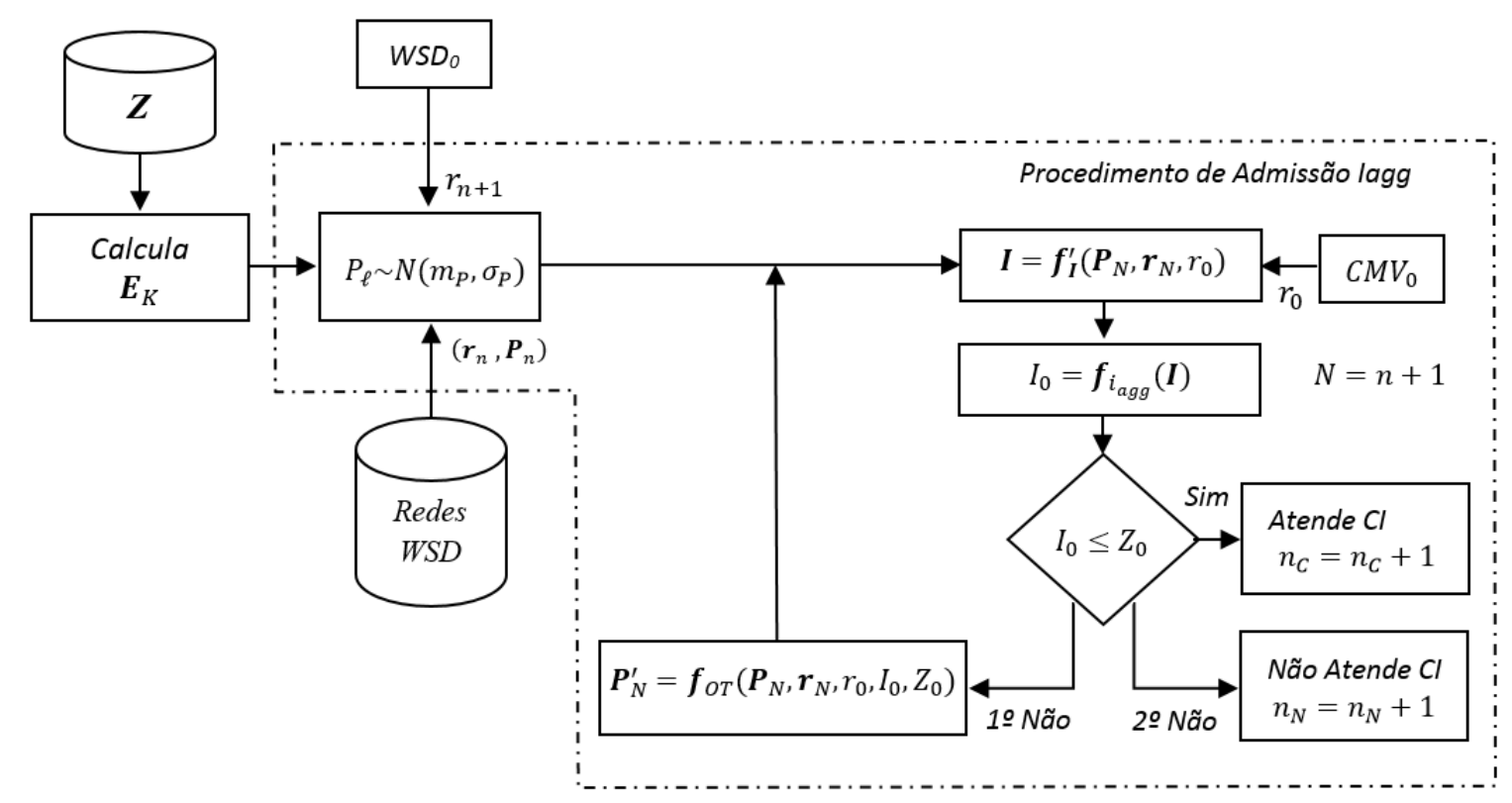

Figura 6.6: Diagrama de blocos do procedimento de admissão Iagg.

As e.i.r.p. $P_{\ell}$ dos WSDs são definidas de forma idêntica a Subseção 6.2.4, ou seja, elas são modeladas como variáveis aleatórias gaussianas estatisticamente independentes e o primeiro bloco atribui os valores da média e desvio padrão da função densidade de probabilidade para a e.i.r.p. do $\mathrm{WSD}_{0}$, $P_{\ell} \sim N\left(m_{p}, \sigma_{p}\right)$. Para fins de comparação, esses valores de $m_{p}$ e $\sigma_{p}$ são os mesmos utilizados no procedimento de admissão Ofcom.

Note que o critério de admissão nesta metodologia é o próprio critério de interferência, desta forma, são eventos equivalentes $\mathrm{A} \equiv \mathrm{C}$ e $\mathrm{B} \equiv \mathrm{N}$, sendo contabilizados apenas os eventos $\mathrm{C}$ e N. Assim, $n_{C}$ e $n_{N}$ indicam, respectivamente, o número de vezes que os eventos $\mathrm{C}$ e $\mathrm{N}$ ocorrem, conforme 
Figura 6.6. Portanto, a admissão é realizada através de uma avaliação do critério de interferência de forma idêntica a realizada na metodologia de admissão Ofcom descrita em 6.2.4.

Após a avaliação do critério de interferência, o $\mathrm{WSD}_{0}$ pode atender o critério e ser admitido, contabilizando o evento C, ou não atender o critério. Neste caso em que o critério de interferência não é atendido pela primeira vez, uma função de otimização é utilizada para reduzir seletivamente as e.i.r.p. dos WSDs para que o critério de interferência seja atendido e o $\mathrm{WSD}_{0}$ seja admitido. A modelagem matemática desta otimização é descrita na Subseção 5.2 .1 .

A função de otimização recebe como entrada o vetor das e.i.r.p. $\boldsymbol{P}_{N}$, o vetor das localizações $\boldsymbol{r}_{N}$ e a localização $r_{0}$ da $\mathrm{CMV}_{0}$, bem como a potência interferente agregada $I_{0}$ e a potência interferente intersistema $Z_{0}$ ambas calculadas na $\mathrm{CMV}_{0}$ que é a célula vítima das interferências. A saída da função de otimização é um novo vetor das e.i.r.p. $\boldsymbol{P}_{N}^{\prime}$ onde algumas e.i.r.p. $P_{\ell}$ foram reduzidas, visando reduzir $I_{0}$ até o mesmo valor de $Z_{0}$, ou em outras palavras, visando minimizar a função objetivo em (5-2).

Considera-se um limite mínimo operacional $P_{\min }$ para a redução das e.i.r.p. durante a otimização, esta restrição pode não permitir que a função objetivo seja minimizada até ter $I_{0}=Z_{0}$. Desta forma, uma nova avaliação do critério de interferência é realizada utilizando o novo vetor das e.i.r.p. $\boldsymbol{P}_{N}^{\prime}$. Se a otimização é bem sucedida, o $\mathrm{WSD}_{0}$ é admitido, contabilizando o evento C. Caso contrário, a otimização não conseguiu reduzir as e.i.r.p. o suficiente para atender o critério de interferência e o $\mathrm{WSD}_{0}$ não é admitido, contabilizando o evento N.

Note que se o $\mathrm{WSD}_{0}$ é admitido na segunda avaliação do critério de interferência, ou seja após uma otimização do vetor e.i.r.p. $\boldsymbol{P}_{N}$, outros WSDs em operação podem ter que reduzir suas e.i.r.p. Assim, o $\mathrm{WSD}_{0}$ admitido deve aguardar que os WSDs em operação afetados reduzam suas e.i.r.p. antes de iniciar sua transmissão. Esta redução das e.i.r.p. deve ocorrer na próxima comunicação do WSD com o banco de dados WSDB. Desta forma, o WSD 0 experimenta um atraso na admissão proporcional ao tempo de retorno dos WSDs afetados pela otimização, conforme a modelagem matemática descrita na Seção 5.2.2. Este atraso é considerado o custo adicional que o $\mathrm{WSD}_{0}$ paga por entrar neste canal de frequência do sistema WSD que, em geral, possui uma densidade alta.

Além dos parâmetros $n_{C}$ e $n_{N}$, outros parâmetros são armazenados durante a simulação para serem utilizados na próxima função, "Analisa Desempenho". Por exemplo, os parâmetros $N$ (número de WSDs otimizados) e $P(\bar{A})$ 
(probabilidade de não atendimento ao critério de interferência) são armazenados para cálculo do tempo médio de admissão conforme (5-10). Outro exemplo, são os parâmetros média e desvio padrão da potência interferente agregada que são armazenados para cálculo da função distribuição de probabilidade complementar conforme (4-25).

\section{3}

\section{Atendimento ao Critério de Interferência}

Os parâmetros média e desvio padrão da função densidade de probabilidade da potência interferente agregada foram armazenados durante a simulação para cada uma das metodologias. Estes parâmetros permitem avaliar a ultrapassagem do critério de interferência através da função distribuição de probabilidade complementar $C_{i_{\text {agg }}}(I)$ desenvolvida na Seção 4.3.2. A expressão de $C_{i_{\text {agg }}}(I)$ em (4-25) é utilizada para cálculo da probabilidade da potência interferente agregada $i_{\text {agg }}$ ultrapassar a potência interferente intersistema $Z_{0}$.

$$
C_{i_{a g g}}\left(Z_{0}\right)=P\left(i_{\text {agg }}>Z_{0}\right)=\int_{\Omega_{\mathbf{r}}} p_{\mathbf{r}}(\mathbf{R}) Q\left(\frac{Z_{0}-m_{i_{a g g \mid \mathbf{r}=\mathbf{R}}}}{\sigma_{i_{a g g \mid \mathbf{r}=\mathbf{R}}}}\right) d \mathbf{R}
$$

A integral em (6-10) é calculada através de simulação Monte Carlo, utilizando um número $N_{R}$ grande de redes WSD para cada densidade. Note que a integral em (6-10) é o valor esperado de

$$
Q\left(\frac{Z_{0}-m_{i_{a g g \mid \mathbf{r}=\mathbf{R}}}}{\sigma_{i_{a g g \mid \mathbf{r}=\mathbf{R}}}}\right)
$$

em relação a r, ou seja,

$$
P\left(i_{a g g}>Z_{0}\right)=E_{\mathbf{r}}\left[Q\left(\frac{Z_{0}-m_{i_{a g g \mid \mathbf{r}=\mathbf{R}}}}{\sigma_{i_{a g g \mid \mathbf{r}=\mathbf{R}}}}\right)\right]
$$

O critério de interferência pode então ser avaliado pelos gráficos das figuras 6.7 e 6.8. Estas figuras apresentam a probabilidade da interferência agregada $i_{\text {agg }}$ ultrapassar a interferência intersistema $Z_{0}$ em função da densidade, $\lambda=\{2.15,4.64,10,21.5,46.4\} \mathrm{WSD} / \mathrm{km}^{2}$, nos canais de frequência DTT 27 e 24, respectivamente, utilizando as e.i.r.p. $P_{\ell}$ com média $m_{p}=$ $\{6.9,8,9,10,11.6\} \mathrm{dBm}$ para as metodologias Ofcom e Iagg.

Note que o critério de interferência em (4-1) define o valor $\epsilon=0.01$ como o limite da probabilidade em (6-11), ou seja, todos os pontos das curvas acima do limite de $10^{-2}$ estão violando o critério de interferência.

Observe que a curva da metodologia Ecc.186 apresenta todos os pontos acima do limite do critério de interferência, ou seja, o critério de interferência 


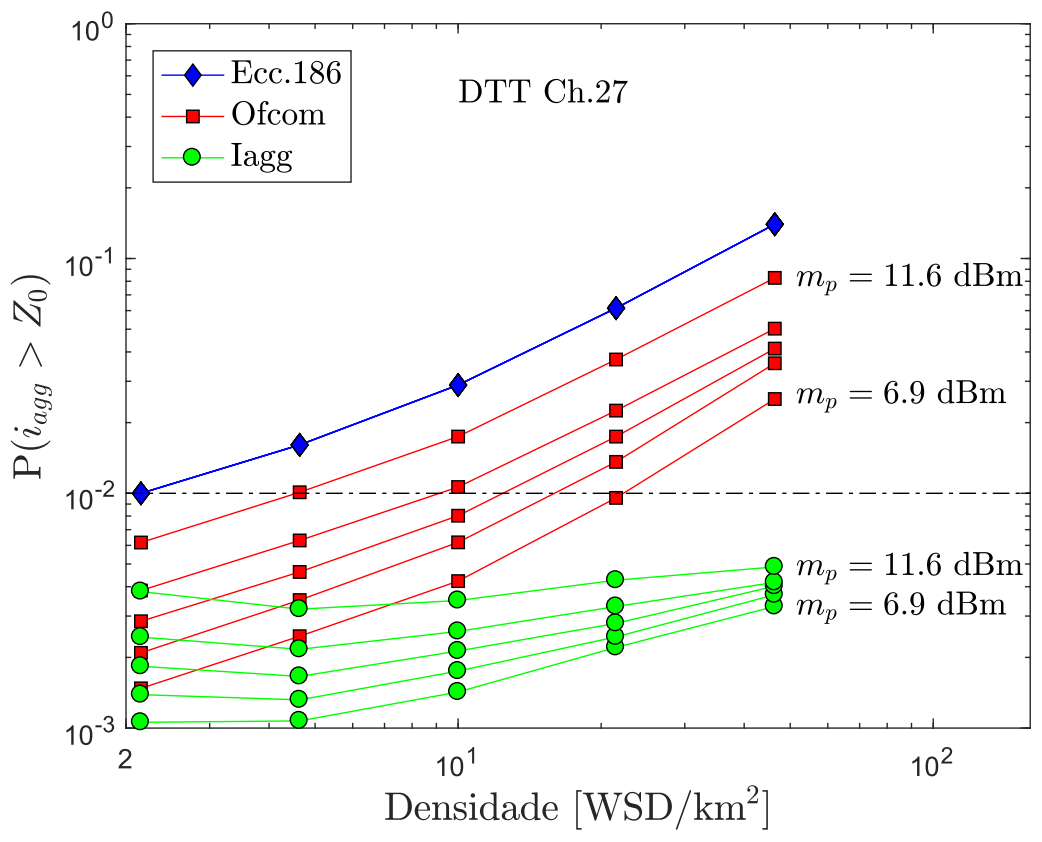

Figura 6.7: Probabilidade da interferência agregada $i_{\text {agg }}$ ultrapassar a interferência intersistema $Z_{0}$ em função da densidade no canal de frequência DTT 27.

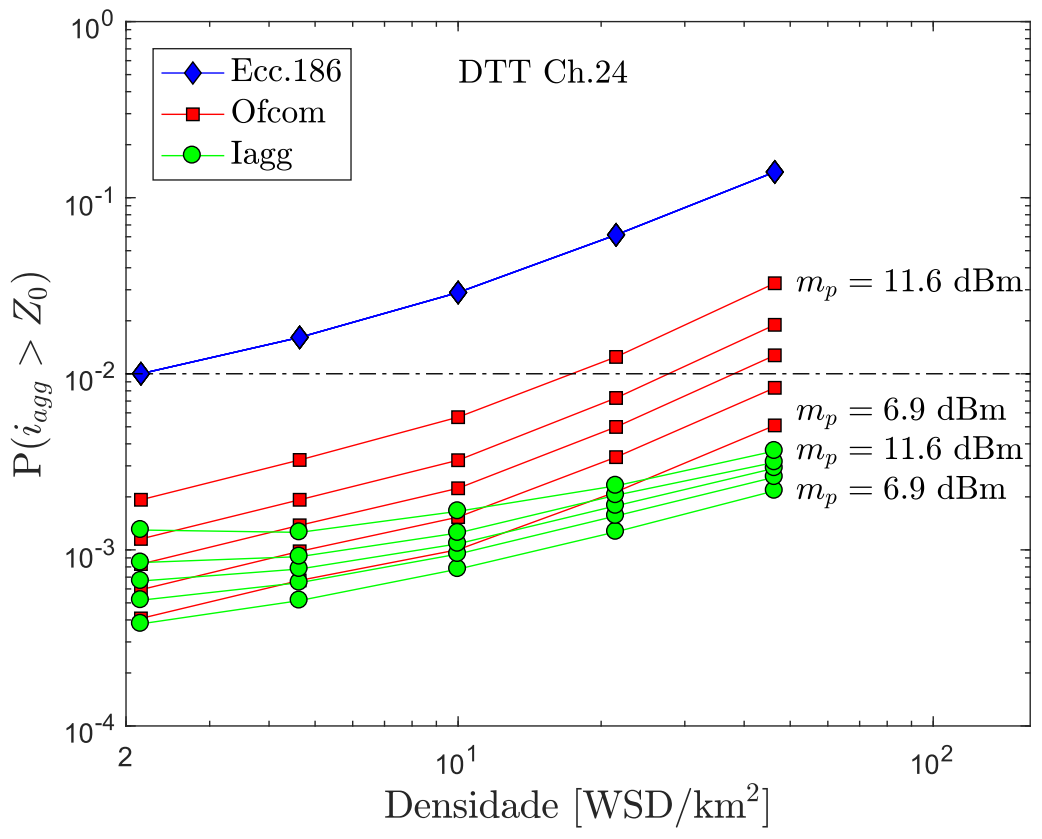

Figura 6.8: Probabilidade da interferência agregada $i_{\text {agg }}$ ultrapassar a interferência intersistema $Z_{0}$ em função da densidade no canal de frequência DTT 24.

não é atendido pela metodologia Ecc.186 para todos os valores de densidade. Este resultado condiz com o resultado da análise na Seção 4.3.2, uma vez que ambas as análises utilizam a mesma metodologia. 
As curvas da metodologia Ofcom iniciam a violação do critério de interferência em valores de densidades diferentes, dependendo da e.i.r.p. $P_{\ell}$ utilizada e do canal de frequência DTT. Considere a densidade $\lambda_{\max }$ como o maior valor de densidade para a qual o critério de interferência é atendido, ou seja, $\lambda_{\max }$ é o valor de densidade que corresponde a interseção entre as curvas e a linha tracejada no limite de $10^{-2}$.

Os canais de frequência DTT 27 e 24 são o primeiro e segundo canal adjacente, respectivamente, do canal de frequência WSD 26 utilizado na simulação. Desta forma, as potências interferentes individuais dos WSDs sofrem uma redução maior no canal de frequência DTT 24 que é mais afastado do canal de frequência WSD. Esta discriminação em frequência é representada pelo parâmetro $\rho(\Delta f)$, conforme a expressão (4-8). Isto se traduz em uma redução na potência interferente agregada o que faz as curvas do canal de frequência DTT 24 da Figura 6.8 estarem mais para baixo em relação as curvas do canal de frequência DTT 27 da Figura 6.7.

A e.i.r.p. $P_{\ell}$ é diretamente proporcional a potência interferente individual do WSD como mostrado em (4-8), consequentemente, o aumento da e.i.r.p. $P_{\ell}$ implica em um correspondente aumento da potência interferente agregada o que eleva a curva no gráfico. Assim sendo, as curvas obtidas com valores maiores de $P_{\ell}$ possuem $\lambda_{\max }$ mais baixo e vice-versa. Observe que para a metodologia Ofcom, o gráfico do canal de frequência DTT 27, apresenta a curva com a maior e.i.r.p. $P_{\ell}, m_{p}=11.6 \mathrm{dBm}$, com $\lambda_{\max }=4.6 \mathrm{WSD} / \mathrm{km}^{2}$, enquanto a curva com a menor e.i.r.p. $P_{\ell}, m_{p}=6.9 \mathrm{dBm}$, apresenta $\lambda_{\max }=21.5$ $\mathrm{WSD} / \mathrm{km}^{2}$.

As curvas da metodologia Iagg apresentam todos os seus pontos abaixo do limite do critério de interferência. Esta é a principal característica que se buscou alcançar com a nova metodologia, em outras palavras, a metodologia Iagg garante a proteção do receptor DTT contra interferências acima do limite.

As considerações feitas sobre o efeito da e.i.r.p. $P_{\ell}$ e do canal de frequência DTT no comportamento das curvas da metodologia Ofcom, também, são válidas para a metodologia Iagg. Entretanto, estes efeitos são menos significativos à medida que a densidade aumenta. Basta observar, na densidade mais alta, $\lambda=46.4 \mathrm{WSD} / \mathrm{km}^{2}$, a forte agrutinação dos pontos o que evidencia o menor efeito da e.i.r.p. $P_{\ell}$ e, observando esta mesma densidade, a pequena diferença das probabilidades entre as curvas do gráfico do canal de frequência DTT 27 para as curvas do gráfico do canal 24.

Neste sentido, podemos afirmar que a metodologia Iagg apresenta nas densidades mais altas uma menor sensibilidade quanto ao serviço de comunicação utilizado, uma vez que o menor e maior valor da e.i.r.p. $P_{\ell}$ estão associado 
aos serviços de comunicação móvel e Wi-Fi, respectivamente, e estes valores correspondem a probabilidades muito próximas na densidade mais alta como mostra as curvas das Figuras 6.7 e 6.8 .

\section{4}

\section{Taxa de Atendimento ao Critério de Interferência}

O evento C, definido na Subseção 6.2.1, caracteriza o atendimento ao critério de interferência. Seja $n_{C}$ o número de vezes que o evento $\mathrm{C}$ ocorreu durante a simulação. A taxa de atendimento ao critério de interferência $T_{C I}$ é calculada utilizando a frequência relativa deste evento.

$$
T_{C I}=\frac{n_{C}}{N_{R}}
$$

onde $N_{R}$ é o número total de simulações realizadas para cada densidade e metodologia.

Na metodologia Ecc.186, a admissão de um novo WSD $\left(\mathrm{WSD}_{0}\right)$ pode ocorrer em uma célula sem ou com WSDs em operação. No primeiro caso, o $\mathrm{WSD}_{0}$ não sofre atraso adicional na sua admissão. No segundo caso, o $\mathrm{WSD}_{0}$ deve aguardar os WSDs em operação, localizados na mesma célula, reduzir suas e.i.r.p. antes de ser admitido. Uma expressão para avaliação deste atraso foi desenvolvida na Seção 3.3 onde o parâmetro tempo médio de admissão $T_{a d}$ foi calculado em (3-16).

$\mathrm{Na}$ metodologia Ofcom não existe atraso adicional na admissão, pois a admissão de um WSD não afeta as e.i.r.p. dos WSDs em operação no sistema. Assim, o atraso na admissão da metodologia Ofcom está limitado ao tempo de processamento para avaliar o critério de admissão pelo banco de dados WSDB. Este tempo de atraso é no mínimo 3 ordens de grandeza inferior ao tempo de atraso adicional das outras metodologias, variando conforme a capacidade de processamento do computador utilizado para o WSDB. Assim sendo, considera-se o tempo médio de admissão igual a zero para a metodologia Ofcom.

Na metodologia Iagg, a admissão do $\mathrm{WSD}_{0}$ pode ser realizada sem ou com otimização das e.i.r.p. dos WSDs. No primeiro caso, o $\mathrm{WSD}_{0}$ não experimenta qualquer atraso adicional na sua admissão. No segundo caso, o $\mathrm{WSD}_{0}$ deve aguardar os WSDs em operação, afetados pela otimização, reduzir suas e.i.r.p. antes de ser admitido. Uma expressão para avaliação do atraso na admissão de um WSD foi desenvolvida na Subseção 5.2.2 onde o parâmetro tempo médio de admissão $T_{a d}$ foi calculado em (5-10).

O tempo médio de admissão $T_{a d}$ possui como limite superior o tempo de retorno máximo $\Delta$. Este parâmetro é definido pelo banco de dados WSDB 
como um tempo fixo para que os WSDs admitidos no sistema retornem periodicamente ao WSDB para revalidar parâmetros e permanecer no canal de frequência. Assim sendo, o valor de $\Delta$ é variável de acordo com o custo de comunicação e a capacidade computacional do WSDB.

Para expressar esta dependência do tempo médio de admissão $T_{a d}$ com o tempo de retorno máximo $\Delta$, define-se o tempo médio de admissão normalizado $t_{n}$ como uma fração do tempo de retorno máximo $\Delta$ que é gasto na admissão do $\mathrm{WSD}_{0}$, ou seja,

$$
t_{n}=\frac{T_{a d}}{\Delta}
$$

As Figuras 6.9 e 6.10 apresentam gráficos da taxa de atendimento ao critério de interferência $T_{C I}$ em função da densidade. 


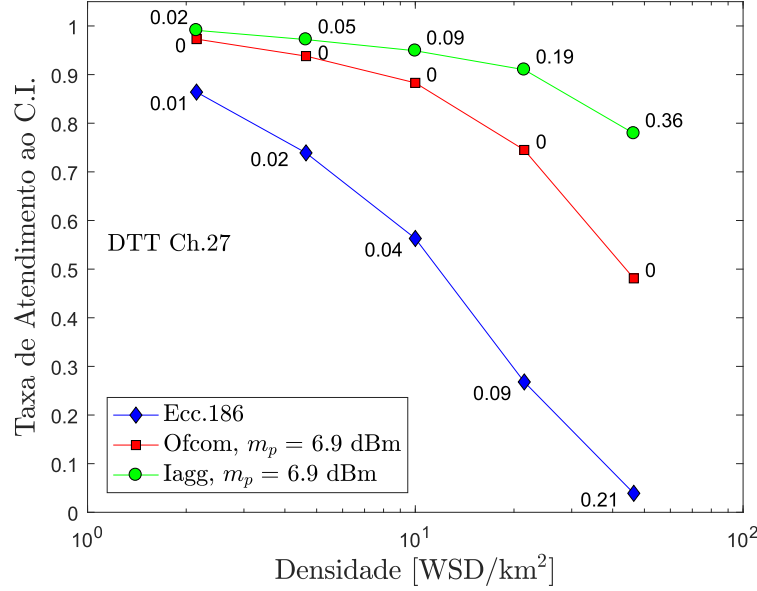

(a)

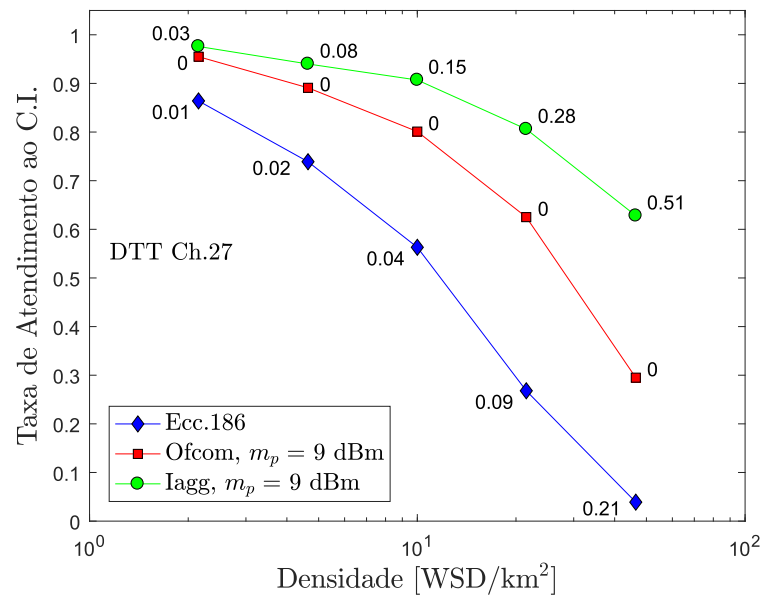

(c)

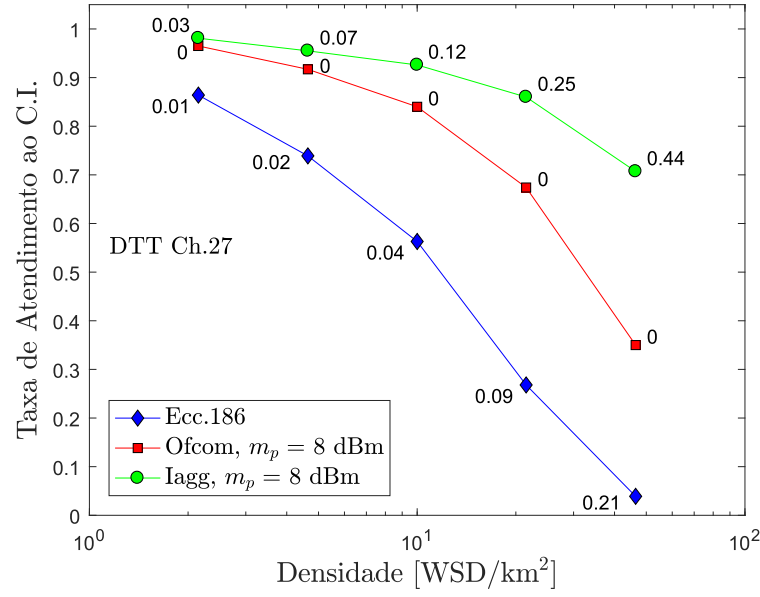

(b)

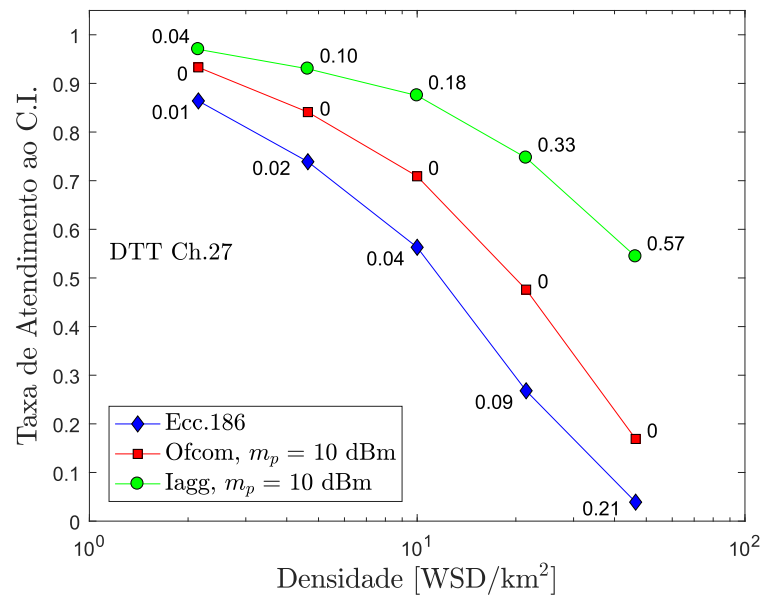

(d)

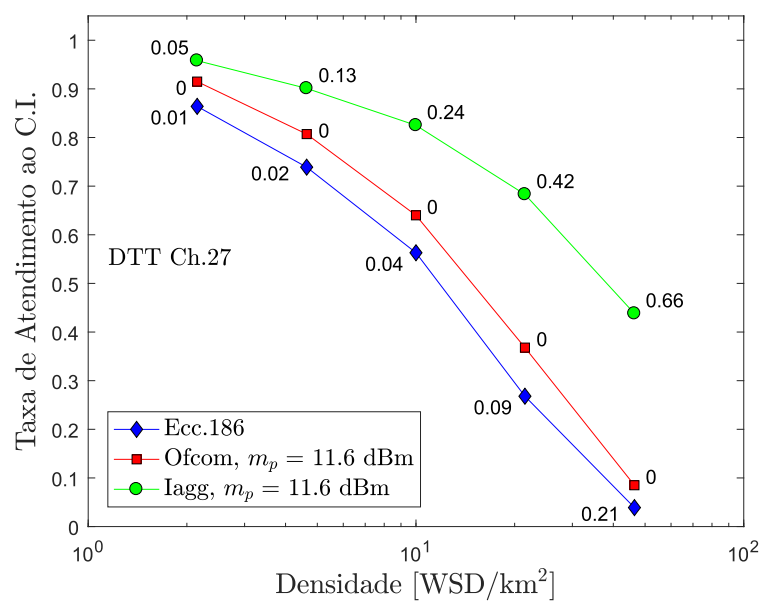

(e)

Figura 6.9: Taxa de atendimento ao C.I. em função da densidade no canal de frequência DTT 27 para as metodologias Ecc.186, Ofcom e Iagg. Cada gráfico utiliza um valor de média para a e.i.r.p. $P_{\ell}$. Os números que aparecem nos pontos das curvas correspondem ao tempo de admissão normalizado $t_{n}$. 


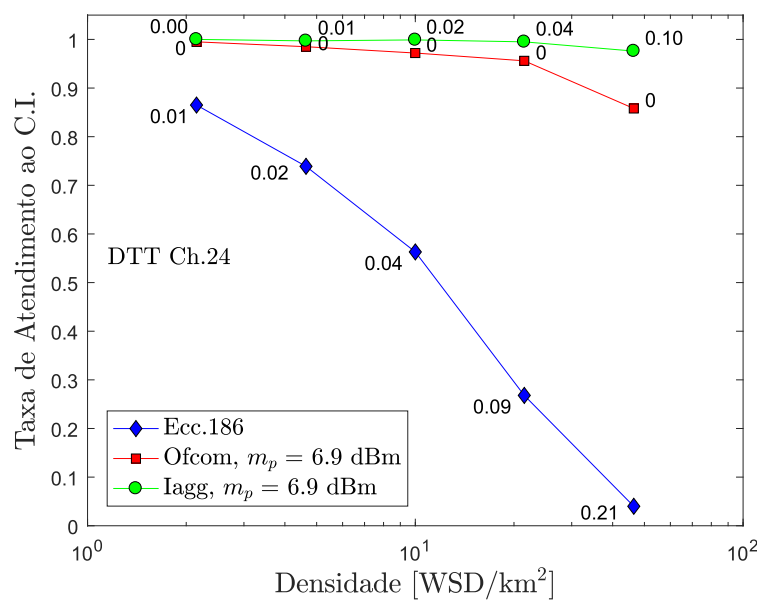

(a)

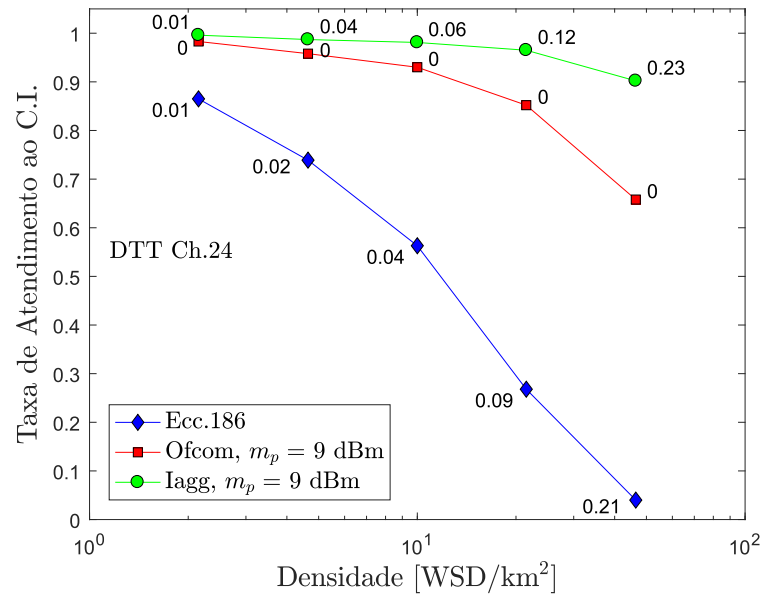

(c)

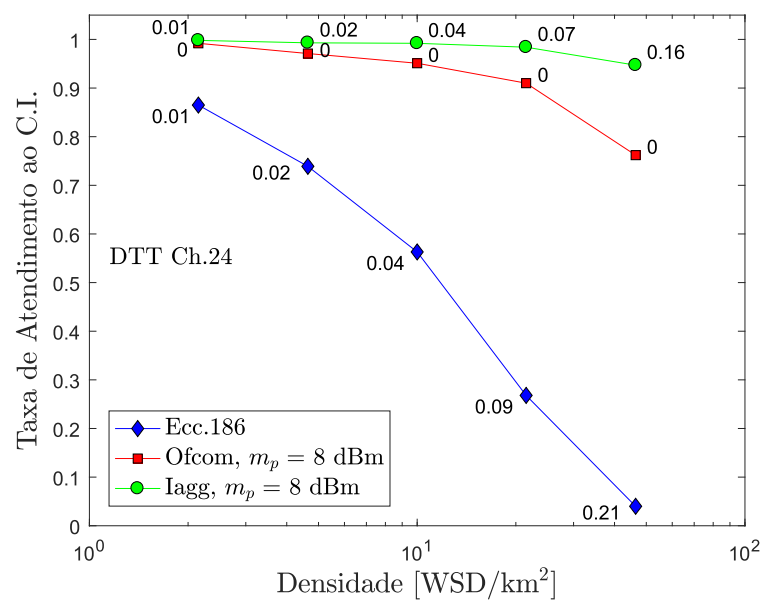

(b)

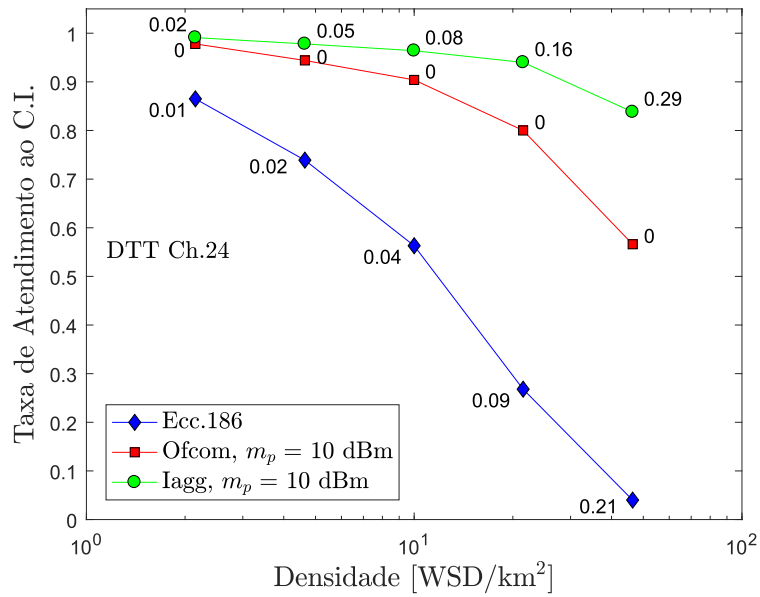

(d)

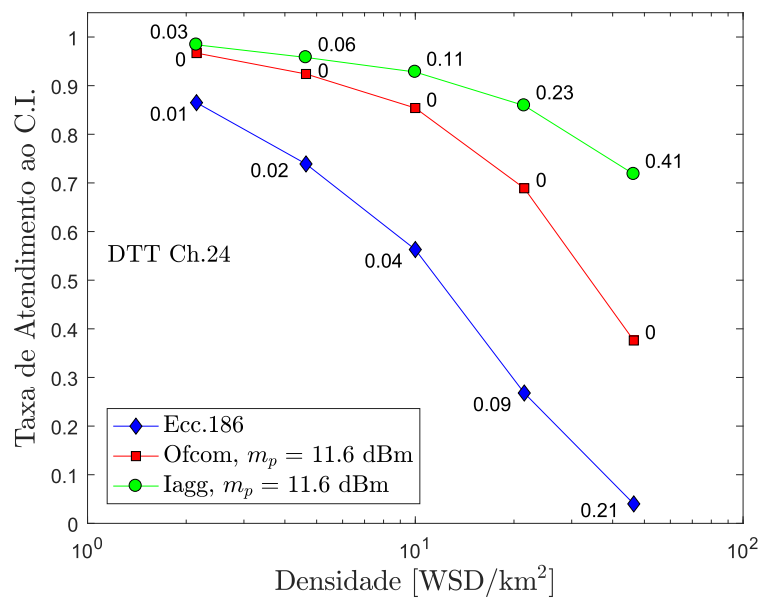

(e)

Figura 6.10: Taxa de atendimento ao C.I. em função da densidade no canal de frequência 24 para as metodologias Ecc.186, Ofcom e Iagg. Cada gráfico utiliza um valor de média para a e.i.r.p. $P_{\ell}$. Os números que aparecem nos pontos das curvas correspondem ao tempo de admissão normalizado $t_{n}$. 
A Figura 6.9 apresenta gráficos para o canal de frequência DTT 27, primeiro canal adjacente ao canal de frequência WSD 26. Enquanto, a Figura 6.10 mostra gráficos para o segundo canal adjacente, ou seja, o canal de frequência DTT 24. Cada um dos cinco gráficos de cada figura mostra as curvas da taxa de atendimento ao critério de interferência $T_{C I}$ em função da densidade para um valor de média da e.i.r.p. $P_{\ell}, m_{p}=\{6.9,8,9,10,11.6\}$ dBm, das metodologias Ofcom e Iagg. O atraso médio na admissão, também, é apresentado nos gráficos através do tempo médio de admissão normalizado $t_{n}$ escrito acima dos pontos das curvas.

Observe que a metodologia Ecc.186 não altera sua curva em nenhum dos gráficos, uma vez que a e.i.r.p. $P_{\ell}$ desta metodologia é calculada de forma determinística nas simulações. Esta metodologia apresenta o pior desempenho na taxa de atendimento ao C.I. em todos os gráficos. Assim, a metodologia Ecc.186 serve como uma referência de pior caso para a avaliação das outras duas metodologias.

A metodologia Ofcom apresenta, em todos os gráficos, um desempenho pior que o desempenho da metodologia Iagg. Note que nas densidades mais baixa o desempenho das duas metodologias é muito próximo, ocorrendo uma piora na curva da metodologia Ofcom à medida que a densidade aumenta. Observe, também, que os gráficos para o canal de frequência DTT 27 mostram que as curvas da metodologia Ofcom se aproximam da curva da metodologia Ecc.186 à medida que a e.i.r.p. $P_{\ell}$ aumenta. De fato, a diferença entre as curvas das duas metodologias no último gráfico 6.9(e) é muito pequena, demonstrando que a metodologia Ecc.186 é o limite de pior caso para o desempenho da metodologia Ofcom.

A metodologia Iagg é superior em todos os gráficos na comparação de desempenho com as outras metodologias. Isto se deve a utilização da otimização das e.i.r.p. na admissão dos WSDs, assim a otimização se mostra como uma etapa fundamental da metodologia Iagg. No entanto, esta melhoria no desempenho apresenta um custo para os WSDs admitidos, já que é devido a otimização que os WSDs admitidos experimentam um atraso maior na admissão.

Observe que o tempo médio de admissão normalizado $t_{n}$ aumenta com o aumento da densidade o que se explica pelo aumento do número de WSDs em operação afetados pela otimização, sendo este número um dos parâmetros do cálculo do tempo médio de admissão conforme (5-10). Além da densidade, os gráficos mostram que $t_{n}$ aumenta, também, com o aumento da e.i.r.p. $P_{\ell}$. Isto é explicado pelo aumento das interferências individuais dos WSDs o que implica no aumento da potência interferente agregada e, consequentemente, 
em uma maior probabilidade de não atendimento do C.I., sendo este último outro parâmetro do cálculo do tempo médio de admissão em (5-10). Assim sendo, a pior situação de atraso está na maior densidade e maior e.i.r.p. $P_{\ell}$ como pode ser comprovado comparando $t_{n}$ no ponto com densidade $\lambda=46.4$ $\mathrm{WSD} / \mathrm{km}^{2}$ e $P_{\ell}=11.6 \mathrm{dBm}$ no último gráfico (e) das figuras 6.9 e $6.10 \mathrm{com}$ os pontos de mesma densidade nos outros gráficos. 


\section{Conclusões}

Neste trabalho foi desenvolvida uma nova metodologia de cálculo, nomeada Iagg, para a admissão de White Space Devices (WSDs) que compartilham, em caráter secundário, a faixa de frequência do sistema primário de televisão digital (DTT). A metodologia de cálculo Iagg limita a potência interferente agregada de um sistema WSD em um receptor vítima do sistema DTT. Esta limitação visa atender ao critério de interferência definido pelo sistema primário, sendo assim garantida a proteção do receptor DTT.

A metodologia Iagg foi proposta para resolver problemas identificados na metodologia de cálculo do regulamento Ofcom [6], em especial, o problema da interferência agregada, pois este regulamento assume como premissa que somente um WSD irradiará por célula e por canal de frequência.

Os principais aspectos da metodologia de cálculo do regulamento Ofcom foram apresentados no Capítulo 2. No Capítulo 3 foi desenvolvido o detalhamento do problema da metodologia Ofcom, demonstrando a vulnerabilidade do receptor DTT à potência interferente agregada dos WSDs através de alguns exemplos. Além disso, desenvolve-se os procedimentos de admissão da metodologia Ofcom e Ecc.186.

A modelagem matemática que serve de base para a metodologia de cálculo proposta é desenvolvida no Capítulo 4. O modelo matemático desenvolve o conceito de célula mais vulnerável e o cálculo dos principais parâmetros da metodologia como o critério de interferência, a potência de transmissão máxima do WSD e a potência interferente agregada.

Ainda no Capítulo 4 são apresentados resultados preliminares que comprovam que a potência interferente agregada viola o critério de interferência em baixas densidades de WSDs na metodologia de cálculo Ofcom. Isto pode ser observado na Figura 4.13, onde o primeiro, segundo e terceiro canal de frequência adjacente apresentam densidades limites de 0.5, 1.2 e $3.1 \mathrm{WSD} / \mathrm{km}^{2}$, respectivamente, ou seja, o critério de interferência não é satisfeito acima destes valores de densidade. Tanto na obtenção destes resultados, quanto no desenvolvimento da metodologia Iagg, foi necessária a compatibilização entre as definições da interferência intersistema $Z$ e intrasistema $P_{U, k}$, conforme descrito na Seção 3.4 . 
Um novo procedimento de admissão, nomeado Iagg, foi desenvolvido no Capítulo 5. Neste procedimento, o critério de admissão é o próprio critério de interferência e a potência interferente agregada é a variável utilizada na avaliação do critério. Uma importante característica do procedimento de admissão Iagg é a redução seletiva das potências de transmissão dos WSDs quando o critério de interferência não é atendido. Esta redução é realizada por uma função de otimização desenvolvida para diminuir a interferência agregada até que o critério de interferência seja atendido, sendo definida uma potência mínima operacional para que os WSDs em operação mantenham uma taxa de transmissão mínima. Através desta função de otimização aumenta-se a capacidade de admissão no sistema em especial nas densidades mais altas.

Ainda no Capítulo 5 são definidas as funções que calculam o tempo médio de admissão e a máscara de otimização. A primeira calcula o custo de admissão do procedimento Iagg que corresponde ao maior atraso na admissão dos WSDs. A segunda define uma forma de reduzir o custo computacional e de comunicação do banco de dados WSDB, através da limitação da região utilizada para o cálculo da interferência.

A análise comparativa das metodologias Ecc.186, Ofcom e Iagg é desenvolvida no Capítulo 6 a partir dos resultados obtidos na simulação. Primeiramente, discute-se as premissas e parâmetros utilizados nesta análise, sendo algumas características dos serviços de comunicação do tipo móvel e Wi-Fi utilizadas para definição das potências de transmissão mínima e máxima dos WSDs. Em seguida, é apresentado o detalhamento da simulação conjunta dos procedimentos de admissão Iagg, Ofcom e Ecc.186. Através desta simulação obtêm-se os parâmetros de desempenho para a comparação das metodologias.

Uma análise do atendimento ao critério de interferência é desenvolvida, considerando algumas potências de transmissão dos WSDs associadas aos procedimentos de admissão Ofcom e Iagg. Esta análise está baseada nos gráficos das figuras 6.7 e 6.8 que representam a probabilidade da interferência agregada ultrapassar o limite de interferência intersistema em função da densidade. Nestes gráficos o critério de interferência define uma linha limite na probabilidade de $10^{-2}$. Observa-se que todas as curvas da metodologia Iagg apresentam-se abaixo do limite do critério de interferência ao contrário das outras metodologias. Esta é a principal característica que se buscou alcançar com a nova metodologia, ou seja, garantir a proteção do receptor DTT contra interferências acima do limite.

Outra característica interessante da metodologia Iagg é observada nestes gráficos pela agrutinação dos pontos nas densidades mais altas. Note que o mínimo e máximo valor das potências de transmissão dos WSDs estão associ- 
ados aos serviços de comunicação móvel e Wi-Fi, respectivamente. Portanto, conclui-se que a metodologia Iagg apresenta uma baixa sensibilidade quanto ao serviço de comunicação utilizado nas altas densidades.

Uma análise de desempenho comparando as metodologias foi efetuada utilizando as figuras 6.9 e 6.10. Estas figuras contêm gráficos da taxa de atendimento ao critério de interferência em função da densidade de WSDs. Cada gráfico corresponde a uma das potências de transmissão dos WSDs utilizadas na simulação. O atraso médio na admissão, também, é apresentado nos gráficos através do tempo médio de admissão normalizado, indicado acima dos pontos das curvas.

Observe que, em todos os gráficos, as curvas da metodologia Iagg estão acima daquelas correspondentes às outras metodologias, demonstrando que a metodologia proposta é superior na comparação de desempenho. Isto se deve a utilização da otimização das potências de transmissão dos WSDs na admissão. Assim, a otimização se mostra como uma etapa fundamental da metodologia Iagg. No entanto, esta melhoria no desempenho apresenta um custo para os WSDs admitidos, já que é devido a otimização que os WSDs experimentam um atraso maior na admissão.

Observe que o tempo médio de admissão normalizado aumenta com o aumento da densidade e, também, da potência de transmissão dos WSDs. Note que a pior condição de atraso está associada ao serviço de comunicação Wi-Fi (canal de frequência DTT 27 , densidade $\lambda=46.4 \mathrm{WSD} / \mathrm{km}^{2}$ e potência de transmissão $\left.P_{\ell}=11.6 \mathrm{dBm}\right)$ com $66 \%$ do tempo de retorno máximo $\Delta$, enquanto a condição associada ao serviço de comunicação móvel (potência de transmissão $\left.P_{\ell}=6.9 \mathrm{dBm}\right)$ para o mesmo canal de frequência DTT e densidade representa $36 \%$ do tempo de retorno máximo $\Delta$. Assim sendo, o atraso adicional na admissão é significativamente reduzido quando o sistema WSD utiliza a potência de transmissão de forma menos agressiva.

É fundamental comentar que ficou demonstrado que a proteção dos receptores do sistema DTT não é efetiva devido a abordagem single-entry da interferência para definição das potências de transmissão dos WSDs na metodologia Ofcom. Neste sentido, a metodologia Iagg garante a proteção do sistema DTT através de uma abordagem de múltiplas entradas da interferência e, adicionalmente, apresenta desempenho superior quando comparada a metodologia anterior. 


\section{Referências bibliográficas}

[1] J. Mitola and G. Q. Maguire Cognitive radio: making software radios more personal, IEEE Personal Communications, Vol 6, No. 4, pp. 13-18, 1999.

[2] S. Kandeepan; G. Andrea; Cognitive Radio Techniques: Spectrum Sensing,Interference Mitigation, and Localization, Artech House, 2012.

[3] A. M. Wyglinski; M. Nekovee and Y. T. Hou; Cognitive radio communications and networks, Elsevier, 2010.

[4] Technical and operational requirements for the possible operation of cognitive radio systems in the "white spaces" of the frequency band $470-790 \mathrm{MHz}$, ECC Report 159, 2010.

[5] Technical and operational requirements for the operation of white space devices under geo-location approach, ECC Report 186, 2013.

[6] Implementing TV white spaces, OFCOM Statement, February 12, 2015.

[7] Implementing TV white spaces, Annexes 1 to 12, OFCOM Statement, February 12, 2015.

[8] Lima, M. V.; Fortes, J. M. P., Aggregate Interference from White Space Devices into Digital Television Systems, International Conference on Computing and Network Communications, December, 2015.

[9] Lima, M. V.; Fortes, J. M. P., Interferência de White Space Devices em receptores de TV Digital, Simpósio Brasileiro de Telecomunicações e Processamento de Sinais - SBrT2017, Setembro, 2017.

[10] S. Schwartz and Y. S. Yeh, On the distribution function and moments of power sums with log-normal components, Bell Syst. Tech. J., vol. 61, September, 1982.

[11] C. L. Ho, Calculating the mean and variance of power sums with two lognormal components, IEEE Trans. Veh. Technol., vol. 44, November, 1995.

[12] P. Pirinen, Statistical power sum analysis for nonidentically distributed correlated lognormal signals, Finnish Signal Processing Symposium (FINSIG'03), May, 2003. 
[13] Abu-Dayya A.A. and Beaulieu N.C. Outage Probabilities in thePresence of Correlated Lognormal Interferers, IEEE Transactions on Vehicular Technology, vol. 43, February 1994.

[14] V. Petrini; H. R. Karimi, TV white space databases: Algorithms for the calculation of maximum permitted radiated power levels, Proc. Dynamic Spectrum Access Networks (DySPAN), October, 2012.

[15] V. Petrini; H. R. Karimi, A framework for calculation of TV white space availability subject to the protection of DTT and PMSE, 24th International Symposium on Personal, Indoor and Mobile Radio Communications, 2013.

[16] H.R. Karimi, Geolocation database for white space devices in the UHF TV bands: Specification of maximum permitted emission levels, International Symposium on Dynamic Spectrum Access Networks DySPAN, 2011.

[17] Hata and Hata-SRD implementation, on-line SEAMCAT User Manual, available at "http://tractool.seamcat.org/wiki/Manual", on February 2015.

[18] Chiu, S. N.; Stoyan, D.; Kendall, W. S.; Mecke, J., Stochastic geometry and its applications, Third Edition, Wiley Series in Probability and Statistics, John Wiley, 2013.

[19] Daley, D. J.; Vere-Jones D., and An Introduction to the Theory of Point Processes: Volume I: Elementary Theory and Methods, Second Edition, Springer, 2003.

[20] F. Baccelli and B. Blaszczyszyn, Stochastic Geometry and Wireless Networks in Foundations and Trends in Networking - Volume 1, Now Publishers, 2009.

[21] M. Haenggi, Stochastic Geometry for Wireless Networks, Cambridge University Press, 2013.

[22] Illian, J., Penttinen, A., Stoyan, H., Stoyan, D., Statistical Analysis and Modeling of Spatial Point Patterns, Wiley, 2008.

[23] Method for point-to-area predictions for terrestrial services in the frequency range $30 \mathrm{MHz}$ to $3000 \mathrm{MHz}$, Recommendation ITU-R P.1546-5, September, 2013.

[24] Directivity and polarization discrimination of antennas in the reception of television broadcasting, Recommendation ITU-R BT.419-3, June, 1990. 
[25] Relatório dos Testes de Interferência do Sinal LTE na TV Digital na faixa de UHF, Laboratório de Pesquisas em TV Digital, Universidade Presbiteriana Mackenzie, novembro, 2013.

[26] Wannstrom, J., Mallinson, K., HetNet/Small Cells, available at "http://www.3gpp.org/hetnet", on January, 2016.

[27] H. EISawy, E. Hossain and M. Haenggi, Stochastic Geometry for Modeling, Analysis, and Design of Multi-Tier and Cognitive Cellular Wireless Networks: A Survey, Communications Surveys \& Tutorials, IEEE, 2013.

[28] Byrd, R. H., J. C. Gilbert, and J. Nocedal., A Trust Region Method Based on Interior Point Techniques for Nonlinear Programming., Mathematical Programming, Vol 89, No. 1, 2000.

[29] Byrd, R.H., Mary E. Hribar, and Jorge Nocedal, An Interior Point Algorithm for Large-Scale Nonlinear Programming, SIAM Journal on Optimization, Vol 9, No. 4, pp. 877-900, 1999.

[30] Waltz, R. A. , J. L. Morales, J. Nocedal, and D. Orban, An interior algorithm for nonlinear optimization that combines line search and trust region steps, Mathematical Programming, Vol 107, No. 3, pp. 391-408, 2006.

[31] Forsgren, A.; Gill, P. E.; and Wright, M. H. Interior Methods for Nonlinear Optimization., SIAM Review, Vol 44, No. 4, pp. 525-597, 2002.

[32] T. S. Rappaport, Wireless Communications: Principles and Practice., Prentice-Hall, 1999.

[33] White Space Devices (WSD); Wireless Access Systems Operating in the 470 $\mathrm{MHz}$ to $790 \mathrm{MHz}$ Frequency Band; Harmonized EN Covering the Essential Requirements of Article 3.2 of the R\&TTE Directive, Harmonized European Standard ETSI EN 301 598, April, 2014.

[34] Jamil I.; Cariou L.; Helard J.F. Preserving Fairness in Super Dense WLANs, Workshop on Advanced PHY and MAC Techniques for Super Dense Wireless Networks, IEEE ICC, 2015.

[35] Additional System Characteristics of an operational IMT network deployed in Australia in the $800 \mathrm{MHz}$ band, ITU document 5-6/81-E, 2009.

[36] Moltchanov, D. Distance distributions in random networks. Ad Hoc Networks, Vol 10, No. 6, pp. 1146-1166, August, 2012. 
[37] Lima, M. V.; Fortes, J. M. P., On the Statistical Behaviour of the Aggregate Interference from WSDs into DTT systems, Conference of the Computational Interdisciplinary Science-CCIS 2016, November, 2016. 
A

\section{Aproximação de Schwartz-Yeh Modificada por Ho}

As potências que serão somadas possuem média e desvio padrão em dB, entretanto é mais conveniente usar logaritmo neperiano ao invés do logaritmo na base 10, sendo feita uma transformação por meio de um multiplicador $\mu=\ln (10) / 10$. Considerando $x_{i}$ a v.a. gaussiana em $\mathrm{dB}$ e $y_{i}$ a correspondente v.a. gaussiana em logaritmo neperiano, temos $m_{y_{i}}=\mu m_{x_{i}}$ e $\sigma_{y_{i}}=\mu \sigma_{x_{i}}$.

Considere $L, L_{1}$ e $L_{2}$ variáveis aleatórias lognormais; $y_{1}, y_{2}, z$ e $w$ variáveis aleatórias gaussianas e $w=y_{2}-y_{1}$. Então, pode-se desenvolver a soma de duas v.a. lognormal como abaixo.

$$
\begin{aligned}
L & =L_{1}+L_{2} \\
L & =e^{y_{1}}+e^{y_{2}}=e^{z} \\
z & =\ln \left(e^{y_{1}}+e^{y_{2}}\right) \\
z & =y_{1}+\ln \left(1+e^{w}\right)
\end{aligned}
$$

A estimativa de $z$ pode ser feita usando $y_{1}$ adicionado ao termo $\ln \left(1+e^{w}\right)$ que pode ser considerado um termo de correção. Para uma boa estimação, $y_{1}$ deve ser a maior das parcelas. A variável aleatória $w$ possui função densidade de probabilidade $f_{w}(w)$ com média $m_{w}$ e variância $\sigma_{w}^{2}$ calculadas como

$$
\begin{aligned}
m_{w} & =m_{y_{2}}-m_{y_{1}} \\
\sigma_{w}^{2} & =\sigma_{y_{2}}^{2}+\sigma_{y_{1}}^{2}-2 \rho_{y_{1} y_{2}} \sigma_{y_{1}} \sigma_{y_{2}} \\
\rho_{y_{1} y_{2}} & =\frac{E\left[\left(y_{1}-m_{y_{1}}\right)\left(y_{2}-m_{y_{2}}\right)\right]}{\sigma_{y_{1}} \sigma_{y_{2}}}
\end{aligned}
$$

Para esta tese, as potências de recepção interferentes $\left(y_{1}\right.$ e $\left.y_{2}\right)$ são consideradas estatisticamente independentes, sendo o coeficiente de correlação $\rho_{y_{1} y_{2}}$ igual a zero. As fórmulas da aproximação de Schwartz-Yeh modificada por Ho para o cálculo da média e variância de $z$ são apresentadas nas equações (A-6) a (A-17).

A distribuição da soma de $n$ variáveis aleatórias lognormal é calculada por um procedimento recursivo. Considere $z_{n}$ o logaritmo da soma desejada. 


$$
z_{n}=\ln \left(\sum_{k=1}^{n} e^{y_{k}}\right)
$$

Dada a sequência $\left\{z_{1}, z_{2}, \ldots, z_{n}\right\}$, define-se $z_{1}=y_{1}$, então através de A-1 escreve-se $z_{2}=z_{1}+\ln \left(1+e^{w}\right)$, sendo $w=y_{2}-z_{1}$. Logo, o cálculo da média e desvio padrão de $z_{2}$ é realizado pelas fórmulas (A-6) a (A-17). O raciocínio é estendido para os próximos $z_{k}$ da sequência.

(1) $z_{3}=z_{2}+\ln \left(1+e^{w}\right) ; w=y_{3}-z_{2}$

(2) $z_{4}=z_{3}+\ln \left(1+e^{w}\right) ; w=y_{4}-z_{3}$

(3) $\ldots$

(4) $z_{n}=z_{n-1}+\ln \left(1+e^{w}\right) ; w=y_{n}-z_{n-1}$

Ou seja, calcula-se $z_{n}$ através do cálculo de cada elemento da sequência $\left\{z_{1}, z_{2}, \ldots, z_{n}\right\}$. Para cada iteração, calcula-se $z_{k+1}=z_{k}+\ln \left(1+e^{w}\right)$, sendo $w=y_{k+1}-z_{k}$ e $z_{1}=y_{1}$. Desta forma, o valor de $z_{k+1}$ é calculado com as mesmas fórmulas apresentadas para obter a média e desvio padrão de $z$ no caso de apenas duas v.a. lognormal, bastando utilizar a equivalência $z_{k+1} \sim z ; z_{k} \sim y_{1} ; y_{k+1} \sim y_{2}$. 


$$
\begin{aligned}
& m_{z}=m_{y_{1}}+G_{1} \\
& \sigma_{z}^{2}=\sigma_{y_{1}}^{2}-G_{1}^{2}+2 \sigma_{y_{1}}^{2}\left(I_{2}+I_{0}\right)+G_{2} \\
& G_{1}=E\left[\ln \left(1+e^{w}\right)\right]=A_{0}+I_{1} \\
& G_{2}=E\left[\ln ^{2}\left(1+e^{w}\right)\right]=I_{3}+2 I_{4}+\sigma_{w}^{2} I_{0}+m_{w} A_{0} \\
& G_{3}=E\left[\left(w-m_{w}\right) \ln \left(1+e^{w}\right)\right]=\sigma_{w}^{2}\left(I_{2}+I_{0}\right) \\
& I_{4}=\sigma_{w}^{2}\left(f_{w}(0) \ln 2-I_{5}\right)+m_{w} I_{6} \\
& A_{0}=\frac{\sigma_{w}}{\sqrt{2 \pi}} e^{-\eta^{2} / 2}+m_{w} I_{0} \\
& \eta=-\frac{m_{w}}{\sigma_{w}} \\
& I_{i}=\int_{0}^{1} h_{i}(v) v^{-1} d v \\
& h_{i}(v)= \begin{cases}\frac{1}{\sqrt{2 \pi}} \exp \left[-(\ln v-\eta)^{2} / 2\right] & i=0, \\
{\left[f_{w}(\ln v)+f_{w}(-\ln v)\right] \ln (1+v)} & i=1, \\
{\left[f_{w}(\ln v)-f_{w}(-\ln v)\right]\left(1+v^{-1}\right)^{-1}} & i=2, \\
{\left[f_{w}(\ln v)+f_{w}(-\ln v)\right] \ln ^{2}(1+v)} & i=3, \\
-f_{w}(-\ln v) \ln v \ln (1+v) & i=4, \\
f_{w}(-\ln v)\left(1+v^{-1}\right)^{-1} & i=5, \\
f_{w}(-\ln v) \ln (1+v) & i=6\end{cases} \\
& v=\exp (-w) \\
& f_{w}(w)=\frac{1}{\sqrt{2 \pi \sigma_{w}^{2}}} \exp \left[-\frac{\left(w-m_{w}\right)^{2}}{2 \sigma_{w}^{2}}\right]
\end{aligned}
$$




\section{B \\ Geometria Estocástica}

A interferência em redes sem fio depende, fortemente, da localização de seus nós. Em redes modernas, essas localizações estão sujeitas a consideráveis incertezas e necessitam ser modeladas como um processo estocástico de pontos em duas ou três dimensões do espaço. Uma área que provê modelos e métodos para análise desses processos é a geometria estocástica [18] [21] [20].

A geometria estocástica é um ramo da probabilidade aplicada e, particularmente, adaptada para o estudo de fenômenos aleatórios no espaço, plano ou em dimensões maiores, sendo intrinsecamente relacionada à teoria de processos pontuais. Esta teoria permite a caracterização estatística de pontos aleatoriamente distribuídos em um espaço Euclidiano d-dimensional $\left(\mathbb{R}^{d}\right)$ [27].

Uma rede de comunicação sem fio pode ser vista como uma coleção de nós, localizados em certo domínio, que podem ser transmissores ou receptores. Em um dado momento, diversos nós transmitem simultaneamente, cada um deles para seu receptor.

A geometria das localizações dos nós possui um papel fundamental, uma vez que determina a razão sinal interferência-ruído (signal to interference plus noise ratio - SINR) em cada receptor. A interferência vista em um receptor é a soma da potência dos sinais recebidos de todos os transmissores, exceto o transmissor do próprio receptor.

A geometria estocástica provê uma maneira natural de definir e calcular características das redes de comunicação, tais como parâmetros de desempenho e capacidade, através de todos os potenciais padrões geométricos dos nós. Modelar redes de comunicação sem fio em termos da geometria estocástica se mostra, particularmente, relevante para redes de larga escala e redes multicamadas, onde a aleatoriedade dos nós se torna ainda maior. As localizações dos elementos de rede são vistas como realizações de um processo pontual. Este é uma teoria fundamental para o estudo da geometria estocástica.

Visualmente, um processo pontual pode ser representado como uma coleção aleatória de pontos no espaço. Tipos diferentes de processos pontuais foram desenvolvidos, visando refletir características específicas de cada tipo de rede. Assim, uma rede pode ser abstraída por um conveniente processo pontual que capture suas propriedades [20]. 


\section{B.1}

\section{Processos pontuais}

Um processo pontual ou padrão de pontos aleatórios desempenha um papel fundamental na geometria estocástica e aparece, diretamente, como resultados das investigações da natureza e da tecnologia. Um processo pontual pode ser definido como um método de alocar pontos aleatoriamente a intervalos geométricos em um espaço Euclideano d-dimensional $\mathbb{R}^{d}$ [19]. Seja $\mathcal{N}$ um conjunto com todas as sequências $\phi \subset \mathbb{R}^{2}$ e que satisfaz as propriedades abaixo:

1. (Finito) Qualquer conjunto fechado $\mathbf{A} \subset \mathbb{R}^{2}$ contém um número de pontos finito.

2. (Simples) Todo $x_{i} \neq x_{j}$ se $i \neq j$. Ou seja, Não há dois pontos que coincidam.

Um processo pontual em $\mathbb{R}^{2}$ é uma variável aleatória que toma valores no espaço $\mathcal{N}$. Processos pontuais são representados pelo símbolo $\Phi$. Uma realização de um processo pontual é representado pelo símbolo $\phi . \Phi(A)$ é o número de pontos de um processo pontual em um conjunto $A \subset \mathbb{R}^{2}$.

O mais elementar exemplo de um processo pontual é àquele que contém apenas um ponto, como mostra a Figura B.1.

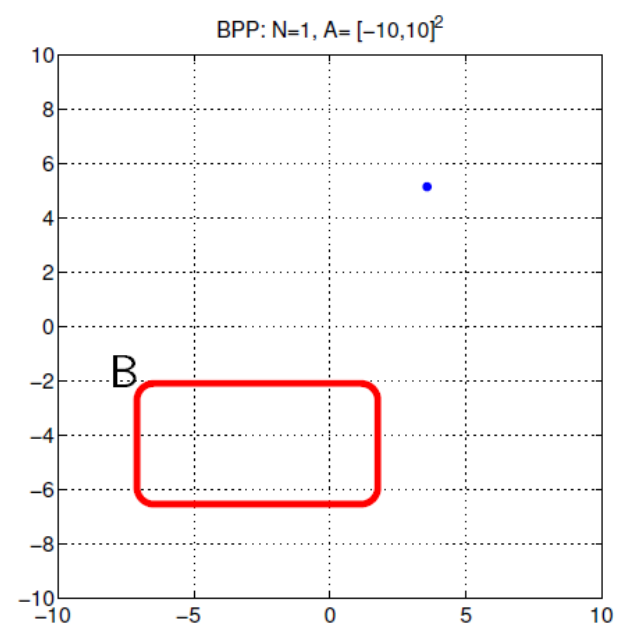

Figura B.1: Exemplo de processo pontual binomial, N=1.

Um ponto aleatório $\mathrm{x}$ uniformemente distribuido em um espaço limitado $\mathbf{A} \subset \mathbb{R}^{2}$ é um ponto aleatório com probabilidade dada por

$$
P(x \in B)=\frac{|B|}{|A|}
$$

onde $B \subset A$ e $|\cdot|$ representa a área do conjunto. 
Processo Pontual Binomial (BPP) de um conjunto $A$ é a superposição de $N$ pontos independentes uniformemente distribuídos sobre o conjunto $A$. A Figura B.2 ilustra uma realização de um BPP.

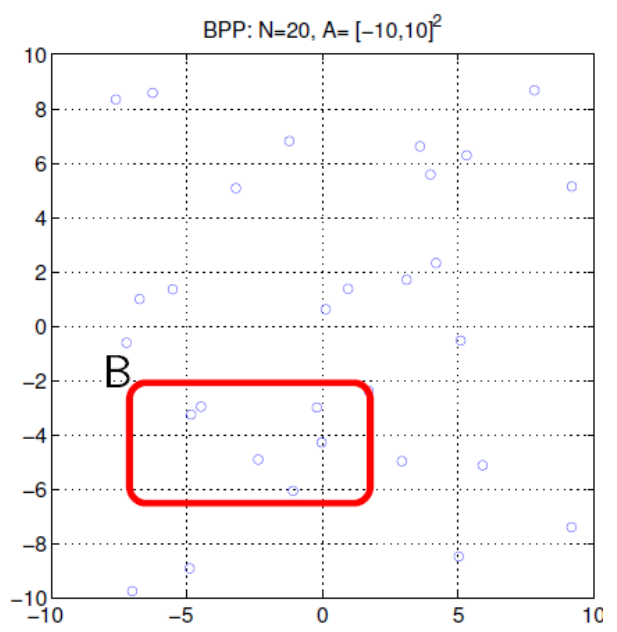

Figura B.2: Exemplo de processo pontual binomial, $\mathrm{N}=20$.

Sendo $B \subset A$, a probabilidade de um conjunto $\mathrm{B}$ possuir $\mathrm{k}$ pontos pode ser expressa como

$$
P(\Phi(B)=k)=\left(\begin{array}{c}
N \\
k
\end{array}\right)\left(\frac{|B|}{|A|}\right)^{k}\left(1-\frac{|B|}{|A|}\right)^{N-k}
$$

A probabilidade nula (void probability) de um processo pontual é a probabilidade de não haver ponto do processo em um dado conjunto de teste B: $P(\Phi(B)=0)$. A expressão (B-3) representa a probabilidade nula de um processo pontual binomial.

$$
P(\Phi(B)=0)=\left(1-\frac{|B|}{|A|}\right)^{N}
$$

Um teorema matemático define que a distribuição de um processo pontual simples $\Phi$ é determinado por sua probabilidade nula de um subconjunto compacto arbitrário. Conjunto compacto é todo conjunto fechado e limitado. Esta propriedade permite determinar se 2 processos pontuais são equivalentes, bastando verificar se possuem a mesma distribuição de probabilidade nula.

Estacionariedade e Isotropia. Para um processo pontual $\Phi=\left\{x_{n}\right\}$ ser estacionário, o processo transladado $\Phi=\left\{x_{n}+x\right\}$ deve ter a mesma distribuição para todo $x \in \mathbb{R}^{d}$. Um processo pontual é isotrópico se possui a mesma distribuição para todo processo rotacionado $\mathbf{r} \Phi=\left\{\mathbf{r} x_{n}\right\}$ onde $\mathbf{r}$ é uma rotação sobre a origem. Um processo é movimento-invariante (motion-invariant) se possuir essas duas propriedades juntas. 
Um processo pontual estacionário se mostra estatisticamente similar de qualquer ponto do espaço e não pode ser definido em um subconjunto do $\mathbb{R}^{2}$. A densidade $\lambda$ de um processo pontual estacionário $\Phi$ é definida como

$$
\lambda=\frac{E[\Phi(B)]}{|B|}, \quad B \subset \mathbb{R}^{2}
$$

\section{B.2}

\section{Processo Pontual de Poisson}

As possíveis variações dos padrões de pontos aleatórios conduzem ao entendimento da posição central que o proceesso pontual de Poisson (PPP) possui entre os modelos teóricos. Um dado padrão de pontos aleatórios pode exibir vários tipos de interações entre seus pontos constituintes. Interações de atração levam a ocorrência de pontos agrupados em clusters. Enquanto, interações de repulsão levam aos pontos apresentarem uma distância hardcore, ou seja, uma distãncia mínima entre eles. O processo pontual de Poisson apresenta interação zero entre os pontos. A Figura B.3, obtida em [21], ilustra essas interações para os processos pontuais.

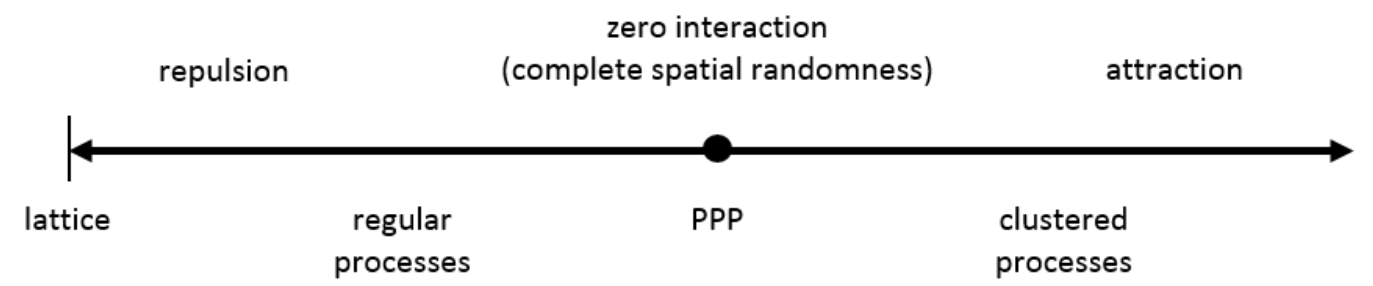

Figura B.3: Interação entre pontos de processos pontuais.

$\mathrm{Na}$ ausência de qualquer interação, um padrão de pontos pode ser imaginado como completamente aleatório. Um modelo teórico de tal padrão é importante como uma base de comparação, ou seja, como um modelo nulo. Assim, um papel central do PPP é servir como uma hipótese nula para testes estatísticos de interação. Outra importante função está no uso do processo pontual de Poisson como um bloco base de construção de outros modelos mais complicados. Definições teóricas dos vários processos pontuais, frequentemente, fazem referência ao PPP. Procedimentos de simulação, frequentemente, incluem a construção de um processo pontual de Poisson que é modificado na forma requisitada.

Um processo pontual de Poisson estacionário $\Phi$ é caracterizado por duas propriedades fundamentais.

1. Distribuição de Poisson para contagem de pontos. O número aleatório de pontos de $\Phi$ em um conjunto B tem uma distribuição de 
Poisson de média $\lambda \cdot|B|$ para uma constante $\lambda$, isto é

$$
P(\Phi(B)=m)=\frac{(\lambda \cdot|B|)^{m}}{m !} \exp (-\lambda \cdot|B|)
$$

O parâmetro $\lambda$ é um parâmetro característico do processo pontual estacionário de Poisson. $\lambda$ indica o número médio de pontos em um conjunto por unidade de volume, é chamado intensidade ou densidade de $\Phi$, sendo $\lambda$ considerado sempre como positivo e finito. Ou seja, um PPP estacionário é completamente caracterizado pelo número $\lambda$. Assim sendo, para todo conjunto B temos.

$$
\lambda \cdot|B|=E(\Phi(B))
$$

2. Espalhamento Independente. O número de pontos de $\Phi$ em k conjuntos disjuntos formam $\mathrm{k}$ variáveis aleatórias independentes para um dado k arbitrário. Esta, também, é conhecida como propriedade da completa aleatoriedade espacial. Seja $A \subset \mathbb{R}^{2}, B \subset \mathbb{R}^{2}$ e $A \cap B=\emptyset$, então $\Phi(A) \perp \Phi(B)$. A Figura B.4 (repetida da Figura 4.3) ilustra dois conjuntos disjuntos de um PPP.

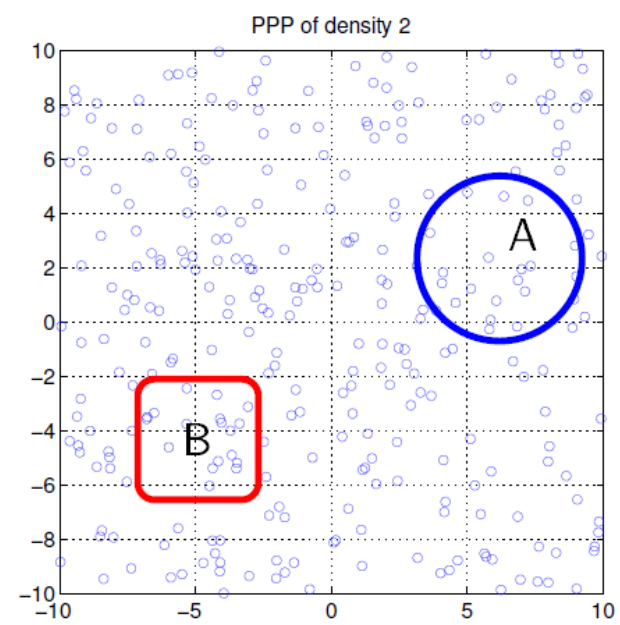

Figura B.4: Independência entre conjuntos disjuntos em um PPP.

Condicionamento e Processo Pontual Binomial. Se $\Phi$ é um processo pontual de Poisson estacionário, então considerar a restrição de $\Phi$ para um conjunto compacto A sob a condição que $\Phi(A)=n$ rende um processo pontual binomial em A com $n$ pontos.

Esta afirmação pode ser provada, mostrando que as probabilidades nula dos processos coincidem. Se K é um subconjunto compacto de A, então a probabilidade nula para $\mathrm{K}$ do condicionado processo pontual de Poisson estacionário é dado por 


$$
\begin{aligned}
P(\Phi(K)=0 \mid \Phi(A)=n) & =\frac{P(\Phi(K)=0 \cap \Phi(A)=n)}{P(\Phi(A)=n)} \\
& =\frac{P(\Phi(K)=0) P(\Phi(A)=n \mid \Phi(K)=0)}{P(\Phi(A)=n)} \\
& =\frac{P(\Phi(K)=0) \cdot P(\Phi(A \backslash K)=n \mid \Phi(K)=0)}{P(\Phi(A)=n)}
\end{aligned}
$$

Pela propriedade (2) do espalhamento independente, temos que $\Phi(A \backslash K)$ é independente de $\Phi(K)$

$$
\begin{aligned}
& P(\Phi(K)=0 \mid \Phi(A)=n)=\frac{P(\Phi(K)=0) \cdot P(\Phi(A \backslash K)=n)}{P(\Phi(A)=n)} \\
&=\frac{e^{-\lambda|K|} e^{-\lambda|A \backslash K|}(\lambda|A \backslash K|)^{n} / n !}{e^{-\lambda|A|}(\lambda|A|)^{n} / n !} \\
&=\frac{(|A \backslash K|)^{n}}{|A|^{n}} \\
&=\frac{(|A|-|K|)^{n}}{|A|^{n}} \\
& P(\Phi(K)=0 \mid \Phi(A)=n)=\left(1-\frac{|K|}{|A|}\right)^{n}
\end{aligned}
$$

Esta última expressão (B-7) coincide com (B-3) para a probabilidade nula de um processo pontual binomial. A teoria geral de processos pontuais simples afirma a igualdade das distribuições de processos pontuais, se suas probabilidades nula forem iguais.

Simulação de um Processo Pontual de Poisson. Utilizando a propriedade de condicionamento de um PPP, é possível simular um processo pontual de Poisson em uma região compacta A em dois estágios.

1. O número de pontos em A é determinado por meio da simulação de uma variável aleatória de Poisson. Em Matlab:

$N=\operatorname{poissrnd}(\lambda|A|)$

2. As posições dos pontos em A são determinadas por meio da simulação de um processo pontual binomial com aquele número de pontos. Considerando uma área $|A|=[-L,+L]^{2}$, temos em Matlab:

points $=$ unifrnd $(-L, L, N, 2)$ 


\section{B.3 \\ Função Distribuição da Distância do Vizinho Mais Próximo}

$\mathrm{Na}$ teoria de processos pontuais, um ponto típico de um processo pontual $\Phi$ é frequentemente considerado. Este é um ponto que deve ser escolhido por um procedimento de seleção em que todo ponto do processo tem a mesma chance de ser selecionado. Por exemplo, a função distribuição da distância do vizinho mais próximo $D(r)$ que descreve a distribuição da distância de um ponto típico $x$ em $\Phi$ para o ponto mais próximo em $\Phi \backslash\{x\}$, ou seja, o vizinho mais próximo de $x$ em $\Phi$. [22]

A idéia de ponto típico é heurísticamente clara, mas precisa ser matematicamente precisa. Pontos amostrados por algum método sistemático não são típicos apenas porque eles tem sido amostrados. A teoria da distribuição Palm torna precisa a noção de ponto típico.

As probabilidades da distribuição Palm são as probabilidades condicionais de eventos de um processo pontual dado que um ponto, o ponto típico, é observado em uma localização específica. Uma abordagem local envolve condicionar a distribuição do processo pontual a haver um ponto em uma dada posição x.

Para discutir a abordagem local, é necessário introduzir alguma notação. Se Y é algum conjunto de configuração que descreve uma propriedade do processo pontual, por exemplo a propriedade $\phi(B)=n$ para algum conjunto $\mathrm{B}$, então

$P(\Phi$ tem propriedade $\mathrm{Y} \| x)=P(\Phi$ tem propriedade $\mathrm{Y} \mid x \in \Phi)$

A probabilidade condicional será entendida como a distribuição Palm de $\Phi$ e o ponto x é o ponto típico. Um evento $\Phi$ que tem propriedade Y pode ser escrito como $\Phi \in Y$, interpretando $\mathrm{Y}$ como um conjunto de configuração. Pela estacionariedade, temos que $\Phi_{-x}$ é um processo pontual transladado $\left\{x_{1}-x, x_{2}-x, \ldots\right\}$, onde $\Phi$ é o conjunto $\left\{x_{1}, x_{2}, \ldots\right\}$.

$$
P(\Phi \in Y \| x)=P\left(\Phi_{-x} \in Y \| o\right)
$$

Nesta notação, um processo pontual estacionário terá uma função distribuição de distância do vizinho mais próximo $D(r)=P(D<r)$, sendo D a distância do ponto mais próximo do processo partindo da origem, dada por

$$
D(r)=P(\Phi(B(o, r))>1 \| o)=1-P(\Phi(B(o, r))=1 \| o)
$$




\section{Função distribuição da distância do vizinho mais próximo para o processo}

pontual de Poisson estacionário. Considere uma função distribuição da distância condicional $D_{\varepsilon}(r)$, assumindo que há um ponto de $\Phi$ na bola $B(o, \varepsilon)$ de centro na origem $o$ e raio $\varepsilon$.

$$
\left.D_{\varepsilon}(r)=1-P(\Phi(B(o, r) \backslash B(o, \varepsilon))=0) \mid \Phi(B(o, \varepsilon))=1\right)
$$

A probabilidade condicional em (B-8) está bem definida para valores positivos de $\varepsilon$ menores que $r$, na condição que a menor bola $B(o, \varepsilon)$ contenha um ponto.

$$
P(\Phi(B(o, \varepsilon))=1)=\lambda \pi \varepsilon^{2} \exp \left(-\lambda \pi \varepsilon^{2}\right)
$$

Utilizando a definição de probabilidade condicional, $P(A \mid B)=P(A \cap$ $B) / P(B)$, e a propriedade (2) do PPP homogêneo, obtemos:

$$
\begin{aligned}
D_{\varepsilon}(r) & =1-\frac{P(\Phi(B(o, r) \backslash B(o, \varepsilon))=0) P(\Phi(B(o, \varepsilon))=1)}{P(\Phi(B(o, \varepsilon))=1)} \\
& =1-P(\Phi(B(o, r) \backslash B(o, \varepsilon))=0) \\
& =1-\exp \left(-\lambda\left(\pi r^{2}-\pi \varepsilon^{2}\right)\right) \\
& =1-\exp \left(-\lambda\left(\pi\left(r^{2}-\varepsilon^{2}\right)\right)\right)
\end{aligned}
$$

É razoável pensar na função distribuição de distância do vizinho mais próximo como o limite da expressão acima quando $\varepsilon \rightarrow 0$. Fazendo $D(r)=$ $\lim _{\varepsilon \rightarrow 0} D_{\varepsilon}(r)$ temos:

$$
D(r)=1-\exp \left(-\lambda \pi r^{2}\right) \text { para } r \geq 0
$$

A função densidade de probabilidade da distância do vizinho mais próximo $d(r)$ pode ser, facilmente, calculada pela derivada da expressão (B-9).

$$
d(r)=2 \lambda \pi r \exp \left(-\lambda \pi r^{2}\right)
$$

A função distribuição da distância do $2^{\circ}, 3^{\circ}, \ldots$ vizinho mais próximo é dada por

$$
D_{k}(r)=1-\sum_{j=0}^{k-1} \exp \left(-\lambda \pi r^{2}\right) \frac{\left(\lambda \pi r^{2}\right)^{j}}{j !} \quad \text { para } r \geq 0
$$

E a função densidade de probabilidade é escrita como

$$
d_{k}(r)=\frac{2\left(\lambda \pi r^{2}\right)^{k}}{r(k-1) !} \exp \left(-\lambda \pi r^{2}\right) \quad \text { para } r \geq 0
$$

A função densidade de probabilidade conjunta $p_{\mathbf{d}_{n}}(\mathbf{r})$ das distâncias dos $n$ vizinhos mais próximos de um PPP foi determinada em [36] como 


$$
p_{\mathbf{d}_{n}}(\mathbf{r})=\left\{\begin{array}{lll}
\exp \left(-\lambda \pi r_{n}^{2}\right)(2 \lambda \pi)^{n} \prod_{k=1}^{n} r_{k} & ; \mathbf{r} \in \mathcal{S} \\
0 & ; \mathbf{r} \notin \mathcal{S}
\end{array}\right.
$$

sendo

$$
\mathcal{S}=\left\{\mathbf{r} \in \mathbb{R}^{n}: r_{1}<r_{2}<\cdots<r_{n}\right\}
$$

Desenvolvemos em [37] o cálculo da função distribuição de probabilidade da interferência agregada através de (B-13) e comparamos o resultado com o da simulação Monte Carlo. 